\title{
Mass support for proposals to reshape policing depends on the implications for crime and safety
}

\author{
Paige E. Vaughn* Kyle Peyton ${ }^{\dagger} \quad$ Gregory A. Huber ${ }^{\ddagger}$ \\ Forthcoming, Criminology \& Public Policy \\ This preprint: 12 December 2021 \\ First draft: 24 February 2021
}

\begin{abstract}
This paper presents novel survey and experimental evidence that reveals the mass public's interpretation of movements to reform, defund, and abolish the police. We find strong support for police reform, but efforts to defund or abolish generate opposition both in terms of slogan and substance. While these differences cannot be explained by differing beliefs about each movement's association with violent protests, racial makeup, or specific programmatic changes, efforts to defund and abolish the police appear unpopular because they seek reduced involvement of police in traditional roles and cuts in police numbers. Our findings suggest that public support for changes to American policing is contingent on the perceived implications for crime and public safety. Proposals like defunding and abolition are therefore unlikely to succeed at the national level. Viable police reform may instead require proposals that target changing how police departments and their officers operate rather than lowering police budgets or decreasing police involvement in responding to crime and calls for service.
\end{abstract}

\footnotetext{
*Assistant Professor of Sociology and Criminology, Spring Hill College (pvaughn@shc.edu, @paigeevaughn); ${ }^{\dagger}$ Research Fellow in Political Science, Institute for Humanities and Social Sciences, Australian Catholic University (kyle.peyton@acu.edu.au, @pylekeyton); ${ }^{\ddagger}$ Forst Family Professor of Political Science, Yale University (gregory.huber@yale.edu). We thank the Center for the Study of American Politics and the Institution for Social and Policy Studies at Yale University for research support. Thanks to Johnathan Mummolo, Justin Pickett, John Shjarback, Ariel White, Jennifer $\mathrm{Wu}$, and three anonymous reviewers for helpful feedback. Replication materials are available at https://doi.org/10.7910/DVN/98DS4F.
} 


\section{Introduction}

The murder of George Floyd by an officer from the Minneapolis Police Department in May 2020 sparked nationwide protests against police violence and in support of the Black Lives Matter (BLM) movement. These protests, which mobilized activists across more than 140 cities, were among the most widespread in the history of the United States (Buchanan, Quoctrung, and Patel, 2020; Putnam, Chenoweth, and Pressman, 2020). As with the police killing of Michael Brown in Ferguson, MO in 2014, both public support for the BLM movement and dissatisfaction with police increased in the aftermath of Floyd's death and persisted alongside these protests (Chudy and Jefferson, 2021; Reny and Newman, 2021). During this period, longstanding concerns about systemic racism and police brutality also received widespread public attention, leading to renewed demand for specific national reforms (e.g., body-worn cameras) as well as broader calls to "reimagine" policing and public safety (e.g., Corley, Westervelt, and Kaste, 2020). Despite the demands for change that persisted throughout 2020, the crisis many described as an opportunity for nationwide police reform has thus far not led to any national legislation, and while structural changes have been supported by - and in some cases implemented in - a handful of municipal governments and police departments, rising crime has prevented sustained change (e.g., Herndon, 2021; Kapos, 2020; Klemko and Sullivan, 2021).

Though in many ways illustrative of the entrenched and crisis-driven nature of police reform in the United States (Walker, 1977), this particular period was unique in that proposals which were previously considered too radical for mainstream politics (e.g., police defunding and abolition) gained widespread public attention for the first time. ${ }^{1}$ One potential explanation for the political salience of these more radical changes is declining confidence in the police, an institution that has historically enjoyed widespread public support and legitimacy. For example, 
although trust in police has long been polarized by race and partisanship (e.g., confidence is consistently highest among Whites and Republicans), 2020 was the first time in Gallup poll history that only a minority of U.S. adults reported trust in police (see Jones, 2020). ${ }^{2}$

At the same time, the 2020 policing crisis erupted during a period of substantial instability that included both the COVID-19 pandemic and a nationwide surge in violent crime. For example, homicides grew by nearly $30 \%$ between 2019 and 2020 (the largest one-year increase on record; see Rosenfeld, Abt, and Lopez, 2021) and nearly 80\% of Americans also believed crime was on the rise in 2020 (the highest level observed since the early 1990s; see McCarthy, 2020). While policy changes like police abolition had never received such widespread political attention, public concerns about crime and public safety were also salient. Even among political elites on the left, there were growing concerns that some of the proposed changes to policing that emerged during the summer of 2020 would alienate potential voters and undermine support for Democrats during the November elections (Grim, 2020).

Are any of the proposals to reshape policing that emerged during this tumultuous period likely to survive, or succeed during the next policing crisis? While criminologists do not typically study the relationship between public opinion and criminal justice policy (see Pickett, 2019 for review), understanding how the mass public interpreted these different proposals can shed new light on these questions. ${ }^{3}$ Here we present novel survey experimental evidence collected during 2020 that allow us to investigate public attitudes toward the proposed changes that emerged during this period and what they believed each sought to accomplish, as well as their beliefs about the activists behind each proposal and their general views about the roles police should play in society. In the following section, we briefly review prior work on the 
relationship between public opinion and criminal justice policy in the United States. Next, we describe our research design and present the findings from our analyses.

\section{The Relationship between Public Opinion and Criminal Justice Policy}

Electorally motivated politicians in the United States are generally attentive to aggregate public opinion and the policy preferences of their constituents (e.g., Erikson, MacKuen, and Stimson, 2002; Mayhew, 1974). Public opinion, or the anticipated public response to policy (Arnold, 1990), therefore constrains policy outcomes, particularly on issues that are already politically salient or likely to become salient (Burstein, 2006; Lax and Phillips, 2012). Focusing on criminal justice-related policy, prior work finds congressional attention to these issues follows public attitudes, with increasing salience of violent crime and disorder preceding punitive policy changes (e.g., Enns, 2016; Nicholson-Crotty, Peterson, and Ramirez, 2009; Ramirez, 2013). As Pickett (2019:415) summarized in a recent review of prior work, "there has been only one consistent predictor of changes in aggregate support for punitive policies: crime rates."

Given that the mass public in the U.S. tends to believe crime is rising even when it is not (see e.g., Gramlich, 2016; McCarthy, 2015), research linking public opinion and criminal justice policy has repeatedly emphasized the role that perceptions about crime and disorder play in explaining support for punitive policy outcomes, regardless of their accuracy (Pfeiffer, Windzio, and Kleimann, 2005; Roberts and Indermaur, 2012; Shi, 2021). ${ }^{4}$ Media coverage, which generally overstates the prevalence of crime and disorder (Smith, 1984; Altheide, 2018), nonetheless still tends to follow underlying crime rates, especially yearly changes in homicides (Enns, 2016; Miller, 2016). In a political environment characterized by a substantial spike in homicides and widespread concerns about crime, public opinion may constrain politicians' enthusiasm for policies that voters believe will increase crime and disorder. 
National surveys conducted in the aftermath of Floyd's murder showed a widespread desire for changes to policing, but despite the significant media attention devoted to these movements, the vast majority of Americans remained opposed to defunding and abolition. ${ }^{5}$ Although popular political movements generally achieve greater social influence, it is unclear whether broad public support is a necessary or sufficient condition for meaningful policy change. For example, movements associated with costly protests can signal issue salience and, under certain circumstances, pressure political elites to adopt policy changes favored by minority groups (Gause, 2020; Gillion, 2013, 2020). On the other hand, if political movements (or the activists associated with them) are perceived to be too extreme, this can undermine public support and even generate political backlash (Feinberg, Willer, and Kovacheff, 2020; Wasow, 2020). Given the unprecedented dissatisfaction with policing and widespread public demands for change that emerged in 2020 , why were the most politically salient proposals to reshape policing so unpopular?

Prior work has identified at least three classes of potential mechanisms that could explain public opposition to these proposals. A first possibility, reflected in statements made by many advocates of defunding and abolition, is that opposition stems from misperceptions about the true underlying goals behind these movements, or the "imaginative limitations" of the mass public (see e.g., Illing, 2020). Prior work on U.S. public opinion has shown that public support for a particular policy is shaped by the underlying beliefs that individuals have about the substantive implications of that policy. For example, Americans' greater opposition to "welfare" compared to "assistance to the poor" reflects underlying differences in the substantive policy programs believed to be associated with each (Huber and Paris, 2013). Similarly, public opposition to proposals to change policing may have reflected a dislike for the slogans (e.g., "defund the 
police") associated with them rather than the substantive policy changes actually sought (e.g., reallocating funding from police departments to social services).

A second possibility, distinct from views about policy slogans, is that opposition reflects negative beliefs about, or attitudes towards, the activists associated with these proposed changes to policing. For example, survey experimental work conducted after Floyd's murder found certain protest tactics that led to increased public fear (e.g., property destruction) also caused an increase in public support for repressive policing (Metcalfe and Pickett, 2021). Despite the fact that protests in 2020 were overwhelmingly peaceful (Armed Conflict Location and Event Data Project, 2020), selective media coverage of certain events (e.g., burning buildings in Minneapolis-Saint Paul) may have cultivated misperceptions that protestors and the movements associated with them were violent (Harlow, Kilgo, Salaverría, and García-Perdomo, 2020). While non-violent social movements have historically mobilized public support, those associated with violence typically increase public fear and opposition (Chenoweth, Stephan, and Stephan, 2011). Related prior work has also demonstrated that policy changes which are perceived to benefit Black individuals tend to generate public opposition in the United States, particularly among White voters (e.g., Gilens, 1999). Therefore, it is possible, perhaps due to media framing, that White individuals perceived those advocating for change as disproportionately Black and were less supportive of the social movements associated with them due to underlying anti-Black prejudice (see also Davenport, Soule, and Armstrong, 2011).

Third, it is possible that the resource reductions or re-allocations explicit in politically salient proposals to reshape policing were perceived as too extreme and potentially threatening to the roles police play in crime control and order maintenance. Fear of crime has occupied a central role as a source of public support for police authority and punitive policy in prior 
empirical work (e.g., Block, 1971; Costelloe, Chiricos, and Gertz, 2009; Singer, Chouhy, Lehmann, Walzak, Gertz, and Biglin, 2019; Tyler and Weber, 1982), and more recent work has also shown the mass public believes police are a cost-effective source of crime prevention (e.g., Metcalfe and Pickett, 2018). Public opposition to abolition and defunding might therefore be explained by elevated fears of crime during a period that saw both a significant increase in homicides and widespread beliefs that crime was rising.

At the same time, it is also important to note that public expectations about the roles that police departments play in society extend well beyond crime control. Since at least the early 1990s, municipal police departments throughout the United States have regularly engaged in "community policing" activities that involve non-enforcement contact and cooperation with the public on matters that are, at best, only indirectly related to crime reduction (Cheng, 2020; Peyton, Sierra-Arévalo, and Rand, 2019; Rivera-Cuadrado, 2021). Perhaps unsurprisingly, national surveys fielded in the aftermath of Floyd's murder showed that majorities were opposed to reductions in spending on police services in general, but also believed officers should continue to play a role in a variety of specific tasks, ranging from vehicle stops to community engagement activities like youth outreach, even if supplemented by social service workers (e.g., Pew, 2020; Peyton, Vaughn, and Huber, 2020).

Of course, changes in the number of police on the street and their involvement in certain activities were not the only policy reforms that these advocates sought. It is also possible, though less likely, that individuals perceived differences in the administrative and procedural reforms accompanying each of these proposals; for example, administrative changes that would make it easier to fire problem officers, implementing civilian review boards, or requiring officers to issue verbal warnings before using their weapons. 
In sum, there are at least three potential explanations for public opposition to the different proposals to reshape policing that emerged during the summer of 2020 . In the next section we empirically investigate these explanations by taking up three questions. First, does opposition to slogans like "defund the police" obscure support for the substantive policy changes behind these proposals? Second, does opposition to different proposals reflect negative beliefs/attitudes about the activists associated with them, or the policy changes they seek to implement? Third, does opposition arise because people associate different proposals with increased crime and decreased public safety? We offer answers to each question using randomized survey experiments that were conducted during the period of nationwide political unrest sparked by Floyd's murder.

\section{Data and Results}

Our core data come from a national survey of U.S. adults conducted in October 2020 (N $=1,137)$. The sample was obtained via the Lucid platform, which provides researchers with access to a sampling frame of over 11 million U.S. adults. Lucid has grown in popularity over the last five years and is now one of the most widely used online survey platforms for academic research. ${ }^{6}$ Like other firms that source from opt-in online panels (e.g., YouGov, Qualtrics), Lucid provides researchers with quota samples of respondents that match U.S. census margins on demographic characteristics, and Lucid's quota samples compare favorably with nationally representative samples on both demographics and psychological traits (see Coppock and McClellan, 2019). As with other recent surveys that rely on quota samples to study criminal justice attitudes (e.g., Graham, Pickett, and Cullen, 2020; Metcalfe and Pickett, 2021), we find that our estimates of key outcome measures, such as support for police abolition $(23 \%)$, defunding (34\%), and reform (66\%), closely match those obtained from probability samples conducted in the preceding months. ${ }^{7}$ For example, an ABC News/Ipsos poll from June 2020 
found that $34 \%$ of U.S. adults supported defunding police departments (Jackson and Newall, 2020); and a Gallup poll from July 2020 found that $58 \%$ believed major police reforms were needed, though only $15 \%$ supported abolishing police departments (Crabtree, 2020).

While it is encouraging that attitudes on key variables of interest in our survey comport well with probability surveys conducted around the same time, making descriptive inferences about the U.S. adult population from quota samples is generally inadvisable because they may still differ from the target population on unobserved characteristics. ${ }^{8}$ However, a large body of prior work has demonstrated that survey experimental estimates obtained from nonprobability samples (including undergraduates and Amazon Mechanical Turk workers) closely match those from probability samples, demonstrating that results from nonprobability samples typically generalize to the broader population (Berinsky, Huber, and Lenz, 2012; Coppock, 2019; Coppock, Leeper, and Mullinix, 2018; Coppock and McClellan, 2019; Mullinix, Leeper, Druckman, and Freese, 2015; Peyton et al., 2021). Our primary focus in this paper is therefore on the inferences that can be made from the survey experimental estimates we obtain.

Following best practices to ensure data quality in online research, we restricted participation to respondents who read and passed an attention screener placed at the beginning of the survey (see Aronow, Kalla, Orr, and Ternovski, 2020; Peyton et al., 2021 for recent work on respondent attentiveness, and Online Appendix Sections C.1 and D.1 for additional details). Of the 2,099 respondents who consented to participate in the survey, 1,137 passed the attention check and completed the survey. This sample of 1,137 individuals was comparable to the U.S. adult population on sex, geographic region, age, and race/ethnicity (see Online Appendix Table C1). Using proportions from the American Community Survey as our population benchmark, we constructed survey weights to adjust for observed differences in education and household income 
(see Online Appendix C.2). Following recommendations by Franco and colleagues (2017), we report weighted estimates here and provide comparisons between weighted and unweighted estimates in Online Appendix B. Consistent with prior work (e.g., Miratrix, Sekhon, Theodoridis, and Campos, 2018), none of the minor differences between our weighted and unweighted experimental estimates are statistically significant or substantively meaningful. The Online Appendix provides additional methodological details about survey design, data collection, and randomization, as well as complete question wordings.

We now turn toward examining whether the potential mechanisms outlined in the previous section can explain different levels of public support for proposals to reshape policing that emerged during the summer of 2020 . We focus on three politically salient proposals that vary in the degree of change sought by their proponents: abolition, defunding, and reform. In each subsection, we provide relevant details about research design and outcome measurement alongside our estimates. Unless otherwise indicated, all estimates are presented graphically in the manuscript, with the underlying point estimates and standard errors in tabular form included in the Online Appendix.

\section{Do Unpopular Slogans Obscure Public Support for Substantive Policy Goals?}

We first examine whether the relative lack of support for the more radical proposals to defund or abolish the police might be explained by a perceived disconnect between their popular slogans and their substantive policy goals. Specifically, we test the observable implication that describing the underlying policy goals of each proposal, rather than the slogan, caused an increase in public support. To do so, we used a within-subjects experiment that randomized the order in which both policy slogans (e.g., "defunding the police") and policy substance (e.g., "Reduce police budgets and reallocate funding to social services.") were presented. ${ }^{9}$ In each 
condition, respondents were asked to indicate their support on a 5-point scale, with response options scored as follows: "None at all" (1), "A little" (2), “A moderate amount" (3), "A lot" (4), and "A great deal" (5). This allows us to obtain one observation for each respondent, across six different conditions $(\mathrm{N}=1,137$ respondents $\mathrm{x} 6$ conditions $=6,822$ observations).

[Table 1 about here]

Table 1 provides a summary, with estimated group means for each condition and the difference between the slogan and substance conditions for each proposal (robust standard errors are estimated to correct for within-respondent clustering). The differences between the slogan and substance conditions demonstrate that describing the underlying policy goals associated with each proposal causes a statistically significant increase in public support for defunding $(0.28$ scale points, SE: $0.08, \mathrm{P}<0.01$ ), and reform (0.62 scale points, SE: $0.08, \mathrm{P}<0.01)$, but not abolition (-0.02 scale points, SE: $0.06, \mathrm{P}=0.74) .{ }^{10}$ Substantively, these effects correspond to a large increase in support for police reform (i.e., from an average of "a moderate amount" to "a lot") and a small increase in support for defunding.

For additional context, note the substantial gap between support for defunding and reform in the slogan condition: 1.36 scale points (SE: $0.08, \mathrm{P}<0.01$ ) on a 5-point scale. The observed increase in support for police defunding in the substance condition suggests that articulating the underlying policy goals, rather than the slogan, caused an increase in public support of about 0.28 scale points. This is somewhat smaller than the observed difference between support for defunding and abolition in the slogan condition ( 0.38 scale points, SE: $0.07, \mathrm{P}<0.01)$, and roughly half the size of the increase in public support caused by articulating the underlying goals associated with police reform $(0.62$ scale points, SE: $0.08, \mathrm{P}<0.01)$. This suggests that although the slogan somewhat depressed public support for the underlying goals of police defunding, this 
can only explain about $20 \%$ of the observed gap between support for defunding and public demand for police reform.

[Figure 1 about here]

Figure 1 shows the group means and 95\% confidence intervals for each of the six conditions. Overall, the ordering of support observed within each condition is the same: the public was significantly more supportive of proposals to reform, rather than defund or abolish, the police regardless of whether descriptions were slogan- or substance-based. Taken together, these results show that public support for proposals to reform and, to a much lesser extent, defund the police can be increased by describing their substantive policy content. However, these results also suggest that the "defund" and "abolish" slogans were not the primary reason for the lack of public support for these proposals.

As the results in Figure 1 clearly demonstrate, public support for police reform significantly exceeded support for defunding and abolition, regardless of how these proposals were described. It is also notable that specifying the policy goals of "police reform" caused the largest increase in public support across all three proposals. This suggests that ambiguity about the meaning of "police reform" may itself have depressed public support, or that whatever people associated with the reform slogan at baseline was less appealing than the substantive description we provided.

Given the similar ordering of support for policies in the substance and slogan conditions, we now turn to examining if any of the other factors discussed above might explain observed differences in support across the policy slogans. That is, we investigate potential mechanisms. Unless otherwise noted, all estimates reported in the following subsections are from betweensubjects experimental designs in which respondents were randomly assigned to a single proposal 
(abolishing, defunding, or reforming) with equal probability. We report all group means graphically, and highlight some key between-group differences. All point estimates, standard errors, and between-group differences (with $P$-values adjusted for multiple comparisons) are reported in Online Appendix Section B.

\section{Does Opposition Reflect Different Beliefs About the Activists Associated with these Proposals?}

To investigate beliefs about the activists associated with each label, we asked respondents to: "Think about people who support [abolishing, defunding, or reforming] the police. Do you believe most of these people oppose or support each of the following?" and included in this list "Destruction of government property" and "Attacks on police officers." Responses were measured using a binary outcome ("Oppose" $=0$; "Support" $=1$ ). Figure 2a shows that roughly $41 \%$ of respondents believed that most supporters of police abolition also supported destruction of property and $46 \%$ supported attacks on police. By comparison, these estimates are $44 \%$ and $42 \%$ for defunding and $37 \%$ and $39 \%$ for reform. These differences across the different slogans are modest in size and none are statistically distinguishable, suggesting that the large gaps in public support among proposals are not explained by large differences in respondents' beliefs about the protest tactics of supporters. It is notable that nearly $40 \%$ of respondents believed most supporters of police reform also supported destruction of property and attacks on police officers, suggesting that a sizeable minority of respondents still associated reform with violent protests.

[Figure 2 about here]

We also investigated perceptions of the racial composition of those supporting each policy proposal. These data come from a supplementary between-subjects experiment conducted on Lucid in February 2021 (see Appendix D for details on survey design and question wordings). In this experiment, 1,756 respondents were randomly assigned to abolishing, defunding, or 
reforming the police with equal probability and then asked to make inferences about the background characteristics of supporters: what proportion were Black, Female, had voted in the 2020 election, and had voted for Biden (presented in randomized order). To reduce measurement error, respondents' estimates were elicited using the frequency format alongside a quantitative benchmark for the U.S. population (see Aaron and Spivey, 1998; Ansolabehere, Meredith, Snowberg, 2013). For example, "Think about the people who support [abolishing, defunding, or reforming] the police. Out of every 100 supporters, how many do you think are Black? For your reference, approximately $13 \%$ of the US population is Black."

Knowing that only $13 \%$ of the U.S. population is Black, respondents estimated, on average, that 53\% (i.e., 53 out of 100) of those who supported police reform were Black, compared to $49 \%$ of those supporting defunding (difference from reform: -4.16 percentage points, $\mathrm{SE}=2.41, \mathrm{P}=0.08$ ), and $46 \%$ of those supporting abolition (difference from reform: 6.65 percentage points, $\mathrm{SE}=2.41, \mathrm{P}<0.01)$. Additionally, compared to those supporting reform, supporters of both abolition and defunding were perceived by respondents to be disproportionately male, less likely to have voted in the 2020 presidential election, and less likely to have voted for Biden (see Appendix Fig. D3, Tables D3.1-D3.2).

In sum: although supporters of all three proposals to change policing were perceived as disproportionately Black compared to U.S. population estimates, the pattern is exactly the opposite of what one would predict if opposition to defunding and abolition originated in beliefs that supporters of these proposals were disproportionately Black relative to supporters of police reform. That is, both abolition and defunding were perceived as having disproportionately lower, not higher, proportions of Black supporters than police reform. 


\section{Does Opposition Reflect Different Beliefs About the Policies Associated with these Proposals?}

We next investigate whether supporters of these different proposals are believed to have different policy preferences. We divide this analysis into two distinct components. First, we examine perceived support for specific police policy changes across each of the three randomly assigned proposals. Second, we examine whether respondents held different beliefs about each group of supporters' preferences for changing various public service roles that police officers play, as well as reductions to the number of police on the streets. Figure 3 shows the proportion of respondents who believed that supporters of each randomly assigned proposal were in favor of eight specific policy changes. Each of these changes were politically salient in the aftermath of Floyd's murder and enjoyed broad public support in contemporaneous public opinion polls (see e.g., Shannon, 2020; Zhou, 2021).

Across all eight proposed changes, we do not find any statistically distinguishable differences between respondents' beliefs about the proportion of supporters that favored these changes (see Appendix Table B3.2-B3.1 for point estimates and comparisons). The largest observed difference was for reducing the use of military equipment by police departments: 11 percentage points higher for abolition $(\mathrm{SE}=0.05, \mathrm{P}=0.26)$ and 9 percentage points higher for defunding $(\mathrm{SE}=0.05, \mathrm{P}=0.07$ ) when compared to reform. Overall, those supporting reform were perceived as less likely than supporters of both defunding and abolition to favor changes to on-the-ground police tactics, but even the largest observed differences were not large enough to explain the substantial gaps between the proportion of respondents supporting police reform (66\%) over abolition (23\%) and defunding (34\%).

[Figure 3 about here] 
We also measured respondents' beliefs about whether supporters of each proposal sought more general policing changes, including eliminating police altogether, replacing them with social services, reducing police spending, and reducing the number of officers on the streets. To measure beliefs about eliminating police departments and replacing police with social services, we used the same binary measure of whether respondents believed most supporters opposed or supported them ("Oppose" =0; "Support" =1). Perceptions of supporters' desired changes to spending on police services and the number of officers on the street were measured using a 5point scale ranging from "Increase a lot" (1) to "Decrease a lot" (5). Figure 4a shows the percentage of respondents who believed supporters of each proposal were in favor of (1) eliminating police departments altogether and (2) replacing police officers with social service workers. Figure 4b shows respondents' beliefs about the degree of reductions to (3) police spending and (4) officer numbers that were sought by supporters of each proposal.

[Figure 4 about here]

In contrast to the minimal differences found in respondents' beliefs about the racial composition of supporters and their associations with violent protest tactics (Fig. 2), as well as their preferences for specific police policy changes (Fig. 3), here we observe substantively meaningful differences that are proportional to average levels of public support for each proposal. First, Figure 4a shows that just $42 \%$ of respondents believed those who supported reforming the police wanted to eliminate police departments, whereas $52 \%$ and $65 \%$ of respondents believed supporters of defunding and abolishing police, respectively, wanted to do so. This is a 23 -percentage point difference between reforming and abolishing the police (difference $=0.23, \mathrm{SE}=0.05, \mathrm{P}<0.01)$, and a 10 -percentage point difference between reforming and defunding the police (difference $=0.10, \mathrm{SE}=0.05, \mathrm{P}=0.06$ ). Likewise, $51 \%$ of respondents 
believed those supporting reform wanted to replace police with social services, compared to $65 \%$ for defunding $($ difference $=0.13 ; \mathrm{SE}=0.05, \mathrm{P}<0.01)$ and $64 \%$ for abolishing $($ diff $=0.14 ; \mathrm{SE}=$ $0.05, \mathrm{P}<0.01)$. These differences were not observed across other areas of government spending, including education, healthcare, housing, and social services; suggesting that proposals for abolishing and defunding police were not perceived to involve significant differences in other government services (see Online Appendix Figure B9 and Tables B9.1-B9.2 for these analyses).

Figure $4 \mathrm{~b}$ shows differences in respondents' beliefs about the degree of reductions to police spending and officer numbers that were sought by supporters of each proposal. First, respondents believed that supporters of abolishing and defunding the police wanted significantly greater reductions to police spending than supporters of police reform. Average scores on the 5point scale were 3.64 for reforming the police, and respondents believed that supporters of both abolition and defunding wanted significantly greater reductions in police spending: differences of $0.49(\mathrm{SE}=0.13, \mathrm{P}<0.01)$ and $0.30(\mathrm{SE}=0.13, \mathrm{P}=0.02)$ scale points, respectively. Second, respondents believed that supporters of abolition and defunding wanted even larger reductions to the number of police on the street: differences of 0.74 scale points $(\mathrm{SE}=0.09, \mathrm{P}<0.01)$ and 0.55 $(\mathrm{SE}=0.09, \mathrm{P}<0.01)$ scale points, respectively, when compared to reform.

These differences of more than half a scale point on a 5-point scale are both statistically and substantively significant. For context, recall from our earlier analyses (see Table 1, Figure 1) that differences between support for the policy substance versus political slogans of abolition and defunding were considerably smaller: -0.02 and 0.28 scale points on a 5-point scale, respectively. The comparatively larger differences observed here suggest that respondents' perceptions about the degree to which supporters of abolition and defunding wanted to reduce the number of police 
on the street offer a much better explanation for public opposition to these proposals than the unpopularity of their political slogans.

In sum, the results in Figure 4 clearly demonstrate that respondents believed both abolishing and defunding the police involved significant reductions in the on-the-ground capacity of police departments. ${ }^{11}$ But what remains unclear is whether people believe reductions to police capacity have any meaningful implications, beyond fewer tax dollars allocated to police departments. We next examine variation in public support for police responses to different calls for service and beliefs about how reducing capacity by decreasing the number of available officers in local police departments is perceived to affect crime and public safety.

To understand variation in public support for police responses to specific calls for service, we asked respondents how their local government should respond to a variety of 911 calls ranging from violent domestic disputes to drug overdoses. Each call for service was presented in random order and respondents selected what they believed to be the most appropriate response from a list of four mutually exclusive options: 1) only the police should be sent; 2) the police should be accompanied by another first responder, such as social services; 3 ) another first responder should be sent without police; or 4) no government response should take place. Sending only the police was the most preferred option across all incidents except for a call about teens playing loud music (see Online Appendix Fig. B7 and Table B7 for the proportions selecting each option across all incidents). Figure 5a shows the proportion of respondents who believed there should be no police involvement (i.e., either option 3 or 4 was selected) across eight specific incidents generating a call for service.

Across all incidents, a minority of respondents believed that police should not be involved in some capacity, with opposition in proportion to the severity of the incident. For 
example, only about $10 \%$ of respondents believed that police should not be involved in responding to a scenario involving a person threatening their spouse with a knife, and fewer than $20 \%$ believed police should not respond to a simple assault outside of a bar. Moreover, few respondents were opposed to police involvement in petty, non-violent incidents. For example, only $21 \%$ of respondents believed police should not be involved in responding to a call alleging attempted use of a counterfeit $\$ 50$ bill at a local store, the same call for service that preceded George Floyd's murder in May of 2020. For nuisance complaints involving emotionally disturbed persons, such as an intoxicated person harassing restaurant patrons or someone yelling racial slurs at people in a voting queue, fewer than $40 \%$ of respondents were opposed to police involvement. Notably, even for incidents where there is the most debate about the utility of law enforcement, such as a drug overdose or teens playing music in a park, a majority of respondents still wanted police to be involved in some capacity. These results demonstrate that the public strongly prefers police involvement across a wide range of calls for service, even when sending a different first responder is posed as an alternative option. This shows there is little appetite among the mass public for policy changes that might reduce a police department's capacity to send officers to even mundane calls that involve no direct threat to public safety.

[Figure 5 about here]

To quantify the perceived implications that reductions to police capacity have on crime and safety, we conducted another experiment that elicited respondents' beliefs about the causal effects of reducing the number of police on the streets. Specifically, we randomly assigned respondents to consider one of four scenarios: the number of police officers in their local police department was reduced by $10 \%, 25 \%, 50 \%$, or $100 \%$. The respondents were then asked to estimate the effect on 1) crime levels, using a 5-point scale from "Much lower" (1) to "Much 
higher" (5); and 2) feelings of personal safety (i.e., fear of crime) using a 5-point scale from "Much more safe" (1) to "Much less safe" (5). Both scales had a neutral midpoint indicating the reductions would have no effect. For simplicity, Figure $5 \mathrm{~b}$ plots the proportion of respondents that believed crime (safety) would increase (decrease) across each of the four randomly assigned scenarios (Tables B5.1b and B5.2 in the Online Appendix show robustness to using the 5-point scales, and Fig. B8.2 shows the response distributions in Panel b across treatment arms).

The results of this experiment provide clear evidence that individuals believe even small reductions to their local police departments' capacity to respond to calls for service will increase crime and decrease safety. Specifically, $55 \%$ of respondents believed even a $10 \%$ reduction to the number of police on the street would increase crime, and $57 \%$ believed they would be less safe as a result. Concerns about crime and safety increase monotonically with the size of reductions: $75 \%$ of respondents believed a $100 \%$ reduction (i.e., eliminating their police department) would increase crime, and $73 \%$ believed this would decrease safety.

Cumulatively, the results presented in Figures 4 and 5 suggest that despite widespread support for police reform in the aftermath of George Floyd's murder, opposition to proposals for abolishing and defunding the police can largely be explained by public opposition to reducing the on-the-ground capacity of police departments, and the perceived impact this would have on crime and safety. Specifically, the mass public believed that proposals to abolish and defund the police were significantly more likely than reform proposals to result in reductions to police services and the number of officers on the street. There was very little public support for reducing funding for police services during a time in which most people preferred police involvement in a wide variety of incidents, both violent and non-violent. Reducing the capacity 
of police departments was unpopular, and even proposals for modest reductions led to concerns about crime and public safety.

\section{Policy Implications and Limitations}

Overall, the results reported here demonstrate a broad consensus in public attitudes toward proposals to reshape policing in the months following George Floyd's murder in May 2020. While the mass public strongly supported police reform during this period of nationwide political unrest, proposals to either defund or abolish the police generated net opposition. Even as a political slogan, "police reform" received widespread support and was significantly more popular than proposals to abolish or defund the police. We also found that articulating the specific policy goals associated with police reform caused a substantial increase in public

support. By comparison, support for proposals to abolish or defund the police was low regardless of whether their underlying policy goals were articulated. Finally, supporters of both abolition and defunding were not disproportionately perceived to be associated with violent protest tactics, or different policy changes related to police administration (e.g., making firing police officers easier) or officer behavior (e.g., banning the use of chokeholds).

In sum, we did not find compelling evidence that public opposition to defunding and abolition could entirely be explained by unpopular political slogans, negative beliefs or attitudes about the supporters of these proposed changes, or different beliefs about the specific administrative and officer-level reforms that were sought. We found consistent evidence that both abolition and defunding were associated with reduced spending on police services and fewer police on the street. Although some elements of the abolition and defunding proposals were popular (e.g., increased social services), the mass public still preferred police involvement 
in a wide variety of activities and was opposed to reduced spending on police services. Further, most believed that fewer officers on the street would increase crime and decrease safety.

In terms of the implications of these findings for policymakers and police agencies, these results show why both abolition and defunding were unpopular in 2020, and why they are unlikely to gain additional public support with greater discussions of their core policy goals, particularly alongside growing concerns about crime and safety. While a greater portion of the public appears open to supplementing the police with non-police in response to some calls for service, removing the police altogether is perceived as too extreme. Even for cases that some view as purely public health matters, such as public drug overdoses, most prefer at least some level of police involvement. The average person is also opposed to reducing the number of officers on the street and believes doing so will increase crime and decrease their safety. In light of this fact, it is not surprising that several municipalities that most fully embraced defunding their police departments have substantially revised those changes in the face of growing public concerns about crime and safety (see e.g., Goodwin, 2021).

In the case of police reform, it appears that advocates would do well to articulate the specific reforms they seek, because this may further increase support for a movement that is already supported by most. Many of these reforms are likely to remain popular even amid growing concerns about crime because specific incremental changes aimed at mitigating harm caused by police are not perceived to undermine public safety and do not threaten individuals' expectations about the services that police departments will provide.

This paper also has several limitations. Because most policing policy is set at the local level and not all communities are the same, focusing on average opinion at the national level may obscure important details about the connections between public opinion and policy changes 
at the local level. While average opinion at the national level is certainly important for understanding political outcomes at the federal level, sub-national estimates could capture variation across specific geographic constituencies. This is a clear avenue for future research.

Our focus on aggregate public opinion may also obscure important heterogeneity by race/ethnicity and partisanship. For example, Democrats generally trust police less than Republicans, and have less punitive policy preferences. Similar differences hold for comparisons between White and Black individuals, with the former group reporting higher levels of trust in police and more punitive policy preferences. These differences have been consistently observed in U.S. public opinion across time and space, at least since the advent of large-scale survey research in the 1960s (see, e.g., Bennett and Tuchfarber, 1975; Brown and Benedict, 2002; Peek, Alston, and Lowe, 1978). Overall, we find similar differences in baseline support for different changes to policing, but the relative differences we focus on here were similar within each group (see Online Appendix Figures B10a-B11b and Tables B10.1-B12.2 for sub-group analyses). For example, support for all three proposals we investigated here was highest among Black respondents, but both abolition and defunding were significantly less popular than reform. Similarly, both Black and White respondents' concerns about crime and safety increased in proportion to the size of potential funding cuts to their local police departments. But sample size constraints limit the statistical power for detecting small but nevertheless substantively important sources of heterogeneity, and future survey experiments designed to reliably estimate how effects might vary across sub-groups is another clear avenue for future research.

Of course, widespread public support for police reform is not a sufficient condition for policy change. While fear of crime has been shown to influence policymaking, police reforms that are not perceived to have negative implications for crime and safety may still be 
unsuccessful. For example, the Senate recently failed to pass the George Floyd Justice in Policing Act, a modest police reform bill supported by both the International Association of Chiefs of Police (IACP) and the Fraternal Order of Police (FOP). At the local level, many efforts for even modest administrative reforms targeting greater officer oversight have floundered in the face of concerted opposition from politicians and police unions (e.g., Dungca and Abelson, 2021). Greater understanding of the institutional conditions that prevent popular police reforms from becoming policy at both the national and local level is another important avenue for future research.

Beyond providing new evidence about public opinion towards recent proposals to reshape policing in the United States, this paper also demonstrates the utility of using survey experiments to explore multiple potential pathways that might explain observed levels of public support. This approach allows for a deeper investigation of the connection between public support for criminal justice policy proposals and their perceived implications for crime and public safety. Nevertheless, we only examined stated beliefs and preferences, which do not necessarily directly map onto political behaviors. While such concerns are usually heighted when attempting to estimate public opinion on sensitive topics, a key limitation of most surveys - ours included - is that they do not provide data on preference intensity. For example, would those who are opposed to police defunding turn out to vote against a candidate who ran on a platform of cutting the police budget, or simply stay home? Another avenue for future research is to investigate the degree to which those seeking to change policing and those skeptical of such changes differ in the strength of their preferences, as those who feel more strongly are likely to have a greater impact on policy outcomes. 


\section{Conclusion}

The murder of George Floyd in May 2020 once again focused public attention on longstanding issues of systemic racism and police brutality in the United States. This is not the first time that a policing crisis has led to widespread public concern about racial bias in policing and the failure of police departments to adequately provide public safety in minority communities; it is a familiar cycle (see e.g., United States National Advisory Commission on Civil Disorders, 1968). Given the unprecedented scale of protests and widespread demands for changes to policing in the aftermath of Floyd's murder, why were most Americans nevertheless opposed to proposals that sought to radically reshape policing? A simple explanation, consistent with the results reported here, is that people interpreted calls for abolishing and defunding the police literally, and feared that reducing the bureaucratic capacity of police departments would lead to increased crime and decreased public safety. This does not mean the mass public is opposed to significant changes to policing. On the contrary, there was widespread support for a variety of changes in 2020, including removing barriers to firing police officers, increasing funding for non-police services, and increasing the role of social service workers in supporting police responses to calls for service. Most people were simply opposed to zero-sum proposals that sought to pay for these changes by taking money away from police departments. Similar proposals are likely to be met with broad opposition during the next policing crisis as well. 


\section{References}

Aaron, E., \& Spivey, M. (1998). Frequency vs. probability formats: Framing the three doors problem. In Proceedings of the twentieth annual conference of the Cognitive Science Society (pp. 13-18).

Altheide, D. L. (2018). Creating fear: News and the construction of crisis. New York, NY: Routledge.

Ansolabehere, S., Meredith, M., \& Snowberg, E. (2013). Asking about numbers: Why and how. Political Analysis, 21(1), 48-69.

Armed Conflict Location and Event Data Project. (2020, September 16). Demonstrations and political violence in America: New data for summer 2020.

https://acleddata.com/2020/09/03/demonstrations-political-violence-in-america-new-datafor-summer-2020/

Arnold, R. D. (1990). The logic of congressional action. New Haven, CT: Yale University Press.

Aronow, P. M., Kalla, J., Orr, L., \& Ternovski, J. (2020). Evidence of rising rates of inattentiveness on Lucid in 2020. SocArXiv, 1-10. https://doi.org/10.31235/osf.io/8sbe4.

Bennett, S. E., \& Tuchfarber, A. J. (1975). The social-structural sources of cleavage on law and order policies. American Journal of Political Science, 19(3), 419-438.

Berinsky, A. J., Huber, G. A., \& Lenz, G. S. (2012). Evaluating online labor markets for experimental research: Amazon.com's Mechanical Turk. Political Analysis, 20(3), 351368. doi:10.1093/pan/mpr057

Buchanan, L., Quoctrung, B. \& Patel, J. K. (2020, July 3). Black Lives Matter may be the largest movement in U.S. history. The New York Times.

https://www.nytimes.com/interactive/2020/07/03/us/george-floyd-protests-crowdsize.html

Block, R. L. (1971). Fear of crime and fear of the police. Social Problems, 19(1), 91-101.

Brown, B., \& Benedict, W. R. (2002). Perceptions of the police: Past findings, methodological issues, conceptual issues and policy implications. Policing: An International Journal of Police Strategies \& Management. 25(3), 543-580.

Burstein, P. (2006). Why estimates of the impact of public opinion on public policy are too high: Empirical and theoretical implications. Social Forces, 84, 2273-2289.

Cheng, T. (2020). Input without influence: The silence and scripts of police and community relations. Social Problems, 67(1), 171-189.

Chenoweth, E., Stephan, M. J., \& Stephan, M. (2011). Why civil resistance works: The strategic logic of nonviolent conflict. New York, NY: Columbia University Press. 
Chudy, J., \& Jefferson, H. (2021, May 22). Support for Black Lives Matter surged last year. Did it last? The New York Times. https://www.nytimes.com/2021/05/22/opinion/blmmovement-protests-support.html

Clifford, S., Sheagley, G., \& Piston, S. (2021). Increasing Precision without Altering Treatment Effects: Repeated Measures Designs in Survey Experiments. American Political Science Review, 115(3): 1-18. https://doi.org/10.1017/S0003055421000241

Converse, P.E. (1964). The nature of belief systems in mass publics. Critical Review, 18(1): 174.

Coppock, A. (2019). Generalizing from survey experiments conducted on Mechanical Turk: A replication approach. Political Science Research and Methods, 7(3), 613-628. doi:10.1017/psrm.2018.10

Coppock, A., Leeper, T. J., \& Mullinix, K. J. (2018). Generalizability of heterogeneous treatment effect estimates across samples. Proceedings of the National Academy of Sciences 115(49), 12441-12446. https://doi.org/10.1073/pnas.1808083115

Coppock, A., \& McClellan, O. A. (2019). Validating the demographic, political, psychological, and experimental results obtained from a new source of online survey respondents. Research \& Politics, 6(1). https://doi.org/10.1177/2053168018822174

Corley, Westervelt, \& Kaste, (2020, June 12). Examples of reimagining police departments that show promise. National Public Radio. https://www.npr.org/2020/06/12/875548066/examples-of-re-imagining-policedepartments-that-show-promise

Costelloe, M. T., Chiricos, T., \& Gertz, M. (2009). Punitive attitudes toward criminals: Exploring the relevance of crime salience and economic insecurity. Punishment \& Society, 11(1), 25-49.

Crabtree, S. (2020, July 22). Most Americans say policing needs 'major changes'. Gallup. https://news.gallup.com/poll/315962/americans-say-policing-needs-major-changes.aspx.

Davenport, C., Soule, S. A., \& Armstrong, D. A. (2011). Protesting while black? The differential policing of American activism, 1960 to 1990. American Sociological Review, 76(1), 152178. DOI: $10.1177 / 0003122410395370$

Davis, A. (2003). Are prisons obsolete? New York, NY: Seven Stories Press.

Du Bois. W.E.B. (1935). Black reconstruction: An essay toward a history of the part which Black folk played in the attempt to reconstruct democracy in America, 1800-1880. New York: Harcourt, Brace, and Company.

Dungca, N., \& Abelson, J. (2021, April 27). When communities try to hold police accountable, law enforcement fights back. The Washington Post. 


\section{https://www.washingtonpost.com/investigations/interactive/2021/civilian-oversight-}

police-accountability/

Enns, P. K. (2016). Incarceration nation: How the United States became the most punitive democracy in the world. New York: Cambridge University Press

Erikson, R. S., MacKuen, M. B., \& Stimson, J. A. (2002). The macro polity. New York, NY: Cambridge University Press.

Esberg, J., \& Mummolo, J. (2018). Explaining misperceptions of crime. Social Science Research Network, 1-93. http://dx.doi.org/10.2139/ssrn.3208303

Esberg, J., Mummolo, J., \& Westwood, S. J. (2020). The stability of criminal justice policy views: Evaluating the effects of factual corrections and appeals to social identity. Working Paper. https://scholar.princeton.edu/sites/default/files/jmummolo/files/emw_2020_ms.pdf

Feinberg, M., Willer, R., \& Kovacheff, C. (2020). The activist's dilemma: Extreme protest actions reduce popular support for social movements. Journal of Personality and Social Psychology, 119(5), 1086. http://dx.doi.org/10.1037/pspi0000230

Franco, A., Malhotra, N., Simonovits, G., \& Zigerell, L. J. (2017). Developing standards for post-hoc weighting in population-based survey experiments. Journal of Experimental Political Science, 4(2), 161-172. https://doi.org/10.1017/XPS.2017.2

Gause, L. (2020). Revealing issue salience via costly protest: how legislative behavior following protest advantages low-resource groups. British Journal of Political Science, 1-21. https://doi.org/10.1017/S0007123420000423

Gerber, A. S., \& Green, D. P. (2012). Field experiments: Design, analysis, and interpretation. New York, NY: Norton.

Gilens, M. (1999). Why Americans hate welfare: Race, media, and the politics of antipoverty policy. Chicago, IL: University of Chicago Press.

Gillion, D. Q. (2013). The political power of protest: Minority activism and shifts in public policy. Cambridge, UK: Cambridge University Press.

Gillion, D. Q. (2020). The loud minority: Why protests matter in American democracy. Princeton, NJ: Princeton University Press.

Goodwin, J. D. (2021, October 10). A year after defund, police departments get their money back. New York Times. https://www.nytimes.com/2021/10/10/us/dallas-policedefund.html

Graham, A., Pickett, J. T. \& Cullen, F. T. (2020). Advantages of matched over unmatched opt-in samples for studying criminal justice attitudes: A research note. Crime \& Delinquency, 67(12), 1962-1981. https://doi.org/10.1177/0011128720977439 
Gramlich, J. (2016). Voters perceptions of crime continue to conflict with reality. Pew Research Center. http://pewrsr.ch/2fZxegQ

Grim, R. (2020, December 10). Inside Biden's meeting with civil rights leaders. The Intercept. https://theintercept.com/2020/12/10/biden-audio-meeting-civil-rights-leaders/

Harlow, S., Kilgo, D. K., Salaverría, R., \& García-Perdomo, V. (2020). Is the whole world watching? Building a typology of protest coverage on social media from around the world. Journalism Studies, 21(11), 1590-1608.

https://doi.org/10.1080/1461670X.2020.1776144

Harmon, A., \& Tavernise, S. (2020, June 12). One big difference about George Floyd protests: Many white faces. New York Times. https://www.nytimes.com/2020/06/12/us/georgefloyd-white-protesters.html

Herndon, A. W. (2021, January 2). How a pledge to dismantle the Minneapolis Police collapsed, New York Times. https:/www.nytimes.com/2020/09/26/us/politics/minneapolis-defundpolice.html

Hollar, J. (2020, June 11). Media acknowledge drive to defund police - but seek to blunt its radical edge. Fairness and Accuracy in Reporting. https://fair.org/home/mediaacknowledge-drive-to-defund-police-but-seek-to-blunt-its-radical-edge/

Huber, G. A., \& Paris, C. (2013). Assessing the programmatic equivalence assumption in question wording experiments: Understanding why Americans like assistance to the poor more than welfare. Public Opinion Quarterly 77(1), 385-397. https://doi.org/10.1093/poq/nfs054

Illing, S. (2020, June 12). The "abolish the police" movement, explained by 7 scholars and activists. Vox. https://www.vox.com/policy-and-politics/2020/6/12/21283813/georgefloyd-blm-abolish-the-police-8cantwait-minneapolis

Imai, K., King, G., \& Stuart, E. A., (2014). Misunderstandings between experimentalists and observationalists about causal inference. In Langan Teele, D. (Ed.), Field experiments and their critics (pp. 196-227). Yale University Press.

Jackson, C., \& Newall, M. (2020, June 12). Americans' concerns about COVID-19 continue to decline. IPSOS. https://www.ipsos.com/en-us/news-polls/abc-coronavirus-poll-wave-12

Jones, J. (2020, August 12). Black, White Adults' Confidence Diverges Most on Police. Gallup. https://news.gallup.com/poll/317114/black-white-adults-confidence-diverges-police.aspx

Kapos, S. (2020, June 24). "It's a nice hashtag": Chicago's Lightfoot pushes police reform, not defunding. Politico. https://perma.cc/9FHU-97HX

Klemko, R., \& Sullivan, J. (2021, June 10). The push to remake policing takes decades, only to begin again. The Washington Post.

https://www.washingtonpost.com/investigations/interactive/2021/police-reform-failure/ 
Lax, J. R., Phillips, J. H. (2012). The democratic deficit in the states. American Journal of Political Science, 56(1), 148-66.

Mayhew, D. R. (1974). Congress: The electoral connection. New Haven, CT: Yale University Press.

McCarthy, J. (2015, October 22). More Americans say crime is rising in the U.S. Gallup. https://news.gallup.com/poll/186308/americans-say-crime-rising.aspx

McCarthy, J. (2020, November 13). Perceptions of increased U.S. crime at highest since 1993. Gallup. https://news.gallup.com/poll/323996/perceptions-increased-crime-highest1993.aspx

Metcalfe, C., \& Pickett, J. T. (2018). The extent and correlates of public support for deterrence reforms and hot spots policing. Law \& Society Review 52(2), 471-502.

https://doi.org/10.1111/lasr.12327

Metcalfe, C., \& Pickett, J. (2021). Public fear of protesters and support for protest policing: An experimental test of two theoretical models. Criminology, 1-30. https://doi.org/10.1111/1745-9125.12291

Miller, L. L. (2016). The myth of mob rule: Violent crime and democratic politics. New York, NY: Oxford University Press.

Miratrix, L. W., Sekhon, J. S., Theodoridis, A. G., \& Campos, L. F. (2018). Worth weighting? How to think about and use weights in survey experiments. Political Analysis, 26(3), 275-291. https://doi.org/10.1017/pan.2018.1

Mullinix, K. J., Leeper, T. J., Druckman, J. N., \& Freese, J. (2015). The generalizability of survey experiments. Journal of Experimental Political Science, 2, 109-138. DOI: 10.1017/XPS.2015.19

Nicholson-Crotty, S., Peterson, D. A., \& Ramirez, M. D. (2009). Dynamic representation(s): Federal criminal justice policy and an alternative dimension of public mood. Political Behavior, 31(4), 629-655.

Peek, C. W., Alston, J. P., \& Lowe, G. D. (1978). Comparative evaluation of the local police. Public Opinion Quarterly, 42(3), 370-379.

Pew Research Center. (2020, July 9). Majority of public favors giving civilians the power to sue police officers for misconduct.

https://www.pewresearch.org/politics/2020/07/09/majority-of-public-favors-givingcivilians-the-power-to-sue-police-officers-for-misconduct/

Peyton, K., Huber, G. A., \& Coppock, A. (2021). The generalizability of online experiments conducted during the COVID-19 Pandemic. Journal of Experimental Political Science, 116. https://doi.org/10.1017/XPS.2021.17 
Peyton, K., Sierra-Arévalo, M., \& Rand, D. G. (2019). A field experiment on community policing and police legitimacy. Proceedings of the National Academy of Sciences, 116(40), 19894-19898.

Peyton, K., Vaughn, P. E., \& Huber, G. A. (2020, August 31). Americans don't support the idea of defunding the police. The Washington Post. https://www.washingtonpost.com/politics/2020/08/31/slogan-defund-police-can-turnamericans-away-movement-against-police-brutality/

Pfeiffer, C., Windzio, M., \& Kleimann, M. (2005). Media use and its impacts on crime perception, sentencing attitudes and crime policy. European Journal of Criminology, 2(3), 259-285. https://doi.org/10.1177/1477370805054099

Pickett, J. T. (2019). Public opinion and criminal justice policy: Theory and research. Annual Review of Criminology, 2, 405-428. https://doi.org/10.1146/annurev-criminol-011518024826

Putnam, L., Chenoweth, E., \& Pressman, J. (2020, June 6). The Floyd protests are the broadest in US history - and are spreading to white, small-town America. The Washington Post. https://www.washingtonpost.com/politics/2020/06/06/floyd-protests-are-broadest-ushistory-are-spreading-white-small-town-america/

Ramirez, M. D. (2013). Punitive sentiment. Criminology, 51(2), 329-364. https://doi.org/10.1111/1745-9125.12007

Reny, T. T., \& Newman, B. J. (2021). The opinion-mobilizing effect of social protest against police violence: Evidence from the 2020 George Floyd protests. American Political Science Review, 1-9. https://doi.org/10.1017/S0003055421000460

Rivera-Cuadrado, W. (2021). Crafting charismatic cops: Community policing and the faulty reputations paradigm. Social Problems, 1-17.

Roberts, L. D., \& Indermaur, D. (2012). Are neighbourhood incivilities associated with fear of crime? In Pietsch, J., \& Aarons, H. (Eds.), Australia: Identity, fear and governance in the 21st Century (pp. 61-78). Canberra, ASTL: Australian National University.

Rosenfeld, R., Abt, T., \& Lopez, E. (2021). Pandemic, social unrest, and crime in US cities: 2020 year-end update. Washington, DC: Council on Criminal Justice.

Shannon, J. (2020, June 29). USA TODAY poll: Americans want major police reform, more focus on serious crime. USA TODAY. https://www.usatoday.com/story/news/nation/2020/06/29/us-police-reform-poll-findssupport-more-training-transparency/3259628001/

Shi, L. (2021). Crime trend perceptions, negative emotions, and public punitiveness: a survey experiment of information treatment. Journal of Experimental Criminology, 1-19. https://doi.org/10.1007/s11292-020-09454-7 
Singer, A.J., Chouhy, C., Lehmann, P.S., Walzak, J.N., Gertz, M., \& Biglin, S. (2019). Victimization, fear of crime, and trust in criminal justice institutions: A cross-national analysis. Crime \& Delinquency, 65(6), 822-844.

https://doi.org/10.1177/0011128718787513

Smith, S. J. (1984). Crime in the news. The British Journal of Criminology, 24(3), 289-295.

Tyler, T. R., \& Weber, R. (1982). Support for the death penalty: Instrumental response to crime, or symbolic attitude? Law \& Society Review, 17, 21-45.

United States National Advisory Commission on Civil Disorders. (1968). Report of the national advisory commission on civil disorders. US Government Printing Office.

Walker, S. (1977). Critical history of police reform: The emergence of professionalism. Lexington, MA: Lexington Books.

Walker, S. (1998). Popular justice: A history of American criminal justice. Oxford University Press.

Wasow O. (2020). Agenda seeding: How 1960s black protests moved elites, public opinion and voting. American Political Science Review, 114(3), 638-659. https://doi.org/10.1017/S000305542000009X

Zhou, L. (2021, April 9). Where Americans stand on policing today. Vox. https://www.vox.com/22372342/police-reform-derek-chauvin 
Table 1. Support for Abolishing, Defunding, or Reforming Police by Political Slogan and Policy Substance

\begin{tabular}{|c|c|c|}
\hline Condition & Description & Mean (SE) \\
\hline \multicolumn{3}{|l|}{ Police abolition: } \\
\hline Slogan & "Abolishing the police" & $1.66(0.05)$ \\
\hline Substance & "Eliminate police and reallocate funds to other activities." & $1.64(0.04)$ \\
\hline Difference & & $-0.02(0.06)$ \\
\hline \multicolumn{3}{|l|}{ Police defunding: } \\
\hline Slogan & "Defunding the police" & $2.04(0.05)$ \\
\hline Substance & $\begin{array}{l}\text { "Reduce police budgets and reallocate funds to social } \\
\text { services." }\end{array}$ & $2.32(0.06)$ \\
\hline Difference & & $0.28(0.08)^{*}$ \\
\hline \multicolumn{3}{|l|}{ Police reform: } \\
\hline Slogan & "Reforming the police" & $3.40(0.06)$ \\
\hline Substance & $\begin{array}{l}\text { "Keep the police on the streets, but make sure they are } \\
\text { well-trained and carefully monitored." }\end{array}$ & $4.02(0.05)$ \\
\hline Difference & & $0.62(0.08)^{*}$ \\
\hline \multicolumn{3}{|c|}{$\begin{array}{l}\text { Notes. } * \mathrm{P}<0.05 \text {. Point estimates with standard errors in parentheses for estimated group means } \\
\text { from within-subjects experiment. Support for each proposal (in both substance and slogan } \\
\text { conditions) was measured using the same 5-point scale ( } 1=\text { "None at all", } 2=\text { "A little"; } 3=\text { "A } \\
\text { moderate amount"; } 4=\text { "A lot"; } 5=\text { "A great deal"). Robustness checks and comparisons } \\
\text { between weighted and unweighted estimates are provided in Appendix B. See Fig B1 for } \\
\text { robustness checks comparing between-subjects and within-subjects estimates, Table B1.1 for } \\
\text { group means and standard errors, and Table B1.2 for estimated effects of substance v. slogan } \\
\text { with and without covariate adjustment. }\end{array}$} \\
\hline
\end{tabular}




\section{Endnotes}

${ }^{1}$ Though calls to dismantle justice systems are not new (e.g., Du Bois, 1935; Davis, 2003), they have traditionally been pushed to the periphery of policy discussions, with calls for more and better policing being emphasized in media and politics (Kesslen, 2020). Policy outcomes have historically been in line with these more politically salient discussions. For example, the 1960s police-community relations crisis culminated in President Johnson allocating billions of federal dollars to local police departments (Walker, 1998).

${ }^{2}$ According to Gallup, in 2020, only 48\% of Americans reported they had "a great deal" or "quite a lot of confidence" in the police. There have historically been large gaps between Democrats and Republicans, as well as Black and White adults, since regular national polls on confidence in the police were introduced. For example, in Gallup's 2020 poll, 56\% of White adults and 19\% of Black adults reported confidence in the police, a 37-point gap that is comparable to the 34-point gap observed by Gallup in the early 1990s.

${ }^{3}$ Following prior work on public opinion (see e.g., Converse, 1964), we use the terms "mass public" and "public" interchangeably to refer to the general population of voting aged adults. We thank an anonymous reviewer for pointing out this potential ambiguity.

4 The literature that examines the divergence between perceptions of crime rates and actual crime rates demonstrates that these misperceptions are difficult to durably counteract. For example, even factual corrections about crime rates delivered via survey experiments are attenuated when embedded in typical crime news articles (Esberg and Mummolo, 2018). And while correcting misperceptions is possible, information alone is not enough to decrease public support for punitive crime control policies (Esberg, Mummolo, and Westwood, 2020).

${ }^{5}$ For example, "defund the police" was mentioned more than 300 times in the two weeks following Floyd's death and the editorial boards of several major newspapers, including the Washington Post and Wall Street Journal, had published positions of support (or opposition) by early June 2020 (see Hollar, 2020).

${ }^{6}$ In 2020, Lucid sold over 2 million completed survey responses to academic clients (see Peyton, Huber, and Coppock, 2021).

${ }^{7}$ Our estimates are based on respondents' answers to the following survey experimental question: "Do you oppose or support [abolishing/defunding/reforming] the police?" where abolishing, defunding, or reforming were randomly assigned with equal probability. Responses were captured on a 7-point scale from "Strongly oppose" (1) to "Strongly support" (7) with a neutral midpoint. We classify those who provided responses above the neutral midpoint as supporters to facilitate comparisons with contemporaneous public opinion polls that report binary support or opposition.

${ }^{8}$ Differences between descriptive estimates obtained from quota samples and nationally representative opinion polls may be indicative of sampling error. However, this sampling error has no bearing on the "internal validity" of sample average treatment effects in survey experiments where inference is based on random assignment of treatments rather than random sampling of potential respondents (see Gerber and Green, 2012; Imai, King, and Stewart, 2008).

${ }^{9}$ In the Online Appendix, we examine robustness to potential ordering effects by comparing these withinsubjects estimates to between-subjects estimates that are constructed by taking the first randomly assigned question item shown to each respondent (see Appendix Fig. B1.1). Consistent with recent research on the potential benefits of within-subjects experiments in public opinion research (Clifford, Sheagley, and Piston, 2021), we do not find evidence of bias due to ordering effects. This suggests that the benefits of increased statistical precision from the within-subjects design, at least in this setting, outweigh the potential bias reduction benefits from a between-subjects design.

10 Standard errors for the difference-in-means estimates reported in the manuscript are estimated as $S E($ difference $)=\sqrt{S E\left(\text { Mean }_{1}\right)^{2}+S E\left(\text { Mean }_{2}\right)^{2}}$, and Normal approximation-based $P$-values are calculated as $2\left(1-\Phi\left(\frac{\mid \text { Mean }_{1}-\text { Mean }_{2} \mid}{\text { SE(difference })}\right)\right)$, where $\Phi(\cdot)$ denotes the CDF for the Normal distribution.

${ }^{11}$ Supplementary analyses in the Online Appendix (see Fig. B6 and Table B6.1-B6.2) also examine perceptions of whether supporters of each proposal were opposed to police handling six broad categories of tasks that local police departments are typically responsible for: violent crimes, property crimes, vice crimes, conducting traffic stops, crime prevention, and maintaining civil order. Public perceptions follow similar patterns as those in Figure 4: across all categories, respondents believed that supporters of abolition wanted the greatest reductions in 
police involvement in order maintenance and crime control, followed by supporters of defunding and reform.

Differences were largest for opposition to police responses to property crimes, enforcement of vice crimes, and crime prevention. 
Table 1. Support for Abolishing, Defunding, or Reforming Police by Political Slogan and Policy Substance

Condition

Description

Mean (SE)

Police abolition:

Slogan

"Abolishing the police"

$1.66(0.05)$

Substance

"Eliminate police and reallocate funds to other activities." $1.64(0.04)$

Difference $-0.02(0.06)$

Police defunding:

Slogan

"Defunding the police"

$2.04(0.05)$

Substance

"Reduce police budgets and reallocate funds to social

$2.32(0.06)$

services."

Difference

Slogan

"Reforming the police"

$3.40(0.06)$

Substance

"Keep the police on the streets, but make sure they are

well-trained and carefully monitored."

Difference

$0.62(0.08) *$

Notes. ${ }^{*} \mathrm{P}<0.05$. Point estimates (standard errors) for estimated group means from withinsubjects experiment. Support for each proposal (in both substance and slogan conditions) was measured using the same 5-point scale ( 1 = "None at all", 2 = "A little"; 3 = "A moderate amount"; 4 = "A lot"; 5 = "A great deal"). Robustness checks and comparisons between weighted and unweighted estimates are provided in Appendix B. See Fig B1 for robustness checks comparing between-subjects and within-subjects estimates, Table B1.1 for group means and standard errors, and Table B1.2 for estimated effects of substance v. slogan with and without covariate adjustment. 
Figure 1. Support for Abolishing, Defunding, or Reforming the Police by Political Slogan and Policy Substance
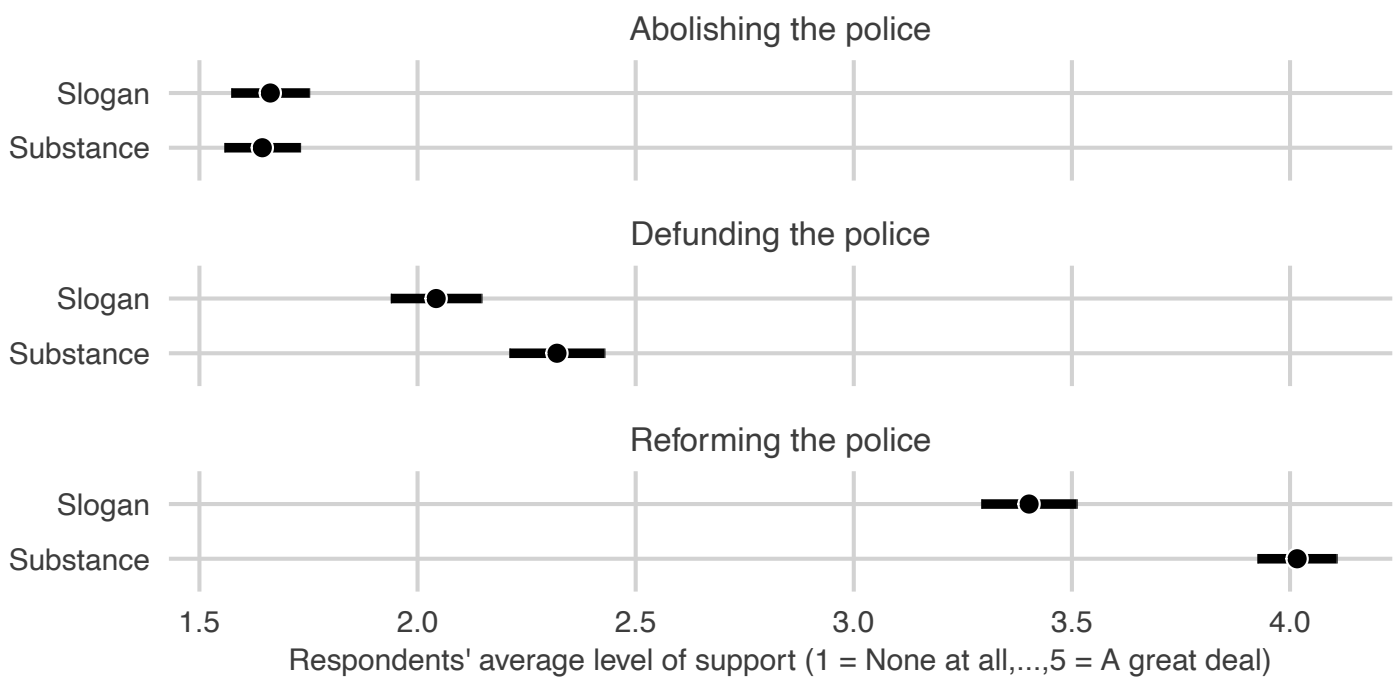

Notes. Point estimates (black dots) and 95\% confidence intervals (black bars) for estimated group means from within-subjects experiment. Support for each proposal (in both substance and slogan conditions) was measured using the same 5-point scale ( 1 = "None at all", 2 = "A little"; 3 = "A moderate amount"; 4 = "A lot"; 5 = "A great deal"). Robustness checks and comparisons between weighted and unweighted estimates are provided in Appendix B. See Fig B1 for robustness checks comparing between-subjects and within-subjects estimates, Table B1.1 for group means and standard errors, and Table B1.2 for estimated effects of substance v. slogan with and without covariate adjustment. 
Figure 2. Respondents' Beliefs About Supporters of Abolishing, Defunding, or Reforming the Police

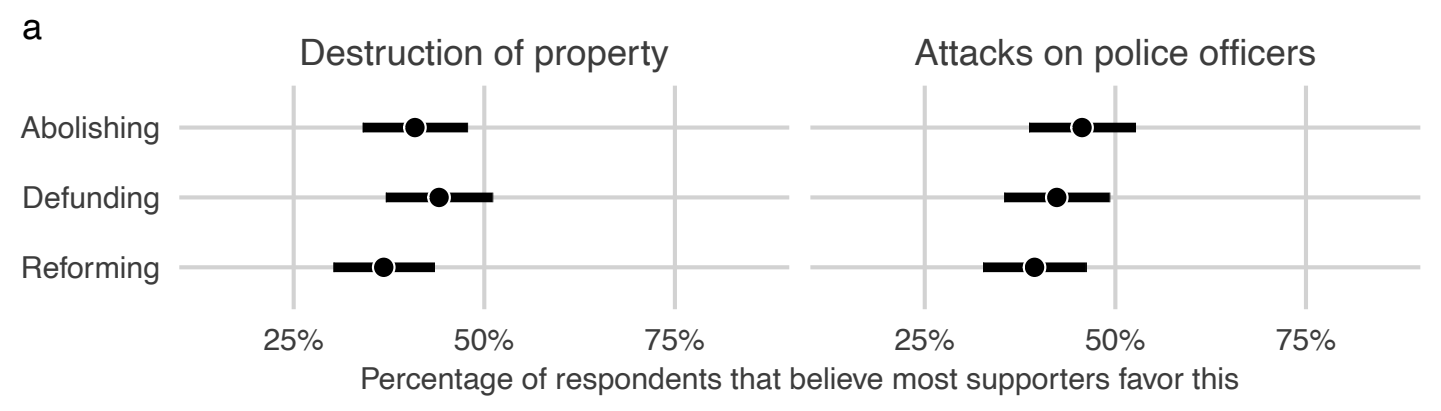

b

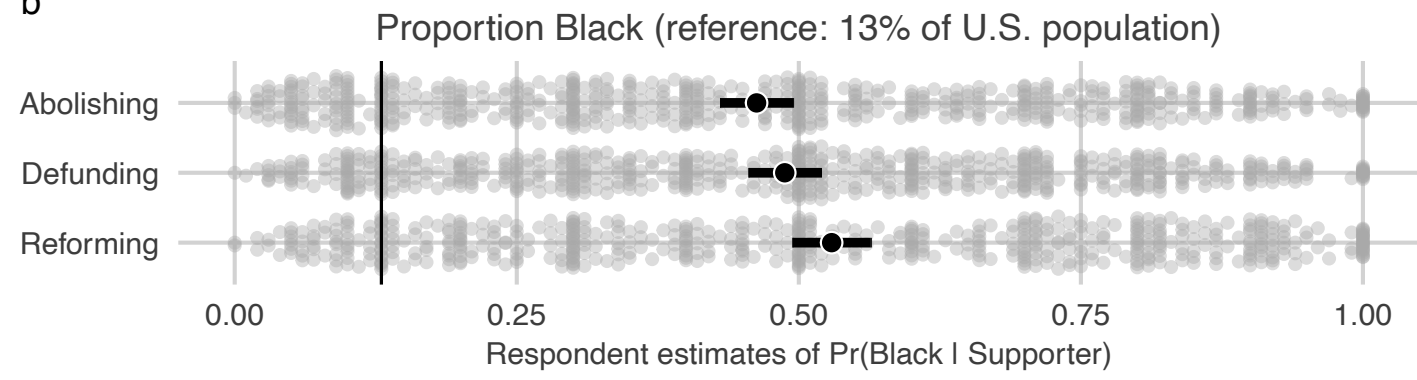

Notes. Point estimates (black dots) and 95\% confidence intervals (black bars) for estimated group means from between-subjects experimental designs that randomly assigned "abolishing", "defunding", or "reforming" the police with equal probability. Panel a: shows the proportion of respondents that believed most supporters of each randomly assigned proposal also supported property destruction and attacks on police officers. Responses were captured using a binary measure of "Oppose" (0) or "Support" (1). Robustness checks and comparisons between weighted and unweighted estimates are provided in Appendix B. See Fig B2 and Table B2.1 for group means, and Table B2.2 for estimated effects (using "reform" as the reference category), with and without covariate adjustment. Panel b: shows respondents' beliefs about the racial composition of those who supported each of the randomly assigned proposals. Light grey dots (jittered to reduce overplotting) denote individual estimates, and the black vertical line denotes the marginal estimates for the U.S. population provided to respondents. Robustness checks and comparisons between weighted and unweighted estimates are provided in Appendix D. See Fig D3 and Table D3.1 for group means, and Table D3.2 for estimated effects (using reform as the reference category), with and without covariate adjustment. 
Figure 3. Respondents' Beliefs About Policy Preferences Among Those Who Supported Abolishing, Defunding, or Reforming the Police

Reduce use of military equipment

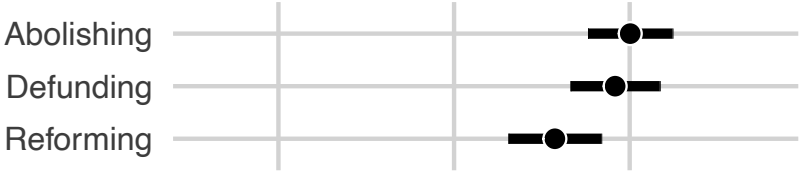

Make firing police easier

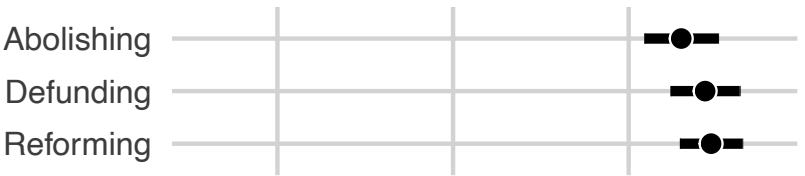

Implement Civilian Review Boards

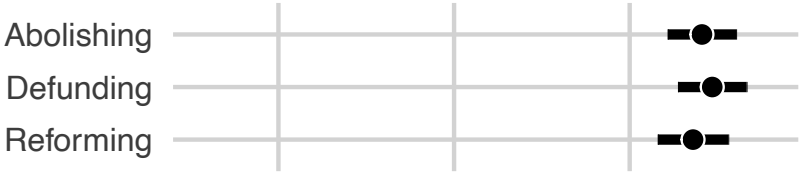

Require police to live where they work

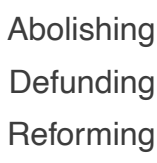

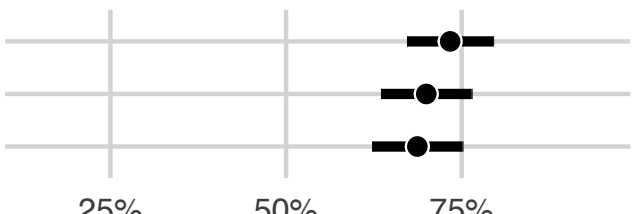

$25 \%$

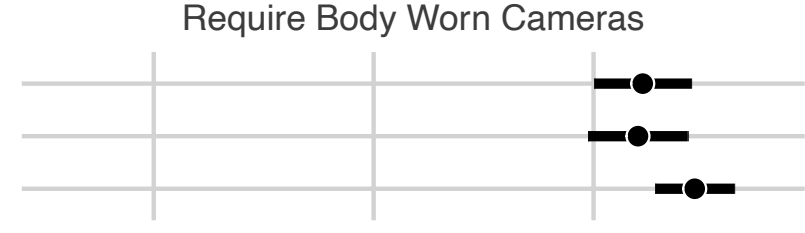

Ban use of chokeholds

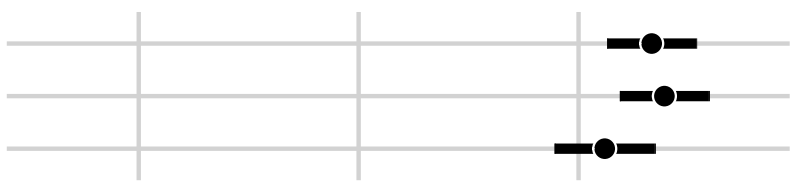

Ban use of no-knock warrants

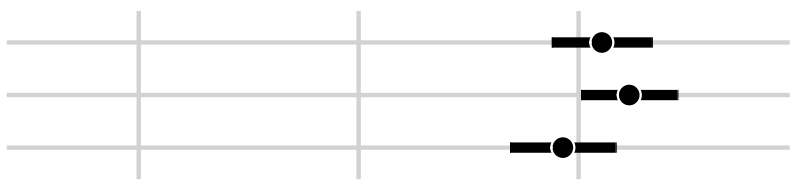

Require warning before shooting

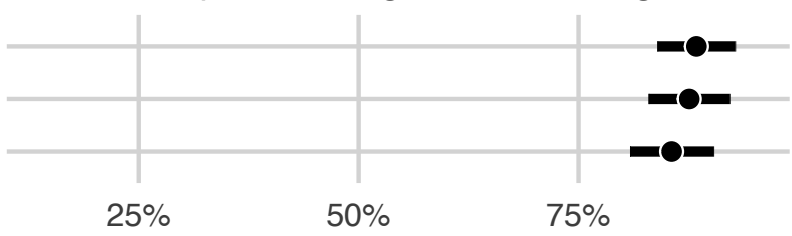

Percentage of respondents that believe most supporters favor this

Notes. Point estimates (black dots) and 95\% confidence intervals (black bars) for estimated group means from between-subjects experimental designs that randomly assigned "abolishing", "defunding", or "reforming" the police with equal probability. Responses to the question "Think about people who support [abolishing, defunding, or reforming]. Do you believe most of these people oppose or support each of the following?" were captured using a binary response ("Oppose" = 0, "Support" = 1). Each individual item was presented in randomized order. Robustness checks and comparisons between weighted and unweighted estimates are provided in Appendix B. See Fig. B3 and Table B3.1 for comparison with unweighted estimates, and Table B3.2 for estimated effects (using "reform" as the reference category), with and without covariate adjustment. 
Figure 4. Respondents' Beliefs About Spending Preferences Among Those Who Supported Abolishing, Defunding, or Reforming the Police

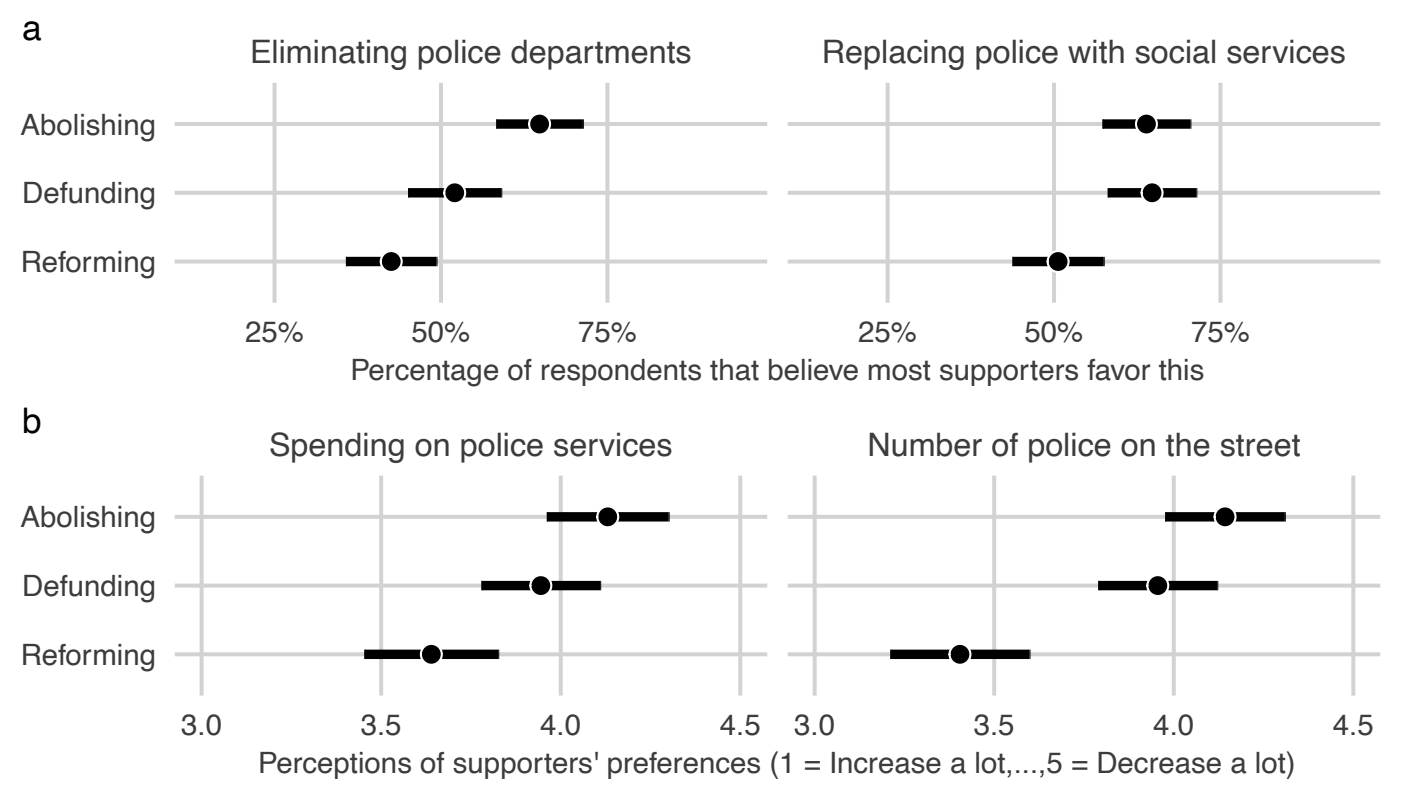

Notes. Point estimates (black dots) and 95\% confidence intervals (black bars) for estimated group means from between-subjects experimental designs that randomly assigned "abolishing", "defunding", or "reforming" the police with equal probability. Panel a: responses to the question "Think about people who support [abolishing, defunding, or reforming] the police. Do you believe most of these people oppose or support each of the following?" were captured using a binary response ("Oppose" =0, "Support" =1). Each item was presented in randomized order.

Panel b: responses to the questions "Think about people who support [abolishing, defunding, or reforming] the police. How do you think they want to change the number of police on the streets?" and "Do you believe most of these people want each of the following to be decreased, kept the same, or increased?" were captured using a 5-point scale ("Increase a lot" = 1, "Increase a little" =2, "Keep the same" =3, "Decrease a little" = 4, "Decrease a lot" =5). Robustness checks and comparisons between weighted and unweighted estimates are provided in Appendix B. See Fig. B4 and Table B4.1 for comparison with unweighted estimates, and Table B4.2 for estimated effects (using reform as the reference category), with and without covariate adjustment. Fig. B8.1 shows the response distributions in panel $\mathrm{b}$ across treatment arms. 
Figure 5. Respondents' Opposition to Police Involvement in Specific Incidents, and the Perceived Impact of Fewer Police Officers on Crime and Safety

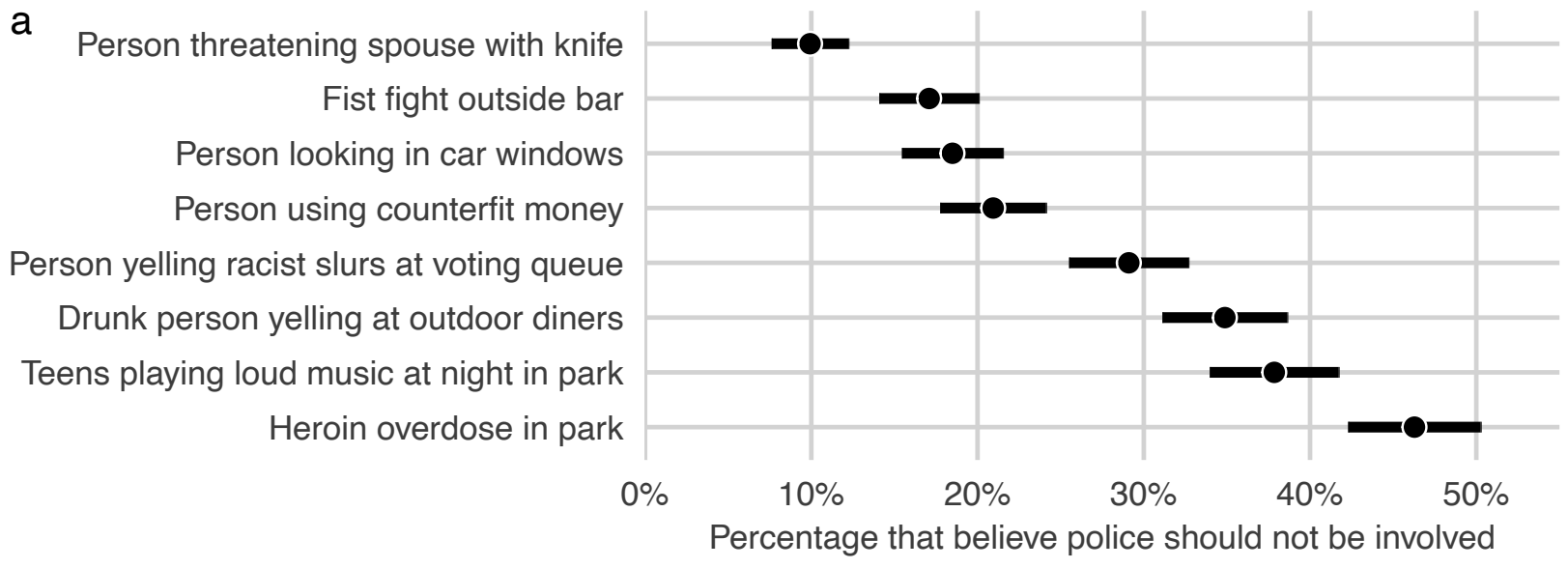

b

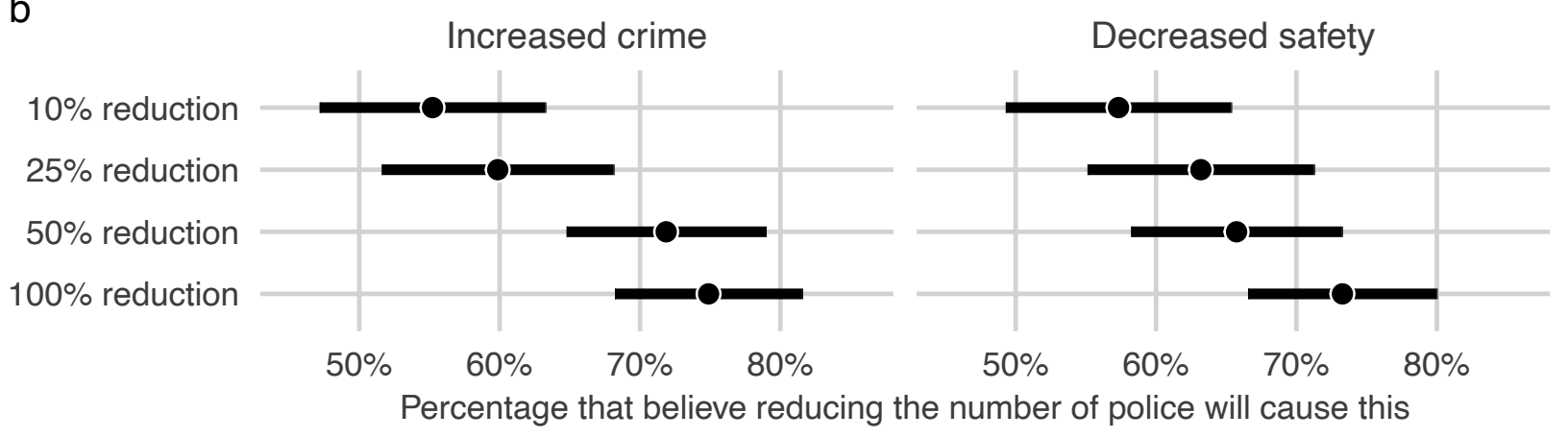

Notes. Point estimates (black dots) and 95\% confidence intervals (black bars) for estimated group means. Panel a: shows the proportion of respondents that believed police should not be sent in response to civilian-initiated 911 calls. Scenarios were presented in random order and respondents could indicate: 1 ) only the police should be sent; 2) the police should be accompanied by another first responder, such as social services; 3) another first responder should be sent without police; or 4) no government response should take place. Responses are recoded using a binary indicator ("Police involvement" $=0$; "No police involvement" =1). Fig. B7 and Table B7 show group means for each response level. Panel b: shows the proportion of respondents that believed reductions $(10 \%, 25 \%, 50 \%$, or $100 \%)$ to the number of police in their local area would cause increased crime / decreased safety. Respondents were presented with one of the four potential reductions (with equal probability) and asked if they believed it would cause the level of crime to change ("Much lower" =1, "Slightly lower" $=2$, "About the same" $=3$, "Slightly higher" = 4, "Much higher" = 5); and whether they would feel more or less safe ("Much more safe" = 1, "Slightly more safe" =2, "About the same" = 3, "Slightly less safe" =4, "Much less safe" =5). Responses greater than the neutral midpoint of 3 were coded 1 (and 0 otherwise) to estimate proportions. Robustness checks and comparisons between weighted and unweighted estimates are provided in Appendix B. See Fig. B5 and Table B5.1a-B5.1b for comparison with unweighted estimates, Table B5.2 for estimated effects on panel b outcomes (using 10\% reduction as the reference category), with and without covariate adjustment. Tables B5.1b and B5.2 show robustness to using 5-point scales, and Fig. B8.2 shows the response distributions in panel $\mathrm{b}$ across treatment arms. 
Mass support for proposals to reshape policing depends on the implications for crime and safety

(Online Appendix) 


\section{Online Appendix}

\section{Contents}

\section{A Design and Question Wordings for Primary Survey}

A.1 Beliefs About Supporters of Abolishing, Defunding, or Reforming the Police

A.2 Respondents' Own Attitudes and Preferences

B Figures and Tables Referenced in Main Text for Primary Survey

C Additional Details for Primary Survey

C.1 Exclusion of Inattentive Survey Respondents

C.2 Survey Representativeness and Weighting Methodology

D Supplemental Survey Experiment

D.1 Exclusion of Inattentive Survey Respondents

D.2 Survey Representativeness and Weighting Methodology

D.3 Figures and Tables Referenced in Main Text

E References for Appendices 


\section{A Design and Question Wordings for Primary Survey}

Figure A1. Summary of Survey Design and Randomizations

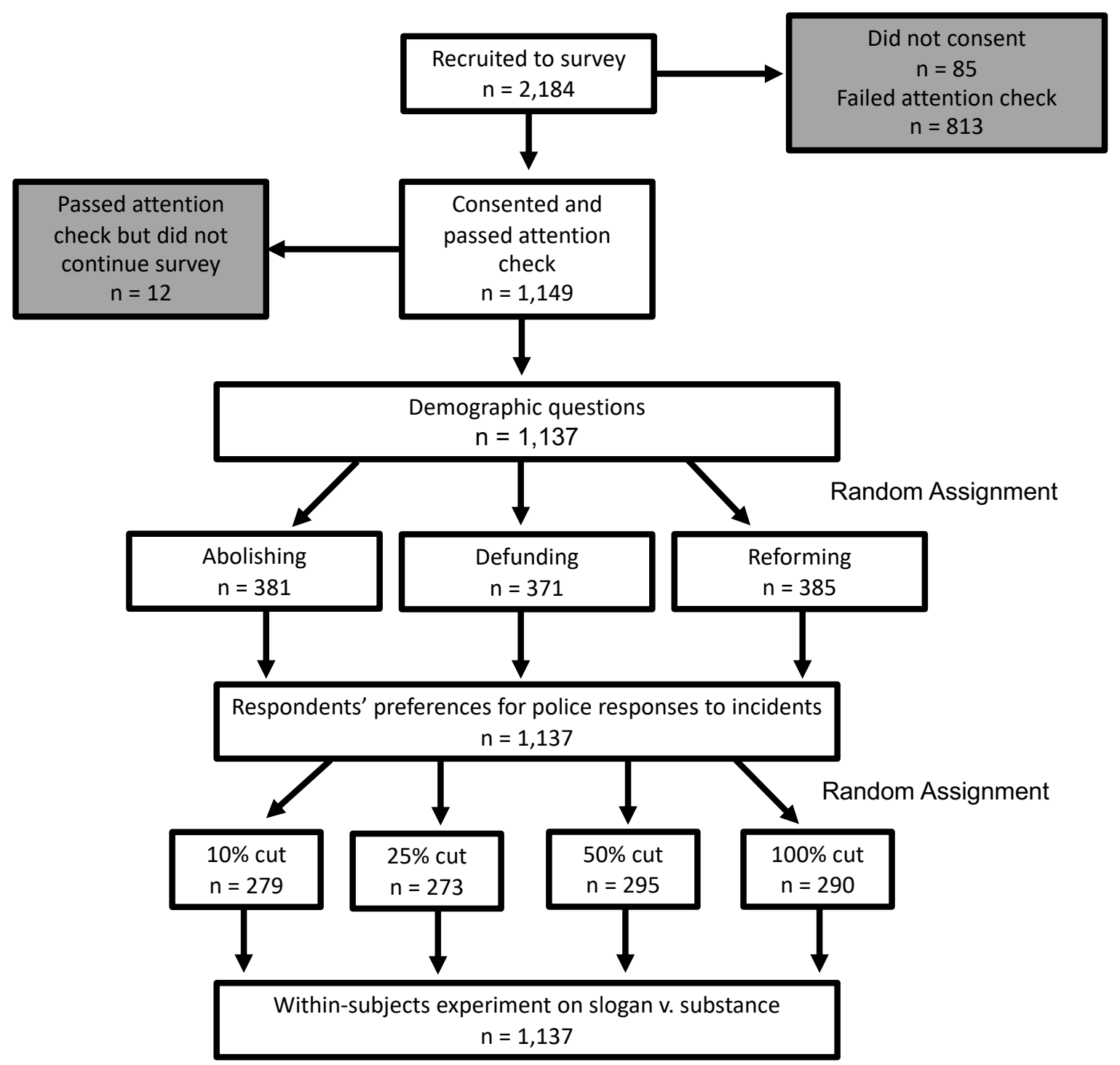

Figure A1 provides a summary of the survey design and the randomizations. Additional details on the attention check questions are provided in Section C. The first between-subjects experiment was administered after collecting respondent demographics. Beliefs about movement supporters were measured within each Abolishing, Defunding, and Reforming arms. See Section A1 for these question wordings, and Section A2 for all other question wordings. Perceived impact of funding cuts on crime and safety were measured within each $10 \% \mathrm{cut}$, 25\% cut, 50\% cut, and $100 \%$ cut arms. The withinsubjects experiment on slogan $\mathrm{v}$. substance was administered at the end of the survey. 


\section{A.1 Beliefs About Supporters of Abolishing, Defunding, or Reforming the Police}

Note that $\$\{\mathrm{e}: / /$ Field $/ \mathrm{Z}\}$ denotes assignment to one of three treatment arms: "abolishing the police," "defunding the police," or "reforming the police". Individual items were presented to respondents in randomized order within each group of questions. Italicized text in brackets denotes response options.

1. General beliefs about movement supporters.

a. Think about people who support $\$\{\mathrm{e}: / /$ Field $/ \mathrm{Z}\}$ the police. Do you believe most of these people oppose or support each of the following? [Oppose; Support]

i. Destruction of government property

ii. Attacks on police officers

iii. Eliminating Police Departments

iv. Replacing police with social workers

v. Protests against police brutality

vi. Protests by Black Lives Matter

vii. Protests to defund the police

2. Beliefs about specific reforms that movement supporters favor.

a. Think about people who support $\$\{\mathrm{e}: / /$ Field $/ \mathrm{Z}\}$ the police. Do you believe most of these people oppose or support each of the following? [Oppose; Support]

i. Reduce police purchases of surplus military equipment

ii. Make it easier to identify and fire police officers who violate department policy or the law

iii. Implement civilian review boards to oversee and audit police policy and behavior

iv. Require police officers to live in the neighborhoods they police

v. Ban police use of chokeholds and strangleholds

vi. Ban police use of "no-knock" warrants

vii. Require police officers to issue a verbal warning before shooting

viii. Require police officers to wear body cameras in interactions with civilians

3. Beliefs about movement supporters' opposition to specific police activities

a. Think about people who support $\$\{\mathrm{e}: / / \mathrm{Field} / \mathrm{Z}\}$ the police. Do you believe they oppose or support police handling each of the following tasks? [Oppose; Support]

i. Responding to and investigating violent crimes (e.g., murder or assault)

ii. Responding to and investigating property crimes (e.g., burglary or theft)

iii. Responding to and investigating "vice" crimes (e.g., public drug use or prostitution)

iv. Maintaining civil order (e.g., regulating the use of public spaces, dealing with loitering and panhandling)

v. Crime prevention (e.g., patrolling high crime areas, monitoring surveillance cameras)

vi. Providing social services (e.g., assisting with juvenile runaways and people with mental illnesses)

vii. Community engagement (e.g., meeting with residents about local issues, coordinating youth outreach programs)

viii. Conducting motor vehicle stops (e.g., traffic violations, sobriety checkpoints) 
4. Beliefs about movement supporters' preferences on spending and changes to the number of police on the streets.

a. Think about people who support $\$\{\mathrm{e}: / /$ Field $/ \mathrm{Z}\}$ the police. Do you believe most of these people want each of the following to be decreased, kept the same, or increased? [Decrease a lot; Decrease a little; Keep the same; Increase a little; Increase a lot]

i. Spending on healthcare

ii. Spending on police

iii. Spending on social services

iv. Spending on education

v. Spending on housing

b. Think about people who support $\$\{$ e: $/ /$ Field $/ Z\}$ the police. How do you think they want to change the number of police on the streets? [Decrease a lot; Decrease a little; Keep the same; Increase a little; Increase a lot]

\section{A.2 Respondents' Own Attitudes and Beliefs}

Note that $\$\{$ e:/Field/Z_cut $\}$. denotes assignment to one of four conditions: " $10 \%$," " $25 \%$," "50\%," or "100\%." Individual items were presented to respondents in randomized order within each group of questions. Italicized text in brackets denotes response options.

1. Support for movement slogans versus substance.

a. We hear a lot of discussions about changes to policing today. How much do you support each of the following? [None at all; A little; A moderate amount; A lot; A great deal]

i. Slogan: Abolishing the police; Defunding the police; Reforming the police

ii. Substance: Eliminate police altogether and reallocate funds to other activities; Reduce police budgets and reallocate funding to social services; Keep the police on the streets, but make sure they are well-trained and carefully monitored.

2. Preferences for government responses to specific incidents.

a. Suppose a person calls 911 to report each of the following incidents. In your view, how should the city/town respond? [Do nothing; Send someone other than the police, like the fire department or social services; Send the police; Send the police and someone else]

i. A man threatening his wife with a knife

ii. Someone trying to pay for goods at a local store with a fake $\$ 50$ bill

iii. A report of a suspicious person peeking into car windows

iv. A person yelling racist slurs at people standing in line to vote

v. A drunk person yelling at people sitting outside at a restaurant

vi. Two people having a fist fight outside of bar

vii. A heroin overdose in a public park

viii. Teenagers loudly playing their music after dark in a public park

3. Perceived impact of police cuts on crime and safety.

a. Suppose the city/town you live in cut the number of police officers by $\$\left\{\mathrm{e}: / / \mathrm{Field} / \mathrm{Z}_{-}\right.$cut $\}$.

i. Would the level of crime be lower, higher, or about the same? [Much higher; Slightly higher; About the same; Slightly lower; Much lower]

ii. Would you feel less safe, more safe, or about the same? [Much less safe; Slightly less safe; About the same; Slightly more safe; Much more safe] 


\section{B Figures and Tables Referenced in Main Text for Primary Survey}

Following each figure, we present the underlying point estimates and standard errors for the group means (weighted and unweighted) in tabular form. Standard errors for the difference-in-means estimates reported in the manuscript are estimated as $S E($ difference $)=\sqrt{S E\left(M e a n_{1}\right)^{2}+S E\left(M e a n_{2}\right)^{2}}$, and Normal approximation-based $P$-values are calculated as $2\left(1-\Phi\left(\frac{\mid \text { Mean }_{1}-\text { Mean }_{2} \mid}{S E(\text { difference })}\right)\right)$, where $\Phi(\cdot)$ denotes the CDF for the Normal distribution.

For all estimated treatment effects reported below, we use "Reforming the police" as the reference category ("control group") so that reported differences for "Abolishing the police" and "Defunding the police" are relative to "Reforming the police." We report unweighted and weighted estimates from both a difference-in-means and covariate-adjusted regression estimator. The covariateadjusted estimator uses the method proposed by Lin (2013), which centers each covariate and interacts it with the treatment indicator. Covariates used for adjustment were all measured pre-treatment. They include respondent demographics (age, sex, region, household income, employment status, race/ethnicity, and education) and political attitudes (partisanship, conservativism, and self-reported political engagement). 
Figure B1. Support for Abolishing, Defunding, or Reforming the Police by Political Slogan and Policy Substance

a

Abolishing the police

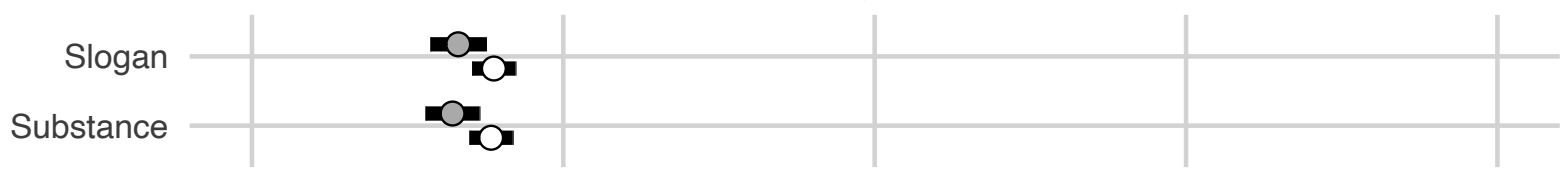

Defunding the police

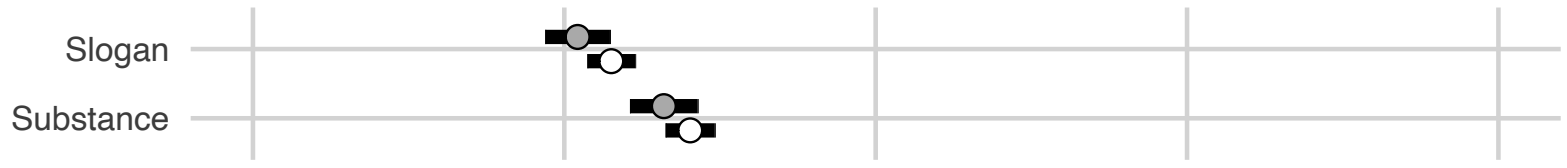

Reforming the police

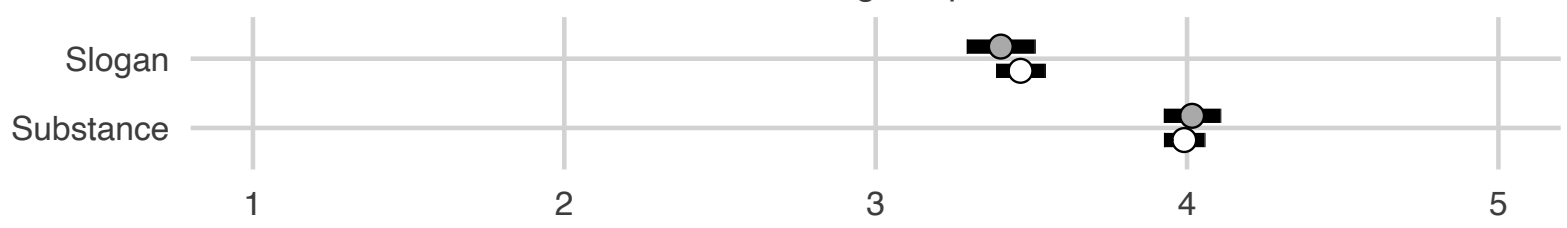

b
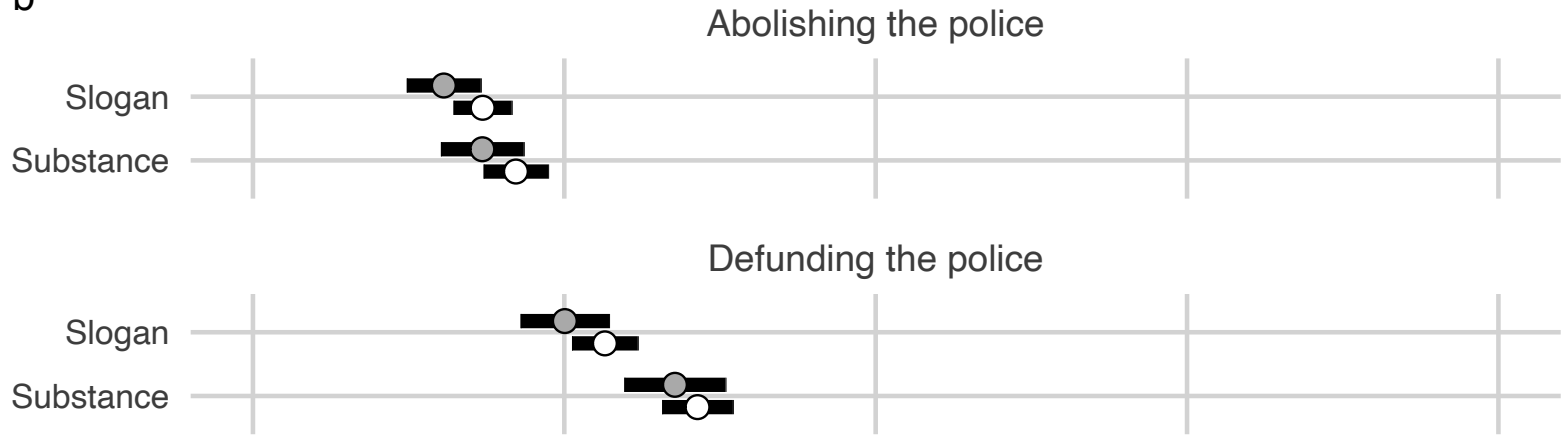

Reforming the police

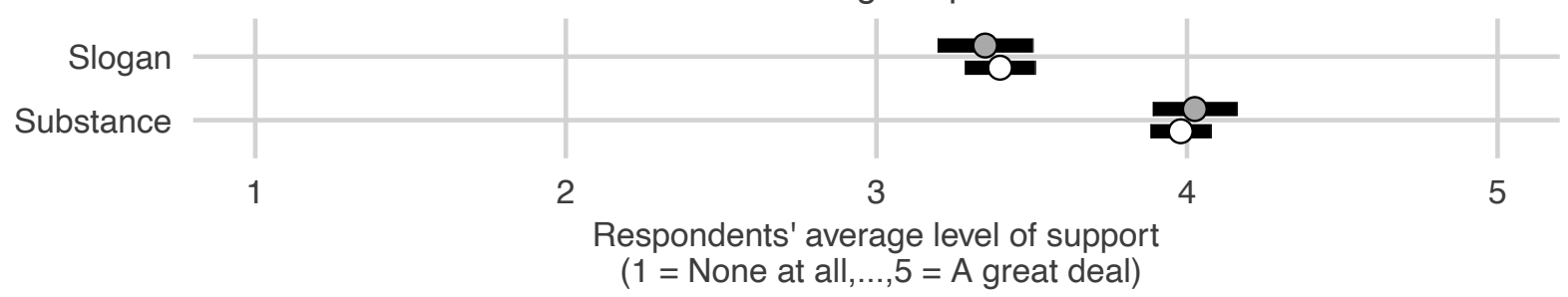

Notes. Panel a provides point estimates and $95 \%$ confidence intervals from the within-subjects estimator, and panel b provides estimates from the between-subjects estimator. Grey dots denote weighted estimates and white dots denote unweighted estimates. The within-subjects estimator is applied to the full sample of 1,137 respondents. The between-subjects estimator for Slogan restricts the sample to the 569 respondents who were randomly assigned to evaluate the Slogan first. The analogous estimator for Substance restricts the sample to the remaining respondents who were randomly assigned to evaluate the Substance first. 
Table B1.1. Group Means for Support for Abolishing, Defunding, or Reforming the Police by Slogan and Substance Conditions

\begin{tabular}{lcccc} 
& \multicolumn{2}{c}{ Slogan } & \multicolumn{2}{c}{ Substance } \\
\cline { 2 - 5 } & Unweighted & Weighted & Unweighted & Weighted \\
\hline Panel a: & & & & \\
Abolishing & $1.78(0.04)$ & $1.66(0.04)$ & $1.77(0.04)$ & $1.64(0.04)$ \\
Defunding & $2.15(0.04)$ & $2.04(0.05)$ & $2.40(0.04)$ & $2.32(0.06)$ \\
Reforming & $3.46(0.04)$ & $3.40(0.06)$ & $3.99(0.03)$ & $4.02(0.05)$ \\
\hline Panel b: & & & & \\
Abolishing & $1.74(0.05)$ & $1.61(0.06)$ & $1.84(0.05)$ & $1.74(0.07)$ \\
Defunding & $2.13(0.05)$ & $2.00(0.07)$ & $2.43(0.06)$ & $2.35(0.08)$ \\
Reforming & $3.40(0.06)$ & $3.35(0.08)$ & $3.98(0.05)$ & $4.03(0.07)$ \\
\hline \hline
\end{tabular}

Notes. Point estimates with standard errors in parentheses.

Table B1.2. Estimated Effects of Substance V. Slogan on Support for Abolishing, Defunding, or Reforming the Police

\begin{tabular}{lllll} 
& \multicolumn{2}{c}{ Difference-in-Means Estimator } & \multicolumn{2}{c}{ Covariate-Adjusted Estimator } \\
\cline { 2 - 5 } & Unweighted & Weighted & Unweighted & Weighted \\
\hline Abolishing & $-0.01(0.03)$ & $-0.02(0.03)$ & $-0.01(0.03)$ & $-0.03(0.04)$ \\
Defunding & $0.25(0.03)^{*}$ & $0.28(0.04)^{*}$ & $0.26(0.03)^{*}$ & $0.29(0.04)^{*}$ \\
Reforming & $0.53(0.04)^{*}$ & $0.61(0.06)^{*}$ & $0.53(0.04)^{*}$ & $0.62(0.06)^{*}$ \\
\hline \hline
\end{tabular}

Notes. Point estimates for within-subjects estimators with robust standard errors clustered at the respondent level in parentheses. The covariate-adjusted estimator includes age, sex, region, household income, employment status, race/ethnicity, education, partisanship, conservativism, and self-reported political engagement. $* \mathrm{P}<0.05$. 
Figure B2. Respondents' Beliefs About Supporters of Abolishing, Defunding, or Reforming the Police

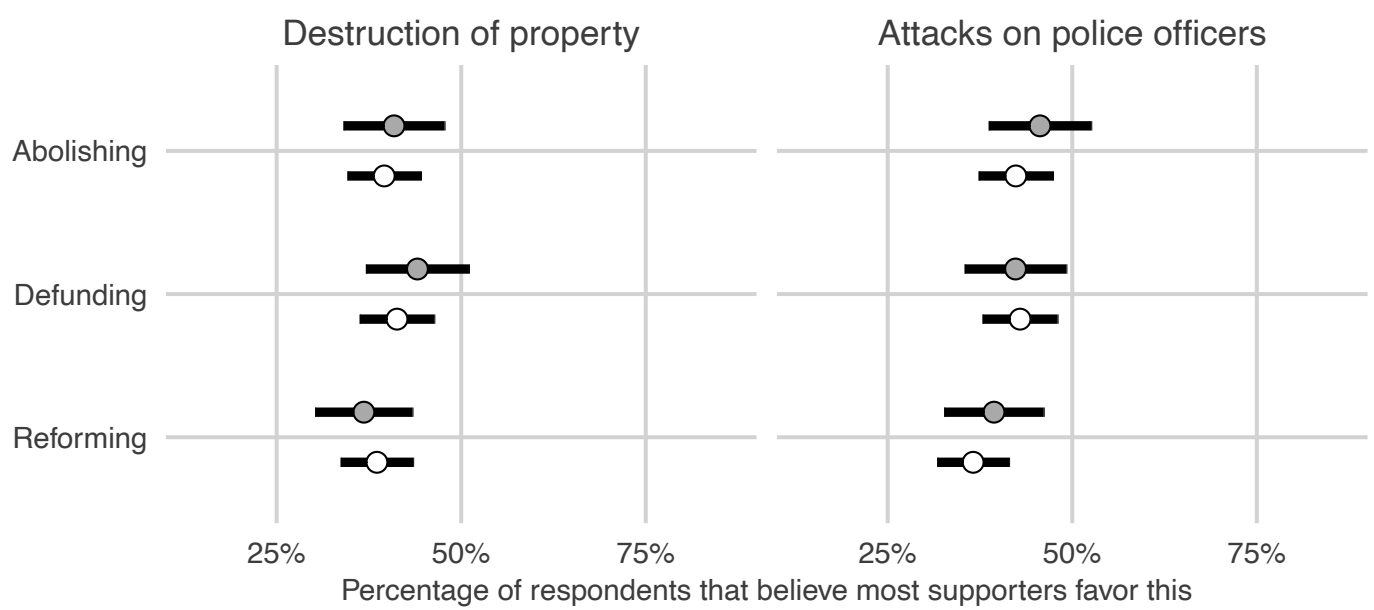

Notes. Point estimates and 95\% confidence intervals are group means from a between-subjects experimental design that randomly assigned "abolishing", "defunding", or "reforming" the police with equal probability. Grey dots denote weighted estimates and white dots denote unweighted estimates.

Table B2.1. Group Means for Beliefs About Supporters of Abolishing, Defunding, or Reforming the Police

\section{Destruction of Property $\quad$ Attacks on Police}

\begin{tabular}{lcccc} 
& Unweighted & Weighted & Unweighted & Weighted \\
\hline Abolishing & $0.40(0.03)$ & $0.41(0.04)$ & $0.42(0.03)$ & $0.46(0.04)$ \\
Defunding & $0.41(0.03)$ & $0.44(0.04)$ & $0.43(0.03)$ & $0.42(0.04)$ \\
Reforming & $0.39(0.03)$ & $0.37(0.03)$ & $0.37(0.03)$ & $0.39(0.03)$ \\
\hline
\end{tabular}

Notes. Point estimates with standard errors in parentheses.

Table B2.2. Estimated Effects on Beliefs About Supporters, with Reforming Police as Reference Category

\begin{tabular}{lllll} 
& \multicolumn{2}{c}{ Destruction of Property } & \multicolumn{2}{c}{ Attacks on Police } \\
\cline { 2 - 5 } & Unweighted & Weighted & Unweighted & Weighted \\
\hline Difference-in-Means Estimator: & & \\
Abolishing & $0.01(0.04)$ & $0.04(0.05)$ & $0.06(0.04)$ & $0.06(0.05)$ \\
Defunding & $0.03(0.04)$ & $0.07(0.05)$ & $0.06(0.04)$ & $0.03(0.05)$ \\
\hline Covariate-adjusted Estimator: & & \\
Abolishing & $0.01(0.04)$ & $0.03(0.06)$ & $0.06(0.04)$ & $0.06(0.05)$ \\
Defunding & $0.05(0.04)$ & $0.11(0.05)$ & $0.08(0.04)$ & $0.05(0.05)$ \\
\hline \hline
\end{tabular}

Notes. Point estimates for between-subjects estimators (Fig. B2) with robust standard errors in parentheses. The covariate-adjusted estimator includes age, sex, region, household income, employment status, race/ethnicity, education, partisanship, conservativism, and self-reported political engagement. P-values are adjusted using the Benjamini and Hochberg (1995) procedure to control the false discovery rate. $* \mathrm{P}<0.05$. 
Figure B3. Respondents' Beliefs About Policy Preferences Among Those Who Supported Abolishing, Defunding, or Reforming the Police
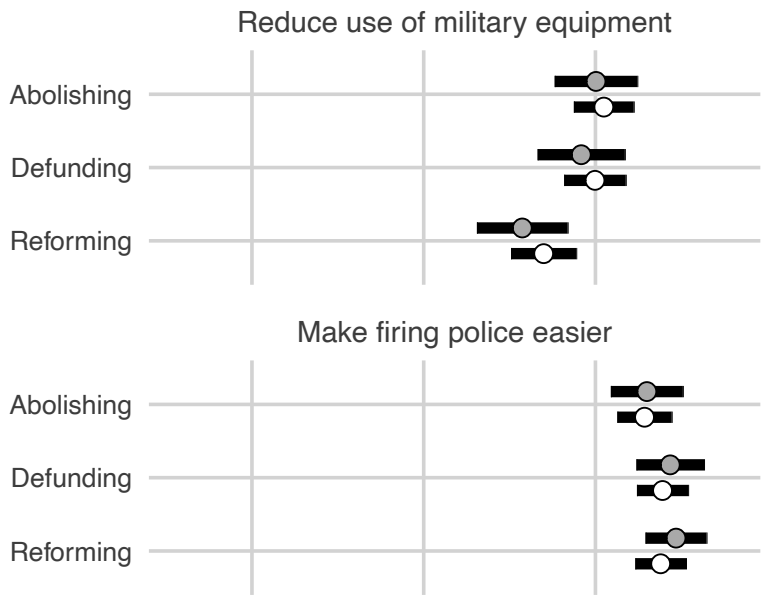

Implement Civilian Review Boards

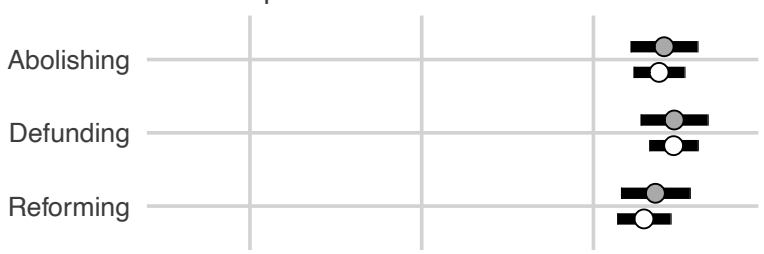

Require police to live where they work

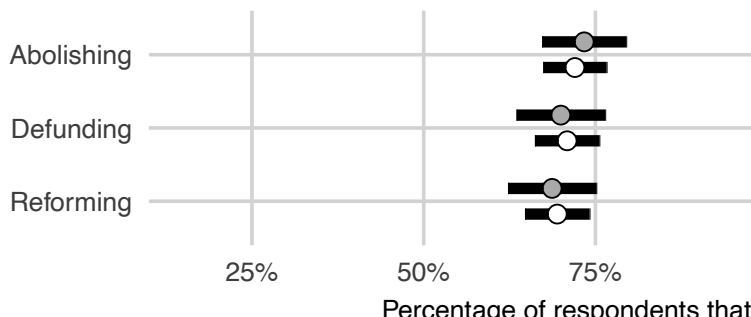

Percentage of respondents that believe most supporters favor this
Require Body Worn Cameras

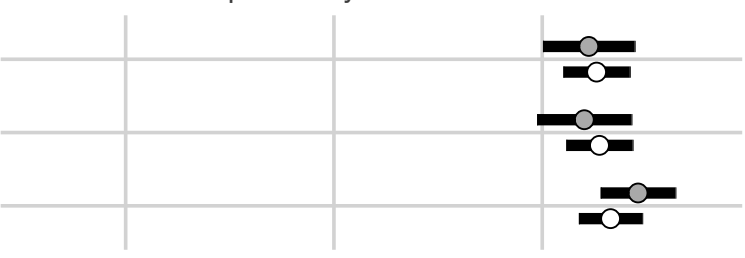

Ban use of chokeholds

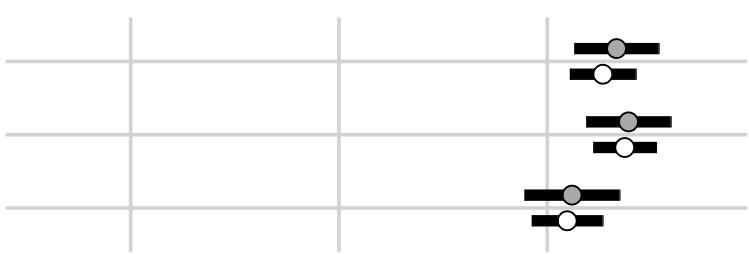

Ban use of no-knock warrants

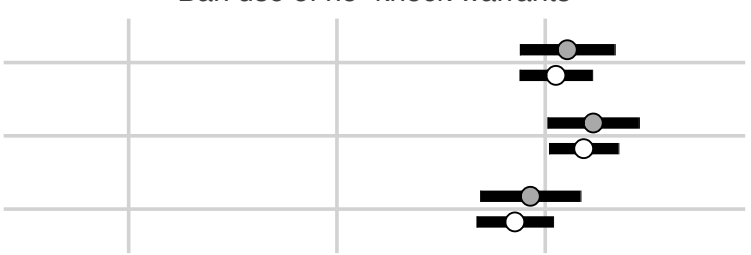

Require warning before shooting

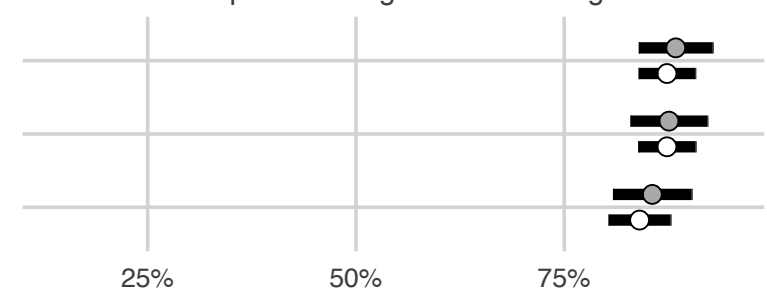

$75 \%$

Notes. Point estimates and 95\% confidence intervals are group means from a between-subjects experimental design that randomly assigned "abolishing", "defunding", or "reforming" the police with equal probability. Grey dots denote weighted estimates and white dots denote unweighted estimates. 
Table B3.1. Group Means for Respondents' Beliefs About Policy Preferences Among Those Who Supported Abolishing, Defunding, or Reforming the Police

\section{Reduce use of military equipment

\author{
Implement Civilian
} \\ Review Boards}

\section{Require police to live where they work}

\begin{tabular}{|c|c|c|c|c|c|c|c|c|}
\hline & Unweighted & Weighted & Unweighted & Weighted & Unweighted & Weighted & Unweighted & Weighted \\
\hline Abolish & $0.76(0.02)$ & $0.75(0.03)$ & $0.82(0.02)$ & $0.82(0.03)$ & $0.85(0.02)$ & $0.85(0.03)$ & $0.72(0.02)$ & $0.73(0.03)$ \\
\hline Defund & $0.75(0.02)$ & $0.73(0.03)$ & $0.85(0.02)$ & $0.86(0.03)$ & $0.87(0.02)$ & $0.87(0.03)$ & $0.71(0.02)$ & $0.70(0.03)$ \\
\hline \multirow[t]{3}{*}{ Reform } & $0.68(0.02)$ & $0.64(0.03)$ & $0.84(0.02)$ & $0.87(0.02)$ & $0.82(0.02)$ & $0.84(0.03)$ & $0.69(0.02)$ & $0.69(0.03)$ \\
\hline & \multicolumn{2}{|c|}{$\begin{array}{c}\text { Require Body Worn } \\
\text { Cameras }\end{array}$} & \multicolumn{2}{|c|}{ Ban use of chokeholds } & \multicolumn{2}{|c|}{$\begin{array}{c}\text { Ban use of no-knock } \\
\text { warrants }\end{array}$} & \multicolumn{2}{|c|}{$\begin{array}{c}\text { Require warning before } \\
\text { shooting }\end{array}$} \\
\hline & Unweighted & Weighted & Unweighted & Weighted & Unweighted & Weighted & Unweighted & Weighted \\
\hline Abolish & $0.81(0.02)$ & $0.81(0.03)$ & $0.82(0.02)$ & $0.83(0.03)$ & $0.76(0.02)$ & $0.78(0.03)$ & $0.87(0.02)$ & $0.88(0.02)$ \\
\hline Defund & $0.82(0.02)$ & $0.80(0.03)$ & $0.84(0.02)$ & $0.85(0.03)$ & $0.80(0.02)$ & $0.81(0.03)$ & $0.87(0.02)$ & $0.88(0.02)$ \\
\hline Reform & $0.83(0.02)$ & $0.86(0.02)$ & $0.77(0.02)$ & $0.78(0.03)$ & $0.71(0.02)$ & $0.73(0.03)$ & $0.84(0.02)$ & $0.86(0.02)$ \\
\hline
\end{tabular}

Notes. Point estimates with standard errors in parentheses.

Table B3.2. Estimated Effects on Respondents' Beliefs About Policy Preferences, with Reforming Police as Reference Category

\begin{tabular}{|c|c|c|c|}
\hline $\begin{array}{c}\text { Reduce use of military } \\
\text { equipment }\end{array}$ & Mak & $\begin{array}{l}\text { Implement Civilian Review } \\
\text { Boards }\end{array}$ & $\begin{array}{l}\text { Require police to live } \\
\text { where they work }\end{array}$ \\
\hline
\end{tabular}

\begin{tabular}{|c|c|c|c|c|c|c|c|c|}
\hline & Unweighted & Weighted & Unweighted & Weighted & Unweighted & Weighted & Unweighted & Weighted \\
\hline \multicolumn{9}{|c|}{ Difference-in-Means Estimator: } \\
\hline Abolish & $0.09(0.03)$ & $0.11(0.05)$ & $-0.02(0.03)$ & $-0.04(0.03)$ & $0.02(0.03)$ & $0.01(0.04)$ & $0.03(0.03)$ & $0.05(0.05)$ \\
\hline Defund & $0.07(0.03)$ & $0.09(0.05)$ & $0.00(0.03)$ & $-0.01(0.03)$ & $0.04(0.03)$ & $0.03(0.04)$ & $0.01(0.03)$ & $0.01(0.05)$ \\
\hline \multicolumn{9}{|c|}{ Covariate-adjusted Estimator: } \\
\hline Abolish & $0.06(0.03)$ & $0.11(0.05)$ & $-0.02(0.03)$ & $-0.03(0.04)$ & $0.02(0.03)$ & $-0.00(0.03)$ & $0.05(0.03)$ & $0.10(0.05)$ \\
\hline \multirow[t]{3}{*}{ Defund } & $0.05(0.04)$ & $0.11(0.05)$ & $0.01(0.03)$ & $0.03(0.03)$ & $0.04(0.03)$ & $0.03(0.03)$ & $0.03(0.04)$ & $0.03(0.05)$ \\
\hline & \multicolumn{2}{|c|}{$\begin{array}{l}\text { Require Body Worn } \\
\text { Cameras }\end{array}$} & \multicolumn{2}{|c|}{ Ban use of chokeholds } & \multicolumn{2}{|c|}{$\begin{array}{c}\text { Ban use of no-knock } \\
\text { warrants }\end{array}$} & \multicolumn{2}{|c|}{$\begin{array}{c}\text { Require warning before } \\
\text { shooting }\end{array}$} \\
\hline & Unweighted & Weighted & Unweighted & Weighted & Unweighted & Weighted & Unweighted & Weighted \\
\hline \multicolumn{9}{|c|}{ Difference-in-Means Estimator: } \\
\hline Abolish & $-0.02(0.03)$ & $-0.06(0.04)$ & $0.04(0.03)$ & $0.05(0.04)$ & $0.05(0.03)$ & $0.04(0.04)$ & $0.03(0.03)$ & $0.03(0.03)$ \\
\hline Defund & $-0.01(0.03)$ & $-0.06(0.04)$ & $0.07(0.03)$ & $0.07(0.04)$ & $0.08(0.03)$ & $0.08(0.04)$ & $0.03(0.03)$ & $0.02(0.03)$ \\
\hline \multicolumn{9}{|c|}{ Covariate-adjusted Estimator: } \\
\hline Abolish & $-0.01(0.03)$ & $-0.05(0.04)$ & $0.03(0.03)$ & $0.04(0.04)$ & $0.05(0.03)$ & $0.06(0.04)$ & $0.04(0.03)$ & $0.05(0.04)$ \\
\hline Defund & $-0.00(0.03)$ & $-0.06(0.04)$ & $0.06(0.03)$ & $0.08(0.04)$ & $0.09(0.03)$ & $0.11(0.04)$ & $0.03(0.03)$ & $0.06(0.04)$ \\
\hline
\end{tabular}

Notes. Point estimates for between-subjects estimators (Fig. B3) with robust standard errors in parentheses. The covariate-adjusted estimator includes age, sex, region, household income, employment status, race/ethnicity, education, partisanship, conservativism, and self-reported political engagement. P-values are adjusted using the Benjamini and Hochberg (1995) procedure to control the false discovery rate. $* \mathrm{P}<0.05$. 
Figure B4. Respondents' Beliefs About Spending Preferences Among Those Who Supported Abolishing, Defunding, or Reforming the Police
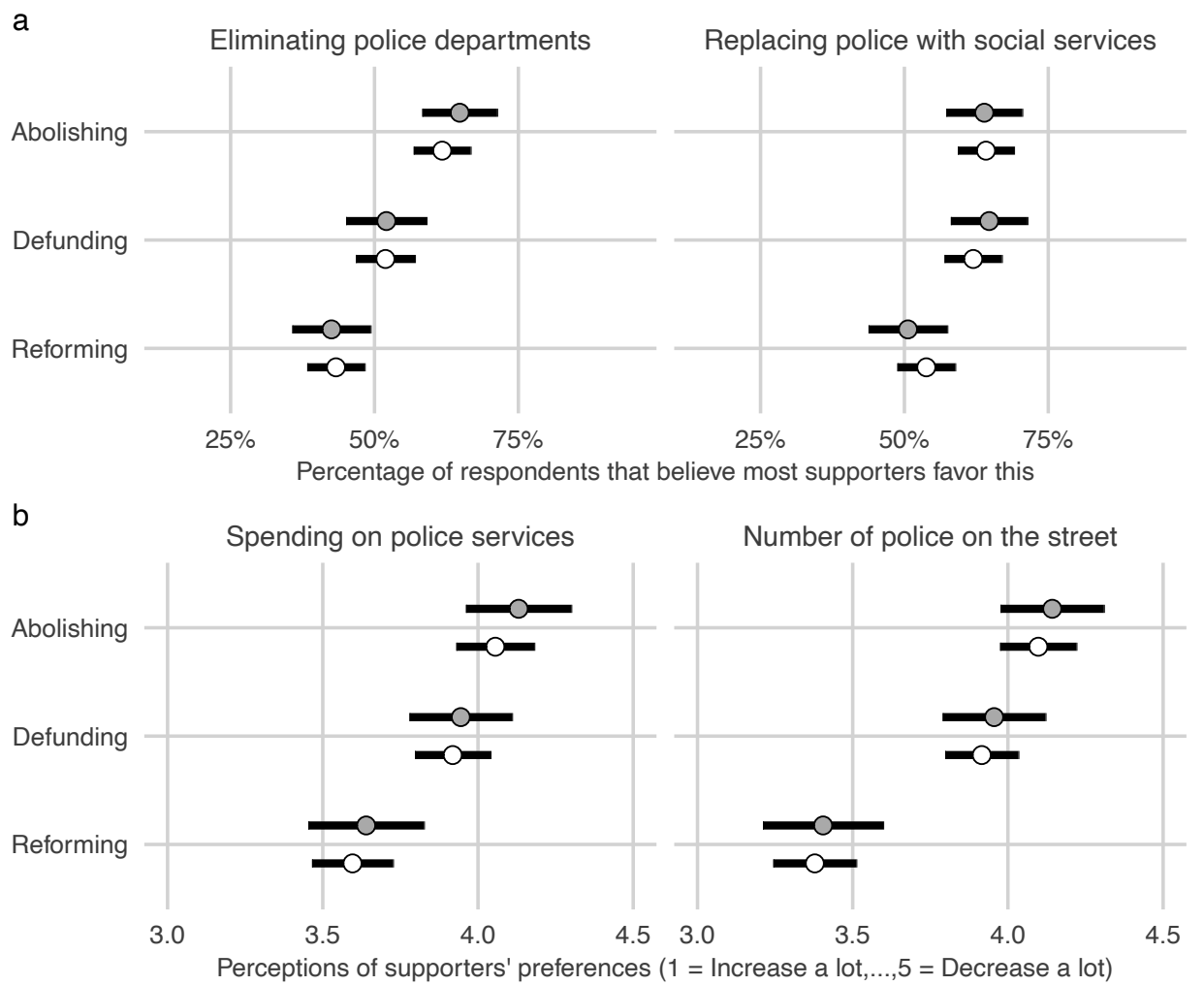

Notes. Point estimates and 95\% confidence intervals are group means from a between-subjects experimental design that randomly assigned "abolishing", "defunding", or "reforming" the police with equal probability. Grey dots denote weighted estimates and white dots denote unweighted estimates.

Table B4.1. Group Means for Respondents' Beliefs About Spending Preferences Among Those Who Supported Abolishing, Defunding, or Reforming the Police

\begin{tabular}{lllll} 
& \multicolumn{2}{c}{ Eliminating police departments } & \multicolumn{2}{c}{ Replacing police with social services } \\
\cline { 2 - 5 } & Unweighted & Weighted & Unweighted & Weighted \\
\hline Abolishing & $0.62(0.03)$ & $0.65(0.03)$ & $0.64(0.03)$ & $0.64(0.03)$ \\
Defunding & $0.52(0.03)$ & $0.52(0.04)$ & $0.62(0.03)$ & $0.65(0.03)$ \\
Reforming & $0.43(0.03)$ & $0.42(0.04)$ & $0.54(0.03)$ & $0.51(0.04)$ \\
& \multicolumn{2}{c}{ Decrease spending on police services } & \multicolumn{2}{c}{ Reduce number of police on the street } \\
& Unweighted & Weighted & Unweighted & Weighted \\
Abolishing & $4.06(0.06)$ & $4.13(0.09)$ & $4.10(0.06)$ & $4.14(0.09)$ \\
Defunding & $3.92(0.06)$ & $3.94(0.08)$ & $3.92(0.06)$ & $3.96(0.08)$ \\
Reforming & $3.60(0.07)$ & $3.64(0.10)$ & $3.38(0.07)$ & $3.40(0.10)$
\end{tabular}

Notes. Point estimates with standard errors in parentheses. 
Table B4.2. Estimated Effects on Beliefs About Spending Preferences, with Reforming Police as Reference Category

Eliminating police departments Replacing police with social

services

\begin{tabular}{|c|c|c|c|c|}
\hline & Unweighted & Weighted & Unweighted & Weighted \\
\hline \multicolumn{5}{|c|}{ Difference-in-Means Estimator: } \\
\hline Abolish & $0.18(0.04)^{*}$ & $0.22(0.05)^{*}$ & $0.10(0.04)^{*}$ & $0.13(0.05)^{*}$ \\
\hline Defund & $0.09(0.04)^{*}$ & $0.10(0.05)$ & $0.08(0.04)^{*}$ & $0.14(0.05)^{*}$ \\
\hline \multicolumn{5}{|c|}{ Covariate-adjusted Estimator: } \\
\hline Abolish & $0.17(0.04)^{*}$ & $0.20(0.05)^{*}$ & $0.07(0.04)$ & $0.10(0.05)$ \\
\hline \multirow[t]{3}{*}{ Defund } & $0.07(0.04)$ & $0.08(0.05)$ & $0.05(0.04)$ & $0.14(0.05)^{*}$ \\
\hline & \multicolumn{2}{|c|}{$\begin{array}{c}\text { Decrease spending on police } \\
\text { services }\end{array}$} & \multicolumn{2}{|c|}{$\begin{array}{c}\text { Reduce number of police on the } \\
\text { streets }\end{array}$} \\
\hline & Unweighted & Weighted & Unweighted & Weighted \\
\hline \multicolumn{5}{|c|}{ Difference-in-Means Estimator: } \\
\hline Abolish & $0.46(0.09)^{*}$ & $0.49(0.13)^{*}$ & $0.72(0.09)^{*}$ & $0.74(0.13)^{*}$ \\
\hline Defund & $0.32(0.09)^{*}$ & $0.30(0.13)^{*}$ & $0.54(0.09)^{*}$ & $0.55(0.13)^{*}$ \\
\hline \multicolumn{5}{|c|}{ Covariate-adjusted Estimator: } \\
\hline Abolish & $0.47(0.09)^{*}$ & $0.53(0.13)^{*}$ & $0.78(0.10)^{*}$ & $0.79(0.14)^{*}$ \\
\hline Defund & $0.37(0.09)^{*}$ & $0.36(0.12)^{*}$ & $0.61(0.09)^{*}$ & $0.59(0.14)^{*}$ \\
\hline
\end{tabular}

Notes. Point estimates for between-subjects estimators (Fig. B4) with robust standard errors in parentheses. The covariate-adjusted estimator includes age, sex, region, household income, employment status, race/ethnicity, education, partisanship, conservativism, and self-reported political engagement. P-values are adjusted using the Benjamini and Hochberg (1995) procedure to control the false discovery rate. $* \mathrm{P}<0.05$. 
Figure B5. Respondents' Opposition to Police Involvement in Specific Incidents, and the Perceived Impact of Fewer Police Officers on Crime and Safety
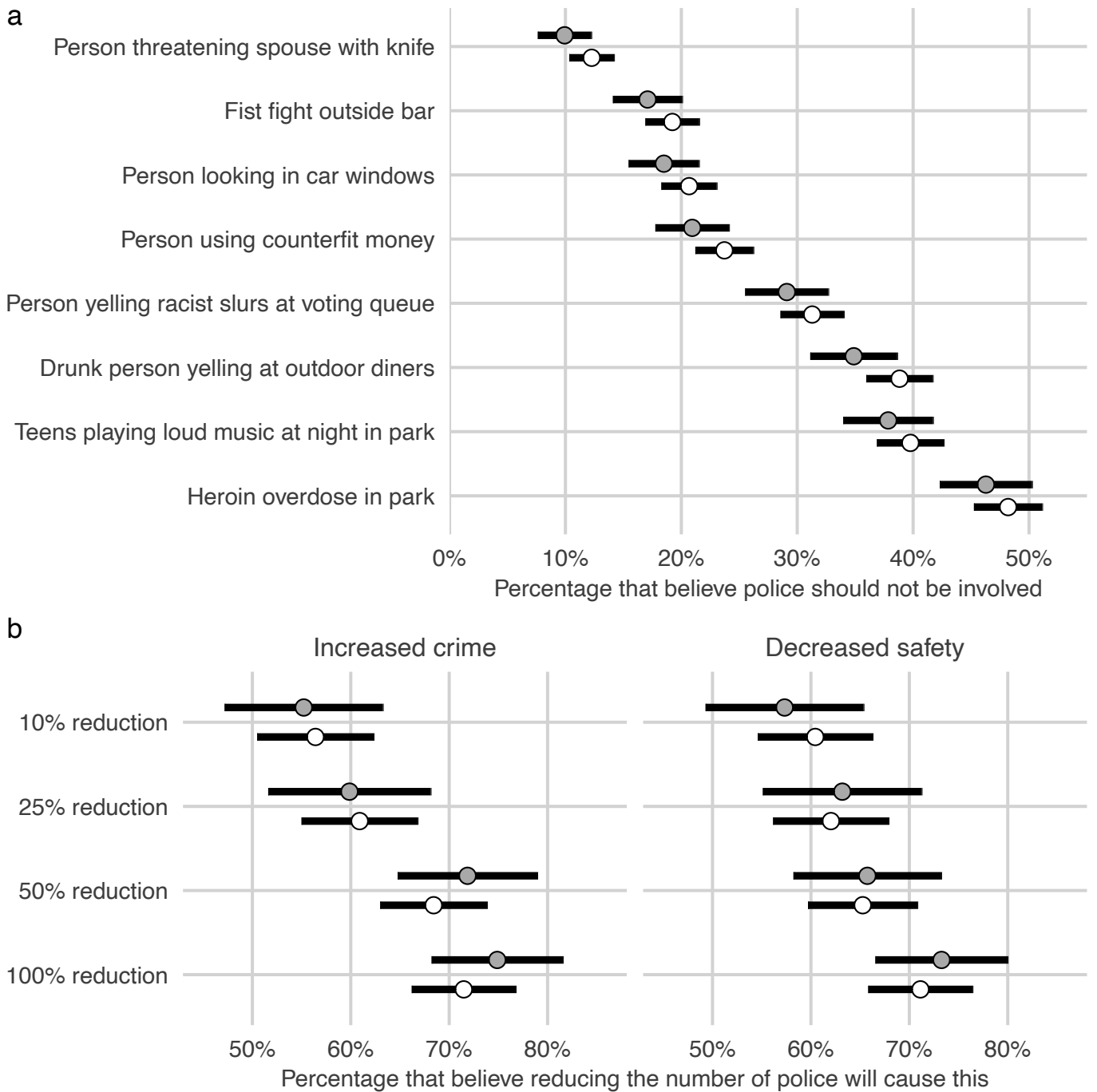

Notes. Grey dots denote weighted estimates and white dots denote unweighted estimates. Panel a: estimated proportion of respondents who believe that police should not be sent in response to a civilian-initiated 911 call. Scenarios were presented in random order and respondents could indicate: 1) only the police should be sent; 2) that the police should be accompanied by another first responder, such as social services; 3) that another first responder should be sent without police; or 4) that no government response should take place. Responses are recoded using a binary indicator ("Police involvement" = 0; "No police involvement" = 1). Fig. B7 and Table B7 show group means at each response level. Panel b: estimated proportion of respondents who believe that randomly assigned reductions $(10 \%, 25 \%, 50 \%$, or $100 \%)$ to the number of police in their local area would cause increased crime / decreased safety. Respondents were presented with one of the four potential reductions (with equal probability) and asked if they believed it would cause the level of crime to change ("Much lower" = 1, "Slightly lower" = 2, "About the same" = 3, "Slightly higher" = 4, "Much higher" =5); and whether they would feel more or less safe ("Much more safe" =1, "Slightly more safe" = 2, "About the same" = 3, "Slightly less safe" = 4, "Much less safe" = 5). Responses greater than the neutral midpoint of 3 were coded 1 (and 0 otherwise) to estimate proportions. See Table B5.1a$\mathrm{B} 5.1 \mathrm{~b}$ for comparison with unweighted estimates, Table B5.2 for estimated effects on panel b outcomes (using 10\% reduction as the reference category), with and without covariate adjustment. Tables B5.1b and B5.2 show robustness to using 5-point scales, and Fig. B8.2 shows the distribution of responses across treatment arms. 
Table B5.1a. Group Means for Respondents' Opposition to Police Involvement in Specific Incidents

\begin{tabular}{|c|c|c|c|c|c|c|c|}
\hline \multicolumn{2}{|c|}{$\begin{array}{l}\text { Person threatening spouse } \\
\text { with knife }\end{array}$} & \multicolumn{2}{|c|}{ Fight outside bar } & \multicolumn{2}{|c|}{$\begin{array}{c}\text { Person looking in car } \\
\text { windows }\end{array}$} & \multicolumn{2}{|c|}{$\begin{array}{c}\text { Person using counterfeit } \\
\text { money }\end{array}$} \\
\hline Unweighted & Weighted & Unweighted & Weighted & Unweighted & Weighted & Unweighted & Weighted \\
\hline $0.12(0.01)$ & $0.10(0.01)$ & $0.19(0.01)$ & $0.17(0.01)$ & $0.21(0.01)$ & $0.18(0.01)$ & $0.24(0.01)$ & $0.21(0.02)$ \\
\hline \multicolumn{2}{|c|}{$\begin{array}{c}\text { Person yelling racist slurs at } \\
\text { voting queue }\end{array}$} & \multicolumn{2}{|c|}{$\begin{array}{c}\text { Drunk person yelling at } \\
\text { outdoor diners }\end{array}$} & \multicolumn{2}{|c|}{$\begin{array}{c}\text { Teens playing loud music } \\
\text { at night in a park }\end{array}$} & \multicolumn{2}{|c|}{ Heroin overdose in park } \\
\hline Unweighted & Weighted & Unweighted & Weighted & Unweighted & Weighted & Unweighted & $\mathrm{We}$ \\
\hline $0.31(0.01)$ & $0.29(0.02)$ & $0.39(0.01)$ & $0.35(0.02)$ & $0.40(0.01)$ & $0.38(0.02)$ & $0.48(0.01)$ & $0.46(0.02)$ \\
\hline
\end{tabular}

Notes. Point estimates with standard errors in parentheses.

Table B5.1b. Group Means for Perceived Impact of Fewer Police Officers on Crime and Safety, with and without Binary Transformation

\begin{tabular}{|c|c|c|c|c|}
\hline & \multicolumn{2}{|c|}{$\begin{array}{c}\text { Increased crime } \\
\text { (binary transformation) }\end{array}$} & \multicolumn{2}{|c|}{$\begin{array}{c}\text { Decreased safety } \\
\text { (binary transformation) }\end{array}$} \\
\hline & Unweighted & Weighted & Unweighted & Weighted \\
\hline $10 \%$ & $0.56(0.03)$ & $0.55(0.04)$ & $0.60(0.03)$ & $0.57(0.04)$ \\
\hline $25 \%$ & $0.61(0.03)$ & $0.60(0.04)$ & $0.62(0.03)$ & $0.63(0.04)$ \\
\hline $50 \%$ & $0.68(0.03)$ & $0.72(0.04)$ & $0.65(0.03)$ & $0.66(0.04)$ \\
\hline \multirow[t]{3}{*}{$100 \%$} & $0.71(0.03)$ & $0.75(0.03)$ & $0.71(0.03)$ & $0.73(0.03)$ \\
\hline & \multicolumn{2}{|c|}{$\begin{array}{l}\text { Crime levels } \\
\text { (5-point scale) }\end{array}$} & \multicolumn{2}{|c|}{$\begin{array}{l}\text { Fear of crime } \\
\text { (5-point scale) }\end{array}$} \\
\hline & Unweighted & Weighted & Unweighted & Weighted \\
\hline $10 \%$ & $3.70(0.06)$ & $3.75(0.08)$ & $3.77(0.06)$ & $3.80(0.08)$ \\
\hline $25 \%$ & $3.75(0.06)$ & $3.72(0.09)$ & $3.81(0.07)$ & $3.84(0.09)$ \\
\hline $50 \%$ & $4.00(0.06)$ & $4.04(0.09)$ & $3.91(0.07)$ & $3.93(0.10)$ \\
\hline $100 \%$ & $4.17(0.06)$ & $4.27(0.08)$ & $4.11(0.07)$ & $4.25(0.08)$ \\
\hline
\end{tabular}

Notes. Point estimates with standard errors in parentheses. 
Table B5.2. Estimated Effects on Perceived Impact of Fewer Police Officers on Crime and Safety, with $10 \%$ Reduction as Reference Category

\begin{tabular}{|c|c|c|c|c|}
\hline & \multicolumn{2}{|c|}{$\begin{array}{l}\text { Increased crime } \\
\text { (binary) }\end{array}$} & \multicolumn{2}{|c|}{$\begin{array}{c}\text { Decreased safety } \\
\text { (binary) }\end{array}$} \\
\hline & Unweighted & Weighted & Unweighted & Weighted \\
\hline \multicolumn{5}{|c|}{ Difference-in-Means Estimator: } \\
\hline $100 \%$ & $0.11(0.04)^{*}$ & $0.16(0.05)^{*}$ & $0.15(0.04)^{*}$ & $0.20(0.05)^{*}$ \\
\hline $50 \%$ & $0.02(0.04)$ & $0.06(0.06)$ & $0.04(0.04)$ & $0.05(0.06)$ \\
\hline $25 \%$ & $0.05(0.04)$ & $0.08(0.06)$ & $0.12(0.04)^{*}$ & $0.17(0.05)^{*}$ \\
\hline \multicolumn{5}{|c|}{ Covariate-adjusted Estimator: } \\
\hline $100 \%$ & $0.12(0.04)^{*}$ & $0.17(0.06)^{*}$ & $0.18(0.04)^{*}$ & $0.20(0.06)^{*}$ \\
\hline $50 \%$ & $0.01(0.05)$ & $0.08(0.06)$ & $0.03(0.05)$ & $0.04(0.06)$ \\
\hline \multirow[t]{3}{*}{$25 \%$} & $0.06(0.04)$ & $0.09(0.06)$ & $0.12(0.04)^{*}$ & $0.16(0.06)^{*}$ \\
\hline & \multicolumn{2}{|c|}{$\begin{array}{l}\text { Crime levels } \\
\text { (5-point scale) }\end{array}$} & \multicolumn{2}{|c|}{$\begin{array}{l}\text { Fear of crime } \\
\text { (5-point scale) }\end{array}$} \\
\hline & Unweighted & Weighted & Unweighted & Weighted \\
\hline \multicolumn{5}{|c|}{ Difference-in-Means Estimator: } \\
\hline $100 \%$ & $0.15(0.04)^{*}$ & $0.20(0.05)^{*}$ & $0.34(0.09)^{*}$ & $0.45(0.12)^{*}$ \\
\hline $50 \%$ & $0.04(0.04)$ & $0.05(0.06)$ & $0.04(0.09)$ & $0.04(0.12)$ \\
\hline $25 \%$ & $0.12(0.04)^{*}$ & $0.17(0.05)^{*}$ & $0.14(0.09)$ & $0.13(0.13)$ \\
\hline \multicolumn{5}{|c|}{ Covariate-adjusted Estimator: } \\
\hline $100 \%$ & $0.18(0.04)^{*}$ & $0.20(0.06)^{*}$ & $0.39(0.09)^{*}$ & $0.52(0.11)^{*}$ \\
\hline $50 \%$ & $0.03(0.05)$ & $0.04(0.06)$ & $0.04(0.10)$ & $0.12(0.12)$ \\
\hline $25 \%$ & $0.12(0.04)^{*}$ & $0.16(0.06)^{*}$ & $0.20(0.10)$ & $0.21(0.13)$ \\
\hline
\end{tabular}

Notes. Point estimates for between-subjects estimators (Fig. B5b) with robust standard errors in parentheses. The covariateadjusted estimator includes age, sex, region, household income, employment status, race/ethnicity, education, partisanship, conservativism, and self-reported political engagement. P-values are adjusted using the Benjamini and Hochberg (1995) procedure to control the false discovery rate. ${ }^{*} \mathrm{P}<0.05$. 
Figure B6. Respondents' Beliefs About What Police Activities Were Opposed Among Those Who Supported Abolishing, Defunding, or Reforming the Police

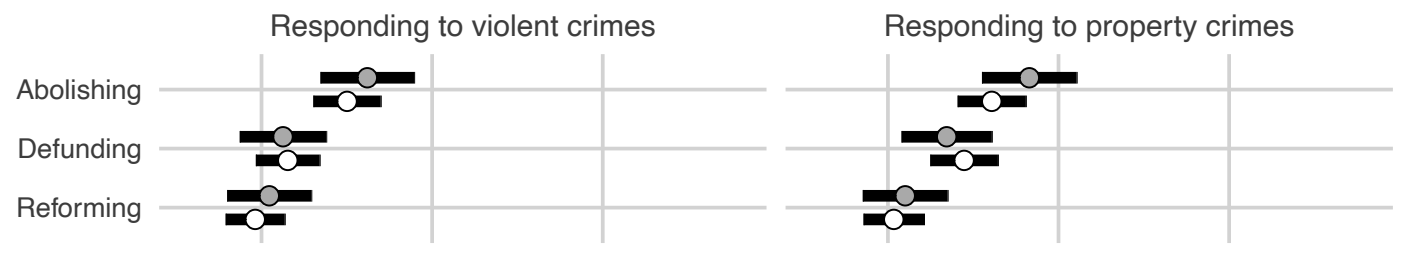

Responding to vice crimes

Crime prevention

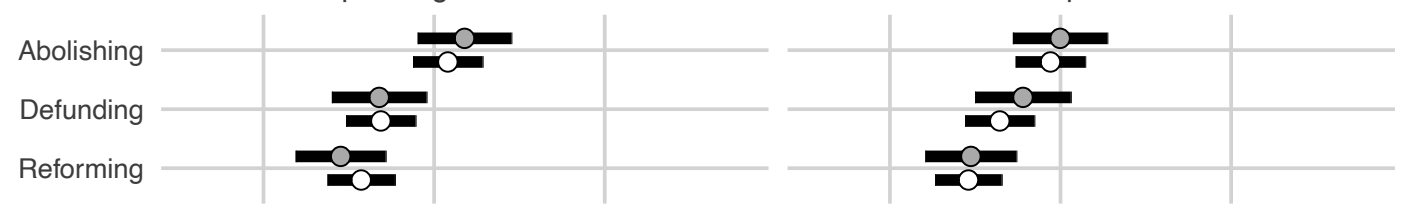

Maintaining civil order Conducting vehicle stops
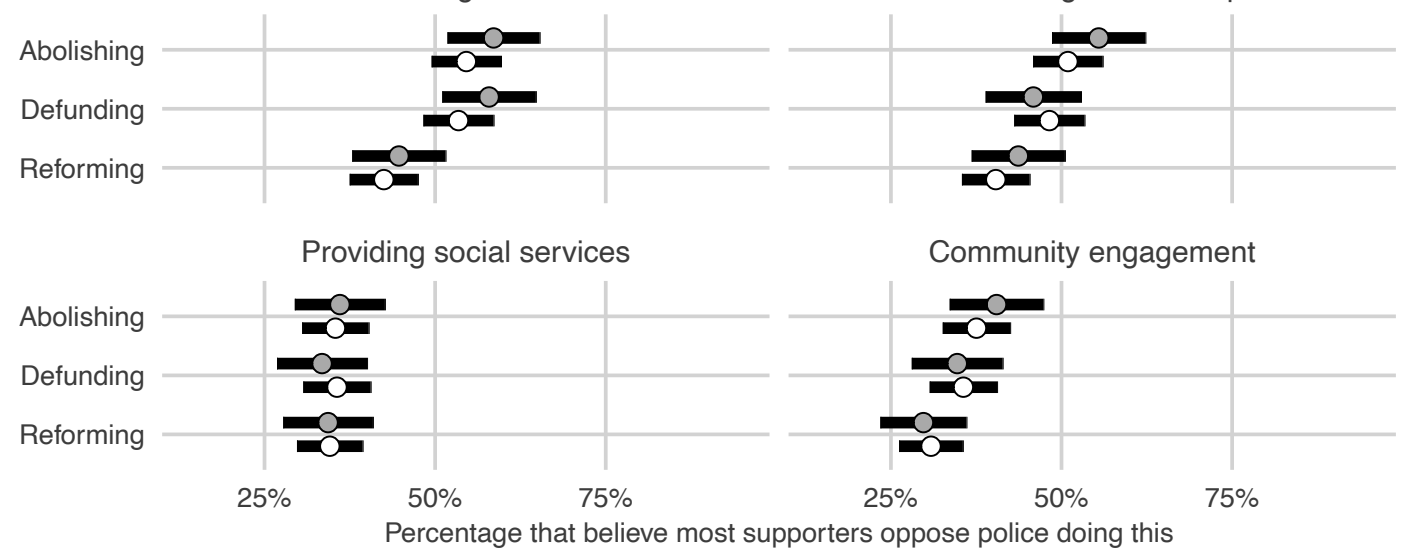

Notes. Point estimates and 95\% confidence intervals are group means from a between-subjects experimental design that randomly assigned "abolishing", "defunding", or "reforming" the police with equal probability. Grey dots denote weighted estimates and white dots denote unweighted estimates. 
Table B6.1. Group Means for Respondents' Beliefs About What Police Activities Were Opposed Among Those Who Supported Abolishing, Defunding, or Reforming the Police

\begin{tabular}{|c|c|c|c|c|c|c|c|c|}
\hline & \multicolumn{2}{|c|}{ Responding to violent crimes } & \multicolumn{2}{|c|}{$\begin{array}{c}\text { Responding to property } \\
\text { crimes }\end{array}$} & \multicolumn{2}{|c|}{$\begin{array}{c}\text { Responding to vice } \\
\text { crimes }\end{array}$} & \multicolumn{2}{|c|}{ Crime prevention } \\
\hline & Unweighted & Weighted & Unweighted & Weighted & Unweighted & Weighted & Unweighted & Weighted \\
\hline Abolish & $0.38(0.03)$ & $0.41(0.04)$ & $0.40(0.03)$ & $0.46(0.04)$ & $0.52(0.03)$ & $0.55(0.04)$ & $0.48(0.03)$ & $0.50(0.04)$ \\
\hline Defund & $.29(0.02)$ & $0.28(0.03)$ & $0.36(0.02)$ & $0.34(0.03)$ & $0.42(0.03)$ & $0.42(0.04)$ & $0.41(0.03)$ & $0.45(0.04)$ \\
\hline \multirow[t]{3}{*}{ Reform } & $4(0.02)$ & 0 . & 0.26 & 0.2 & 0.39 & 0.36 & $0.36(0.03)$ & 0.37 \\
\hline & \multicolumn{2}{|c|}{ Maintaining civil order } & \multicolumn{2}{|c|}{ Conducting vehicle stops } & \multicolumn{2}{|c|}{ Providing social services } & \multicolumn{2}{|c|}{$\begin{array}{l}\text { Community } \\
\text { engagement }\end{array}$} \\
\hline & Unweighted & Weighted & Unweighted & Weighted & Unweighted & Weighted & Unweighted & Weighted \\
\hline Abolish & $0.51(0.03)$ & $0.55(0.04)$ & $0.55(0.03)$ & $0.59(0.03)$ & $0.35(0.03)$ & $0.36(0.03)$ & $0.38(0.03)$ & $0.41(0.04)$ \\
\hline Defund & $0.48(0.03)$ & $0.46(0.04)$ & $0.53(0.03)$ & $0.58(0.04)$ & $0.36(0.03)$ & $0.33(0.03)$ & $0.36(0.03)$ & $0.35(0.03)$ \\
\hline Reform & $0.40(0.03)$ & $0.44(0.04)$ & $0.42(0.03)$ & $0.45(0.04)$ & $0.35(0.02)$ & $0.34(0.03)$ & $0.31(0.02)$ & $0.30(0.03)$ \\
\hline
\end{tabular}

Notes. Point estimates with standard errors in parentheses.

Table B6.2. Estimated Effects on Beliefs About What Police Activities Were Opposed, with Reforming Police as Reference Category

\section{Responding to Violent Responding to Property Responding to Vice Crimes \\ Crimes \\ Crimes}

Crime Prevention

\begin{tabular}{|c|c|c|c|c|c|c|c|c|}
\hline & Unweighted & Weighted & Unweighted & Weighted & Unweighted & Weighted & Unweighted & Weighted \\
\hline \multicolumn{9}{|c|}{ Difference-in-Means Estimator: } \\
\hline Abolish & $0.13(0.03)^{*}$ & $0.14(0.05)^{*}$ & $0.14(0.03)^{*}$ & $0.18(0.05)^{*}$ & $0.13(0.04)^{*}$ & $0.18(0.05)^{*}$ & $0.12(0.04)^{*}$ & $0.13(0.05)^{*}$ \\
\hline Defund & $0.05(0.03)$ & $0.02(0.04)$ & $0.10(0.03)^{*}$ & $0.06(0.05)$ & $0.03(0.04)$ & $0.06(0.05)$ & $0.05(0.04)$ & $0.08(0.05)$ \\
\hline \multicolumn{9}{|c|}{ Covariate-Adjusted Estimator: } \\
\hline Abolish & $0.13(0.04)^{*}$ & $0.12(0.05)^{*}$ & $0.14(0.03)^{*}$ & $0.18(0.05)^{*}$ & $0.14(0.04)^{*}$ & $0.20(0.05)^{*}$ & $0.11(0.04)^{*}$ & $0.12(0.05)^{*}$ \\
\hline \multirow[t]{3}{*}{ Defund } & $0.06(0.03)$ & $0.02(0.05)$ & $0.13(0.03)^{*}$ & $0.08(0.05)$ & $0.06(0.04)$ & $0.09(0.05)$ & $0.06(0.04)$ & $0.06(0.05)$ \\
\hline & \multicolumn{2}{|c|}{ Maintaining civil order } & \multicolumn{2}{|c|}{ Conducting vehicle stops } & \multicolumn{2}{|c|}{ Providing social services } & \multicolumn{2}{|c|}{ Community engagement } \\
\hline & Unweighted & Weighted & Unweighted & Weighted & Unweighted & Weighted & Unweighted & Weighted \\
\hline \multicolumn{9}{|c|}{ Difference-in-Means Estimator: } \\
\hline Abolish & $0.13(0.03)^{*}$ & $0.14(0.05)^{*}$ & $0.14(0.03)^{*}$ & $0.18(0.05)^{*}$ & $0.13(0.04)^{*}$ & $0.18(0.05)^{*}$ & $0.12(0.04)^{*}$ & $0.13(0.05)^{*}$ \\
\hline Defund & $0.05(0.03)$ & $0.02(0.04)$ & $0.10(0.03)^{*}$ & $0.06(0.05)$ & $0.03(0.04)$ & $0.06(0.05)$ & $0.05(0.04)$ & $0.08(0.05)$ \\
\hline \multicolumn{9}{|c|}{ Covariate-Adjusted Estimator: } \\
\hline Abolish & $0.13(0.04)^{*}$ & $0.12(0.05)^{*}$ & $0.14(0.03)^{*}$ & $0.18(0.05)^{*}$ & $0.14(0.04)^{*}$ & $0.20(0.05)^{*}$ & $0.11(0.04)^{*}$ & $0.12(0.05)^{*}$ \\
\hline Defund & $0.06(0.03)$ & $0.02(0.05)$ & $0.13(0.03)^{*}$ & $0.08(0.05)$ & $0.06(0.04)$ & $0.09(0.05)$ & $0.06(0.04)$ & $0.06(0.05)$ \\
\hline
\end{tabular}

Notes. Point estimates for between-subjects estimators (Fig. B5) with robust standard errors in parentheses. The covariate-adjusted estimator includes age, sex, region, household income, employment status, race/ethnicity, education, partisanship, conservativism, and self-reported political engagement. P-values are adjusted using the Benjamini and Hochberg (1995) procedure to control the false discovery rate. $* \mathrm{P}<0.05$. 

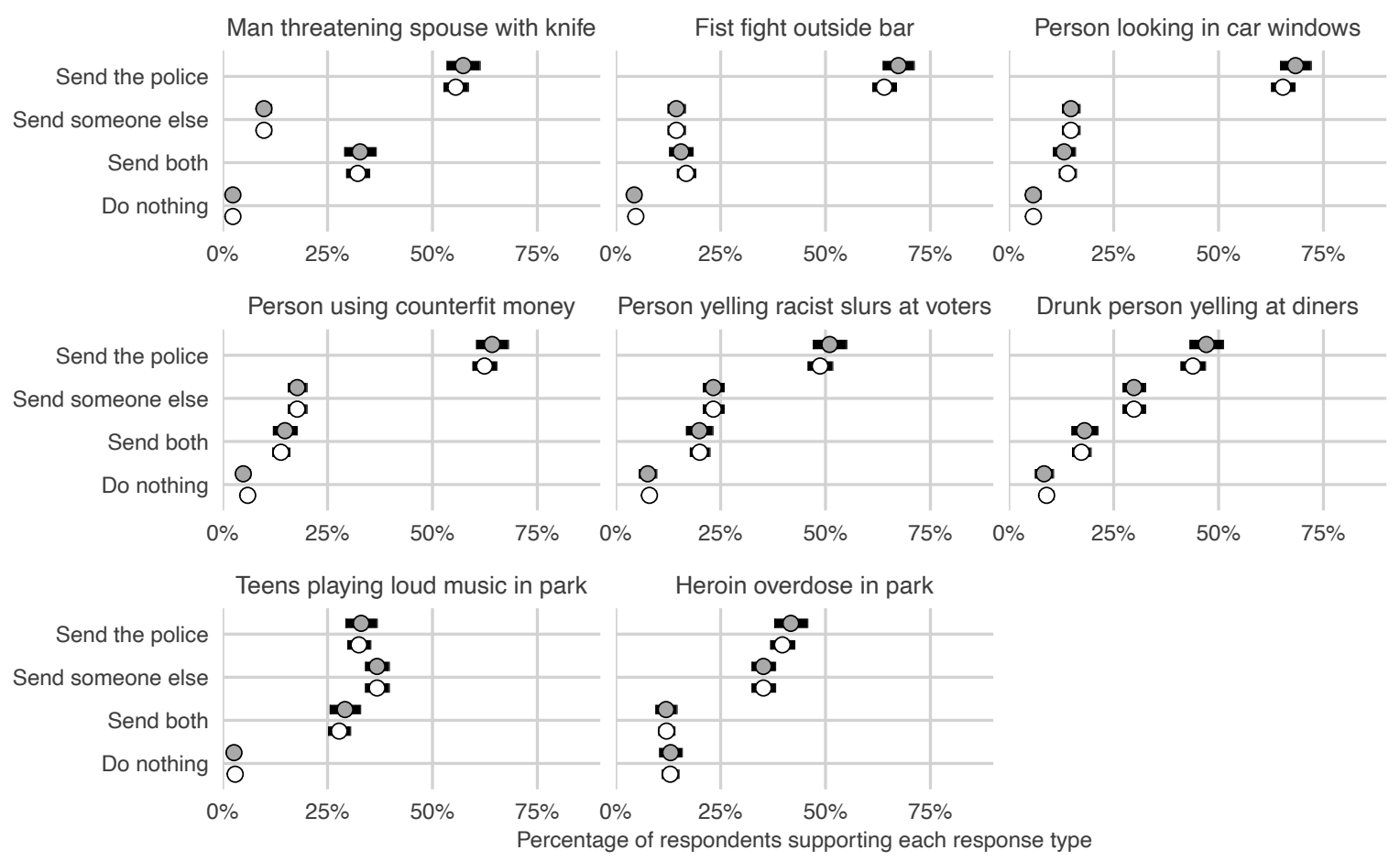

Notes. Point estimates and 95\% confidence intervals are group means for respondents' preferred response to a civilianinitiated 911 call. Grey dots denote weighted estimates and white dots denote unweighted estimates. Scenarios were presented in random order and respondents could indicate: 1) only the police should be sent;2) that the police should be accompanied by another first responder, such as social services; 3 ) that another first responder should be sent without police; or 4) that no government response should take place.

Table B7. Group Means on Respondents’ Preferred Responses to Specific Incidents Generating 911 Calls

\begin{tabular}{lllllllll} 
& \multicolumn{2}{c}{$\begin{array}{c}\text { Person threatening } \\
\text { spouse with knife }\end{array}$} & \multicolumn{2}{c}{ Fight outside bar } & \multicolumn{2}{c}{$\begin{array}{c}\text { Person looking in car } \\
\text { windows }\end{array}$} & \multicolumn{2}{c}{$\begin{array}{c}\text { Person using counterfeit } \\
\text { money }\end{array}$} \\
\cline { 2 - 9 } & Unweighted & Weighted & Unweighted & Weighted & Unweighted & Weighted & Unweighted & Weighted \\
\hline Police & $0.56(0.01)$ & $0.57(0.02)$ & $0.64(0.01)$ & $0.67(0.02)$ & $0.65(0.01)$ & $0.68(0.02)$ & $0.62(0.01)$ & $0.64(0.02)$ \\
Someone else & $0.10(0.01)$ & $0.10(0.01)$ & $0.14(0.01)$ & $0.14(0.01)$ & $0.15(0.01)$ & $0.15(0.01)$ & $0.18(0.01)$ & $0.18(0.01)$ \\
Send both & $0.32(0.01)$ & $0.33(0.02)$ & $0.17(0.01)$ & $0.16(0.01)$ & $0.14(0.01)$ & $0.13(0.01)$ & $0.14(0.01)$ & $0.15(0.01)$ \\
Do nothing & $0.02(0.01)$ & $0.02(0.01)$ & $0.05(0.01)$ & $0.04(0.01)$ & $0.06(0.01)$ & $0.06(0.01)$ & $0.06(0.01)$ & $0.05(0.01)$ \\
& \multicolumn{2}{c}{ Person yelling racist } & \multicolumn{2}{c}{ Drunk person yelling at } & Teens playing loud & Heroin overdose in park \\
& slurs at voting queue & \multicolumn{2}{c}{ outdoor diners } & music at night in a park & & \\
\hline
\end{tabular}

Notes. Point estimates with standard errors in parentheses. 
Figure B8.1. Distribution of Beliefs About Movement Supporters' Preferences for Spending on Police Services and the Number of Police on the Street by Treatment Arm

a
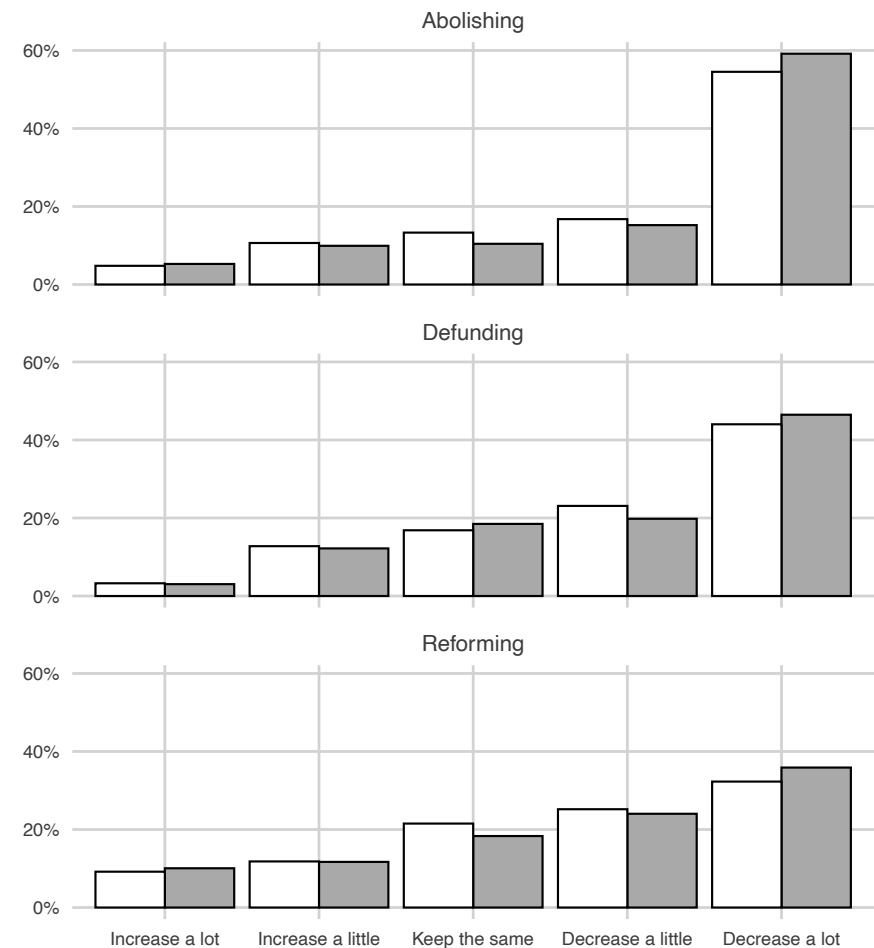

b

Number of police on the street

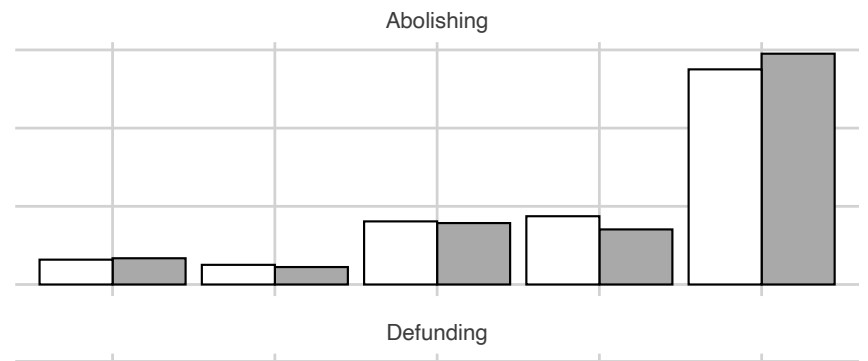

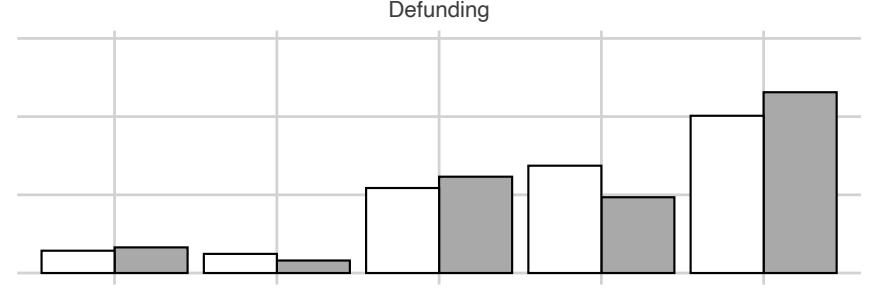

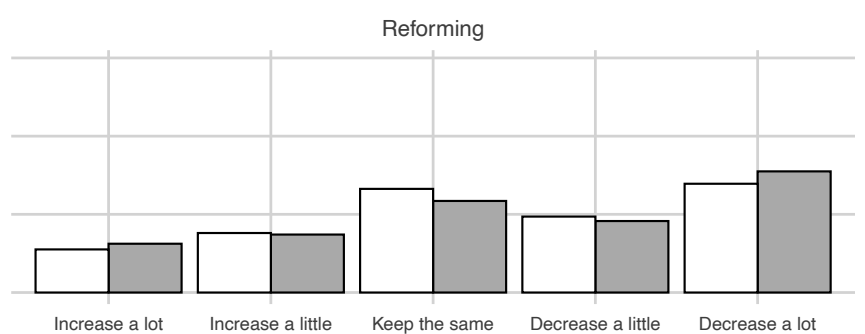

Notes. Grey bars denote weighted proportions and white bars denote unweighted proportions. Panel a: "Think about people who support [abolishing, defunding, or reforming] the police. How do you think they want to change the number of police on the streets?" and Panel b: "Do you believe most of these people want each of the following to be decreased, kept the same, or increased?" were captured using a 5-point scale ("Increase a lot" =1, "Increase a little" $=2$, "Keep the same" = 3, "Decrease a little" = 4, "Decrease a lot" =5). 
Figure B8.2. Distribution of Perceived Impact of Cuts to Police Numbers on Crime and Safety by Treatment Arm
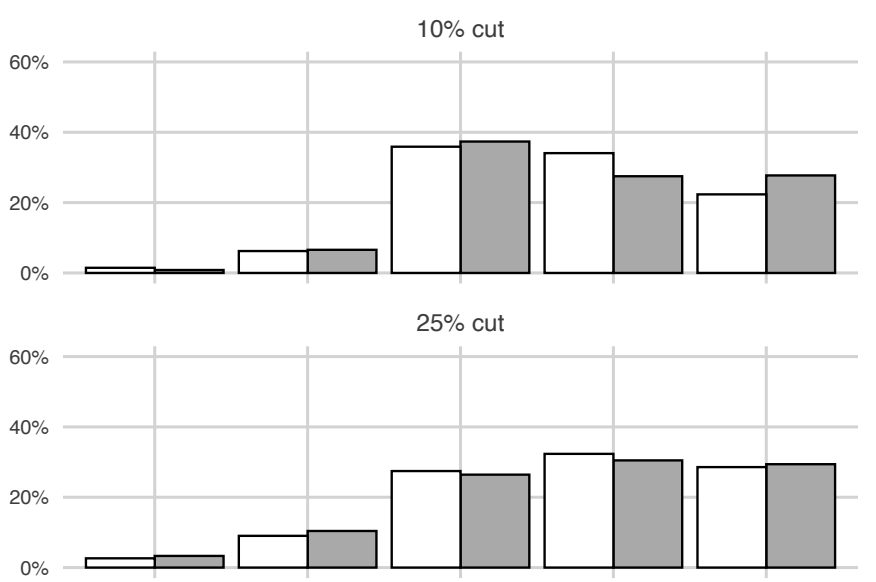

$50 \%$ cut

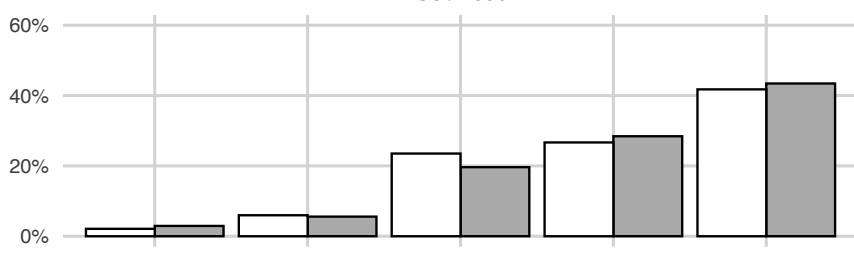

$100 \%$ cut

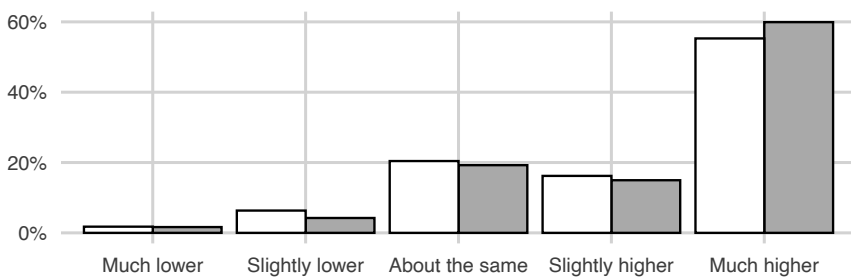

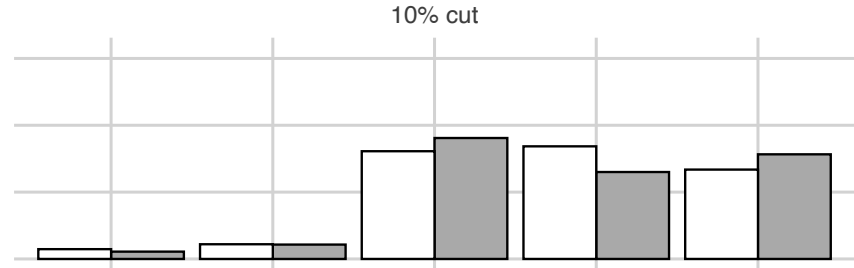

$25 \%$ cut

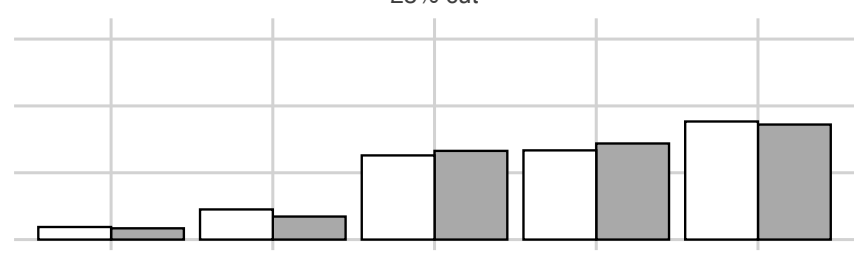

$50 \%$ cut

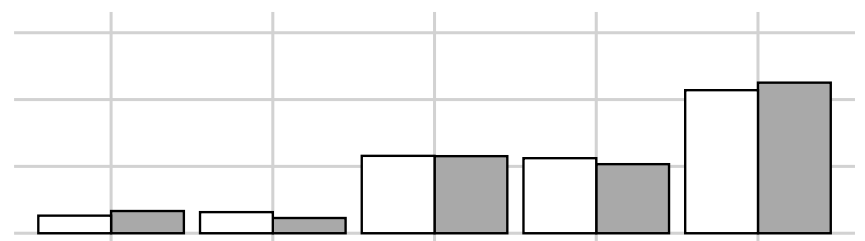

$100 \%$ cut

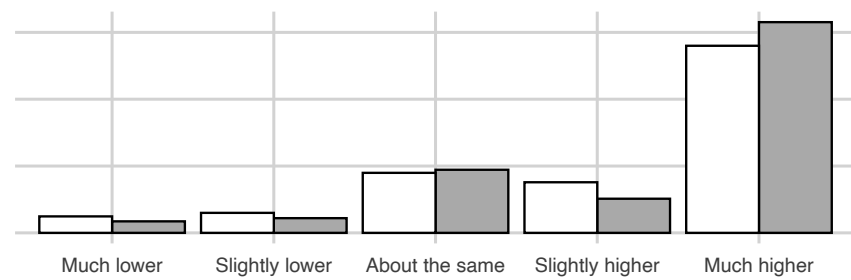

Notes. Grey bars denote weighted proportions and white bars denote unweighted proportions. Panel a: "Suppose the city/town you live in cut the number of police officers by $[10 \%, 25 \%, 50 \%$, or $100 \%]$. Would the level of crime be lower, higher, or about the same?" ("Much lower" = 1, "Slightly lower" = 2, "About the same" = 3, "Slightly higher" = 4, "Much higher" =5). Panel b: "Would you feel less safe, more safe, or about the same?" ("Much more safe" = 1, "Slightly more safe" $=2$, "About the same" = 3, "Slightly less safe" = 4, "Much less safe" =5). 
Figure B9. Respondents' Beliefs About Non-Police Spending Preferences Among Those Who Supported Abolishing, Defunding, or Reforming the Police

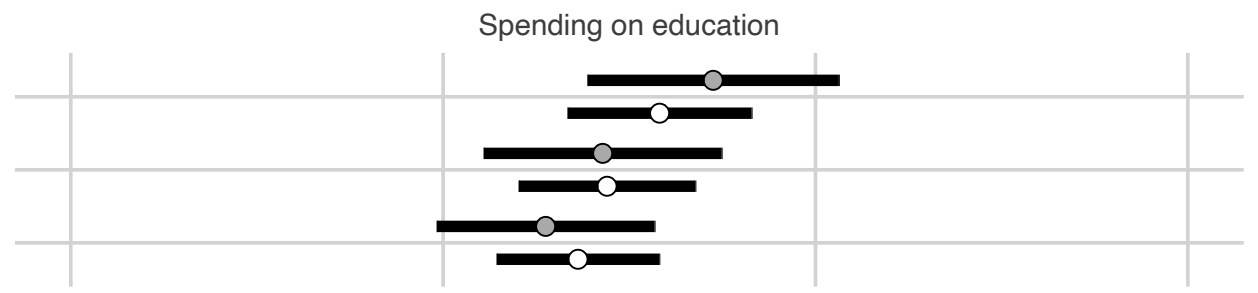

Spending on healthcare

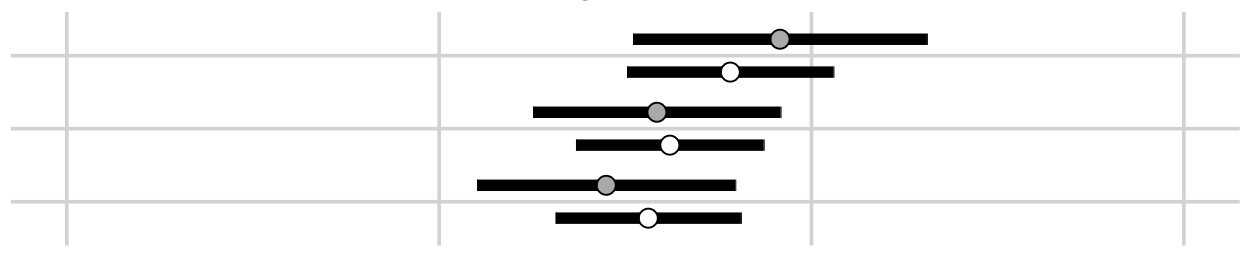

Spending on housing

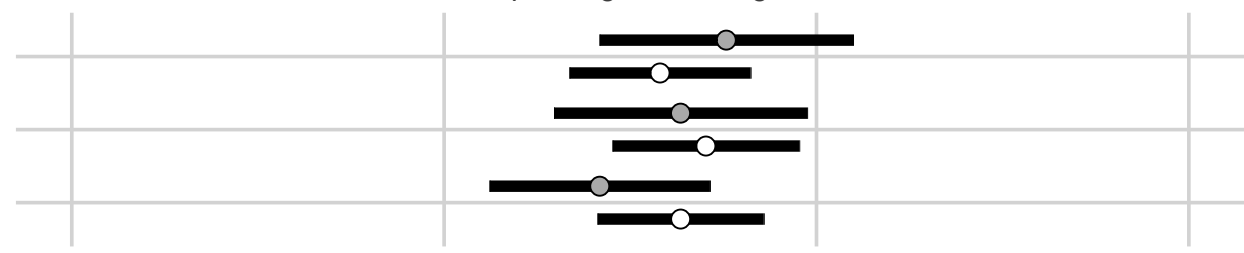

Spending on social services

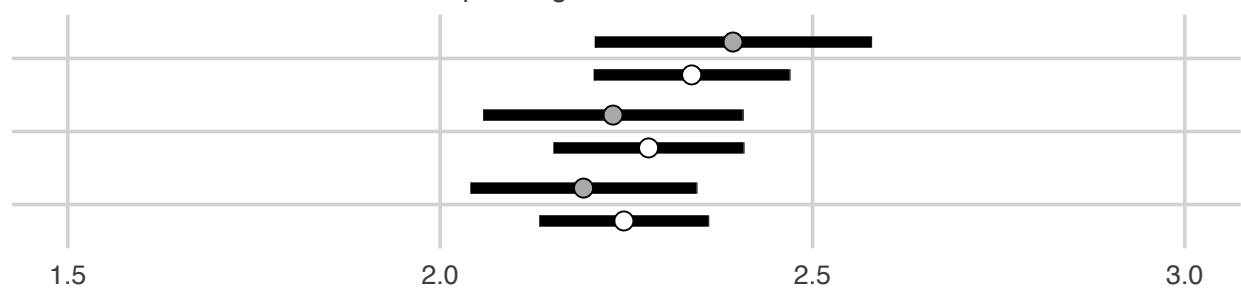

Perceptions of supporters' preferences

$(1=$ Increase a lot, $\ldots, 5=$ Decrease a lot $)$

Notes. Point estimates and 95\% confidence intervals are group means from a between-subjects experimental design that randomly assigned "abolishing", "defunding", or "reforming" the police with equal probability. Grey dots denote weighted estimates and white dots denote unweighted estimates. Responses to the question "Think about people who support [abolishing, defunding, or reforming] the police. How do you think they want to change the number of police on the streets?" and "Do you believe most of these people want each of the following to be decreased, kept the same, or increased?" were captured using a 5-point scale ("Increase a lot" = 1, "Increase a little" =2, "Keep the same" = 3, "Decrease a little" = 4, "Decrease a lot" $=5$ ). 
Table B9.1. Group Means for Beliefs About Supporters' Non-Police Spending Preferences Among Those Who Supported Abolishing, Defunding, or Reforming the Police

\begin{tabular}{lllllllll} 
& \multicolumn{2}{c}{$\begin{array}{c}\text { Spending on } \\
\text { education }\end{array}$} & \multicolumn{2}{c}{$\begin{array}{c}\text { Spending on } \\
\text { healthcare }\end{array}$} & \multicolumn{2}{c}{$\begin{array}{c}\text { Spending on } \\
\text { housing }\end{array}$} & $\begin{array}{c}\text { Spending on } \\
\text { social services }\end{array}$ \\
\cline { 2 - 9 } & Unweighted & Weighted & Unweighted & Weighted & Unweighted & Weighted & Unweighted & Weighted \\
\hline Abolish & $2.29(0.06)$ & $2.36(0.09)$ & $2.39(0.07)$ & $2.46(0.10)$ & $2.29(0.06)$ & $2.38(0.09)$ & $2.34(0.07)$ & $2.39(0.09)$ \\
Defund & $2.22(0.06)$ & $2.21(0.08)$ & $2.31(0.06)$ & $2.29(0.08)$ & $2.35(0.06)$ & $2.32(0.09)$ & $2.28(0.07)$ & $2.23(0.09)$ \\
Reform & $2.18(0.06)$ & $2.14(0.07)$ & $2.28(0.06)$ & $2.22(0.09)$ & $2.32(0.06)$ & $2.21(0.07)$ & $2.25(0.06)$ & $2.19(0.08)$ \\
\hline \hline
\end{tabular}

Notes. Point estimates with standard errors in parentheses.

Table B9.2. Estimated Effects on Beliefs About Supporters' Non-Police Spending Preferences, with Reforming Police as Reference Category

\begin{tabular}{|c|c|c|c|c|c|c|c|c|}
\hline & \multicolumn{2}{|c|}{$\begin{array}{l}\text { Spending on } \\
\text { education }\end{array}$} & \multicolumn{2}{|c|}{$\begin{array}{c}\text { Spending on } \\
\text { healthcare }\end{array}$} & \multicolumn{2}{|c|}{$\begin{array}{l}\text { Spending on } \\
\text { housing }\end{array}$} & \multicolumn{2}{|c|}{$\begin{array}{c}\text { Spending on } \\
\text { social services }\end{array}$} \\
\hline & Unweighted & Weighted & Unweighted & Weighted & Unweighted & Weighted & Unweighted & Weighted \\
\hline \multicolumn{9}{|c|}{ Difference-in-Means Estimator: } \\
\hline Abolish & $0.11(0.08)$ & $0.22(0.11)$ & $0.11(0.09)$ & $0.23(0.13)$ & $-0.03(0.08)$ & $0.17(0.11)$ & $0.09(0.09)$ & $0.20(0.12)$ \\
\hline Defund & $0.04(0.08)$ & $0.08(0.11)$ & $0.03(0.09)$ & $0.07(0.12)$ & $0.03(0.09)$ & $0.11(0.11)$ & $0.03(0.09)$ & $0.04(0.12)$ \\
\hline \multicolumn{9}{|c|}{ Covariate-adjusted Estimator: } \\
\hline Abolish & $0.15(0.09)$ & $0.27(0.13)$ & $0.16(0.10)$ & $0.25(0.13)$ & $-0.00(0.09)$ & $0.13(0.12)$ & $0.14(0.09)$ & $0.27(0.13)$ \\
\hline Defund & $0.05(0.09)$ & $0.09(0.12)$ & $0.04(0.09)$ & $0.10(0.12)$ & $0.01(0.09)$ & $0.05(0.11)$ & $-0.00(0.09)$ & $0.01(0.12)$ \\
\hline
\end{tabular}

Notes. Point estimates for between-subjects estimators with robust standard errors in parentheses. The covariate-adjusted estimator includes age, sex, region, household income, employment status, race/ethnicity, education, partisanship, conservativism, and selfreported political engagement. P-values are adjusted using the Benjamini and Hochberg (1995) procedure to control the false discovery rate. ${ }^{*} \mathrm{P}<0.05$. 
Figure B10a. Support for Abolishing, Defunding, or Reforming the Police by Race/Ethnicity
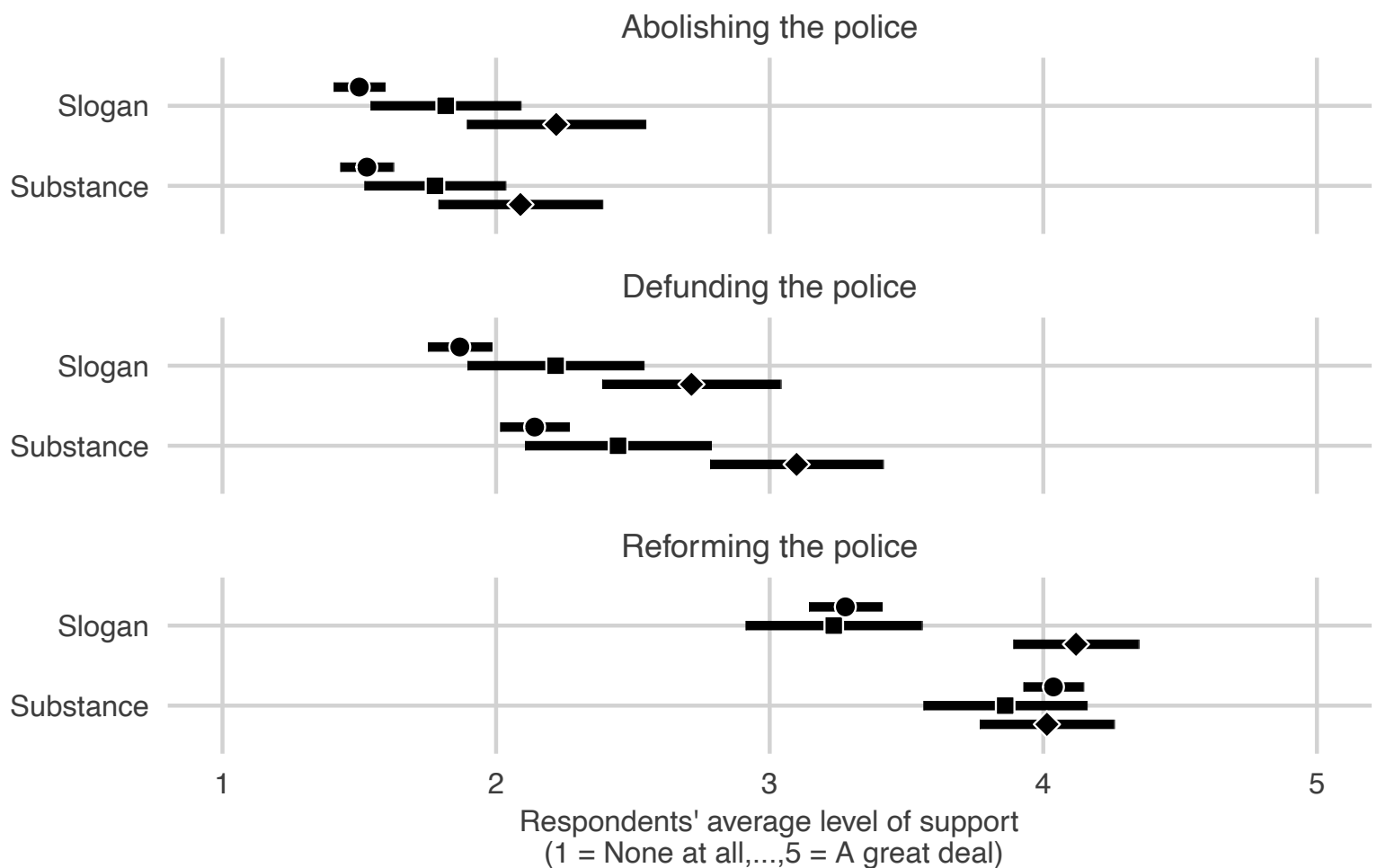

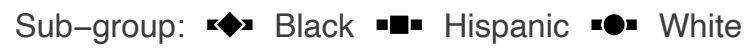

Notes. Point estimates and 95\% confidence intervals are group means from within-subjects experimental design (see Fig B1) for Black $(n=141)$, non-Hispanic White $(n=755)$, and Hispanic $(n=136)$ sub-groups. Responses to the question "Here are three different changes to how police operate that might be considered. How much do you support each one?" were measured using a 5-point scale ( $1=$ "None at all", 2 = "A little"; 3 = "A moderate amount"; 4 = "A lot"; 5 = "A great deal"). See Tables B10.1-B10.2 for point estimates, standard errors, and comparisons between weighted and unweighted estimates. 
Figure B10b. Support for Abolishing, Defunding, or Reforming the Police by Partisanship
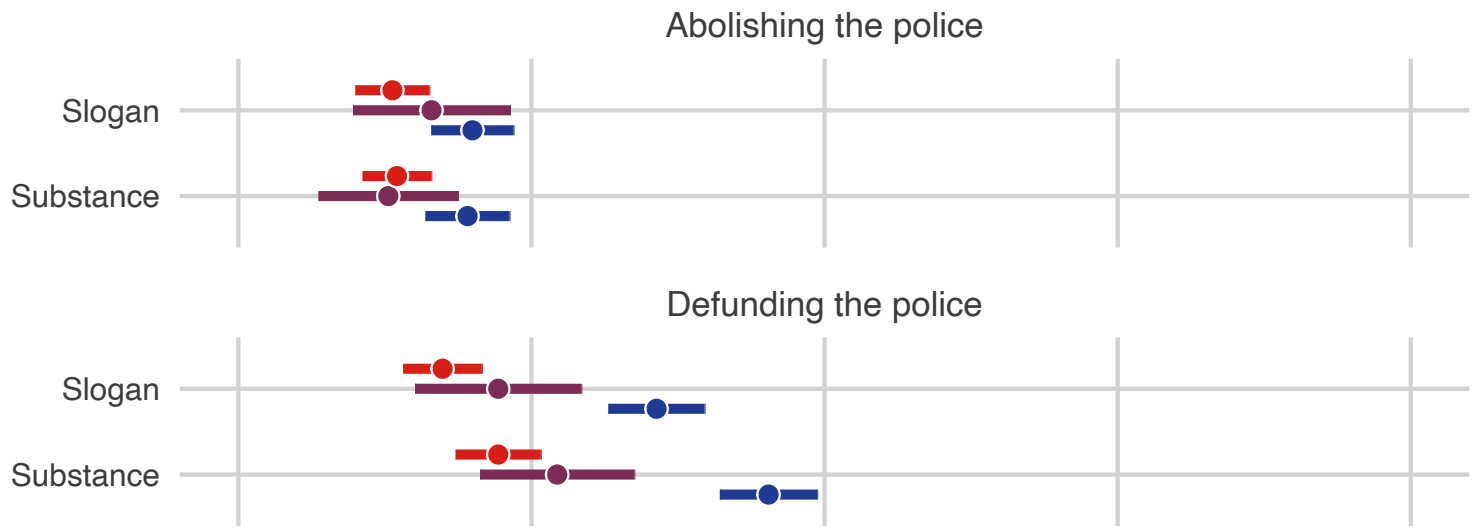

Reforming the police

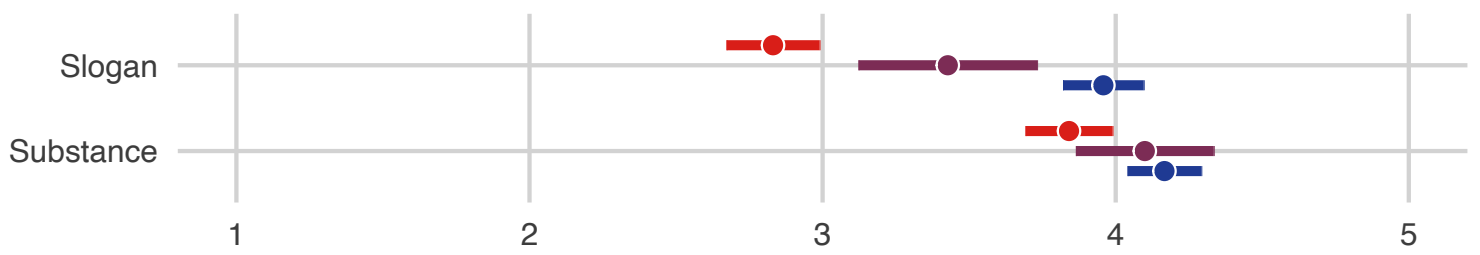

Respondents' average level of support

$(1=$ None at all, $\ldots, 5=$ A great deal)

Sub-group: -O= Democrat -Or Independent =0- Republican

Notes. Point estimates and 95\% confidence intervals are group means from within-subjects experimental design (see Fig B1) for Democrat $(n=538)$, Independent $(n=136)$, and Republican $(n=463)$ sub-groups. Partisanship is measured with the standard 7-point branching question used in the American National Election Studies (ANES) Survey. Therefore, Democrat and Republican sub-groups include weak supporters, strong supporters, and those that lean toward one party or another, whereas Independents do not lean one way or the other. Responses to the question "Here are three different changes to how police operate that might be considered. How much do you support each one?" were measured using a 5-point scale $(1=$ "None at all", 2 = "A little"; 3 = "A moderate amount"; 4 = "A lot"; 5 = "A great deal"). See Tables B10.1-B10.2 for point estimates, standard errors, and comparisons between weighted and unweighted estimates. 
Table B10.1. Weighted Group Means for Support for Abolishing, Defunding, or Reforming the Police by Race/Ethnicity and Partisanship

\begin{tabular}{lcccccc} 
& \multicolumn{3}{c}{ Slogan } & \multicolumn{3}{c}{ Substance } \\
\cline { 2 - 6 } Race/ethnicity: & Black & Hispanic & White & Black & Hispanic & White \\
\cline { 2 - 7 } & $2.22(0.17)$ & $1.82(0.14)$ & $1.50(0.05)$ & $2.09(0.15)$ & $1.78(0.13)$ & $1.53(0.05)$ \\
Abolishing & $2.71(0.17)$ & $2.22(0.16)$ & $1.87(0.06)$ & $3.10(0.16)$ & $2.45(0.17)$ & $2.14(0.06)$ \\
Refunding & $4.12(0.12)$ & $3.23(0.16)$ & $3.28(0.07)$ & $4.01(0.12)$ & $3.86(0.15)$ & $4.04(0.06)$ \\
\hline Partisanship: & \multicolumn{1}{c}{ Democrat } & Independent & Republican & Democrat & Independent & Republican \\
\hline Abolishing & $1.80(0.07)$ & $1.66(0.14)$ & $1.53(0.06)$ & $1.78(0.07)$ & $1.51(0.12)$ & $1.54(0.06)$ \\
Defunding & $2.43(0.08)$ & $1.89(0.14)$ & $1.70(0.07)$ & $2.81(0.09)$ & $2.09(0.13)$ & $1.89(0.07)$ \\
Reforming & $3.96(0.07)$ & $3.43(0.15)$ & $2.83(0.08)$ & $4.17(0.06)$ & $4.10(0.12)$ & $3.84(0.07)$ \\
\hline \hline
\end{tabular}

Notes. Point estimates with standard errors in parentheses.

Table B10.2. Unweighted Group Means for Support for Abolishing, Defunding, or Reforming the Police by Race/Ethnicity and Partisanship

\begin{tabular}{|c|c|c|c|c|c|c|}
\hline \multirow{2}{*}{ Race/ethnicity: } & \multicolumn{3}{|c|}{ Slogan } & \multicolumn{3}{|c|}{ Substance } \\
\hline & Black & Hispanic & White & Black & Hispanic & White \\
\hline Abolishing & $2.29(0.11)$ & $2.04(0.11)$ & $1.63(0.04)$ & $2.15(0.11)$ & $1.92(0.10)$ & $1.67(0.04)$ \\
\hline Defunding & $2.68(0.12)$ & $2.36(0.12)$ & $2.01(0.05)$ & $2.93(0.11)$ & $2.47(0.11)$ & $2.28(0.05)$ \\
\hline Reforming & $4.00(0.09)$ & $3.36(0.11)$ & $3.37(0.05)$ & $3.96(0.09)$ & $3.81(0.10)$ & $4.03(0.04)$ \\
\hline \multicolumn{7}{|l|}{ Partisanship: } \\
\hline & Democrat & Independent & Republican & Democrat & Independent & Republican \\
\hline Abolishing & $1.91(0.05)$ & $1.67(0.09)$ & $1.66(0.05)$ & $1.88(0.05)$ & $1.53(0.09)$ & $1.71(0.05)$ \\
\hline Defunding & $2.45(0.06)$ & $1.89(0.10)$ & $1.88(0.06)$ & $2.82(0.06)$ & $2.08(0.10)$ & $2.01(0.06)$ \\
\hline Reforming & $3.95(0.05)$ & $3.34(0.11)$ & $2.94(0.06)$ & $4.11(0.05)$ & $4.02(0.09)$ & $3.85(0.05)$ \\
\hline
\end{tabular}

Notes. Point estimates with standard errors in parentheses. 
Figure B11a. Support for Abolishing, Defunding, or Reforming the Police by Race/Ethnicity
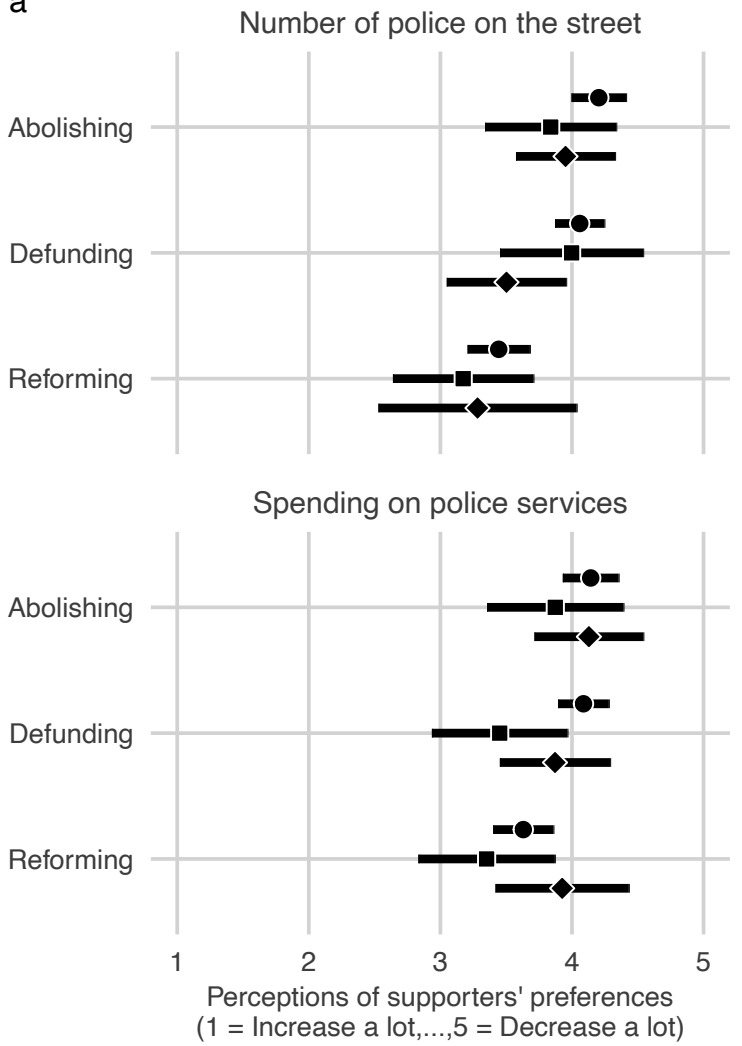

b

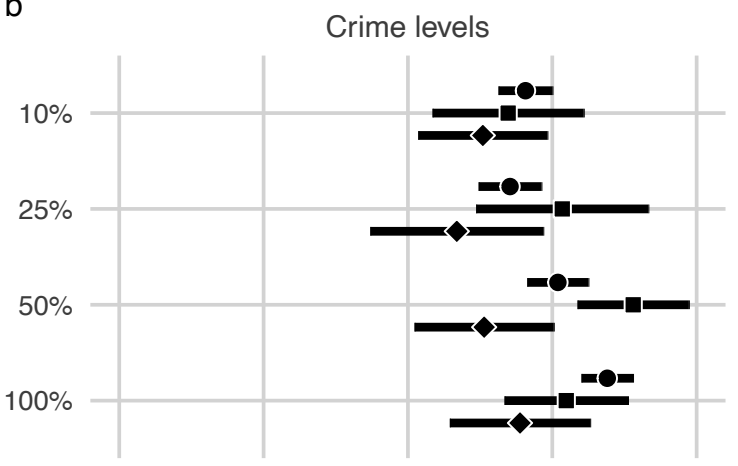

Fear of crime

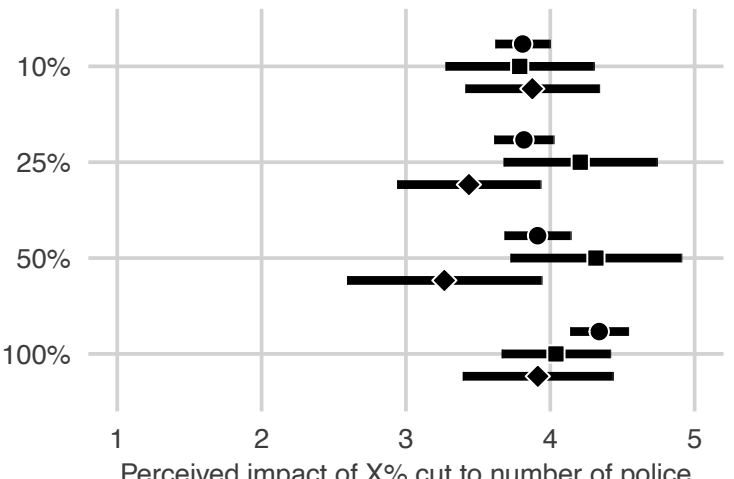

Perceived impact of $\mathrm{X} \%$ cut to number of police

( 1 = Much lower, ...,5 = Much higher)

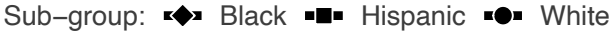

Notes. Point estimates and 95\% confidence intervals are group means from between-subjects experiments for Black $(\mathrm{n}=$ 141), non-Hispanic White $(\mathrm{n}=755)$, and Hispanic $(\mathrm{n}=136)$ sub-groups. Panel a: responses to the questions "Think about people who support [abolishing, defunding, or reforming] the police. How do you think they want to change the number of police on the streets?" and "Do you believe most of these people want each of the following to be decreased, kept the same, or increased?" were captured using a 5-point scale ("Increase a lot" =1, "Increase a little" =2, "Keep the same" = 3,

"Decrease a little" $=4$, "Decrease a lot" =5). Panel b: responses to the question "Suppose the city/town you live in cut the number of police officers by $[10 \%, 25 \%, 50 \%, 100 \%]$. Would the level of crime be lower, higher, or about the same?" were captured using a 5-point scale ("Much lower" = 1, "Slightly lower" = 2, "About the same" = 3, "Slightly higher" = 4, "Much higher" =5). Responses to the question "Would you feel less safe, more safe, or about the same?" were captured using a 5point scale ("Much more safe" = 1, "Slightly more safe" =2, "About the same" = 3, "Slightly less safe" = 4, "Much less safe" $=5$ ). See Tables B11.1-B12.2 for point estimates, standard errors, and comparisons between weighted and unweighted estimates. 
Figure B11b. Support for Abolishing, Defunding, or Reforming the Police by Partisanship

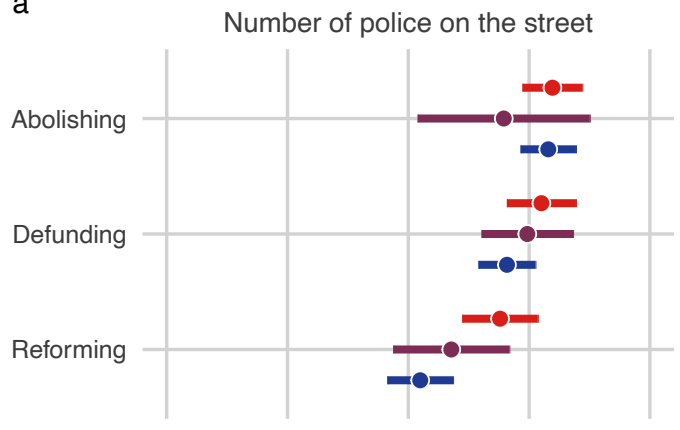

Spending on police services

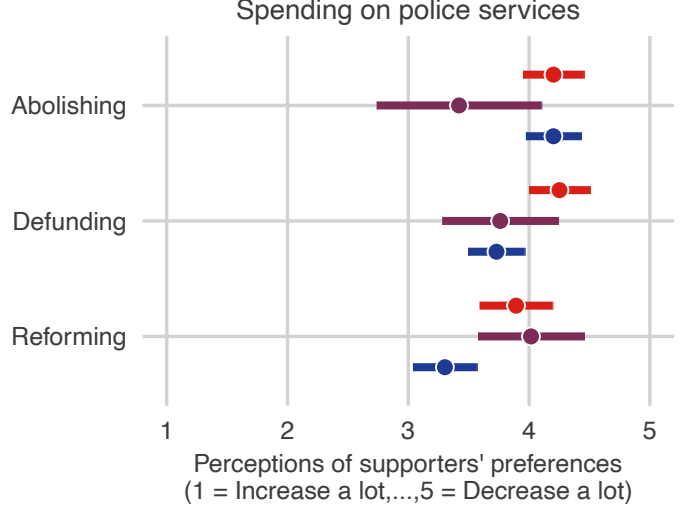

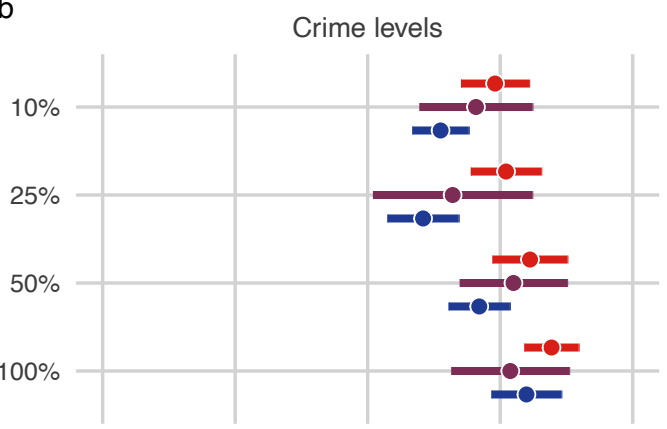

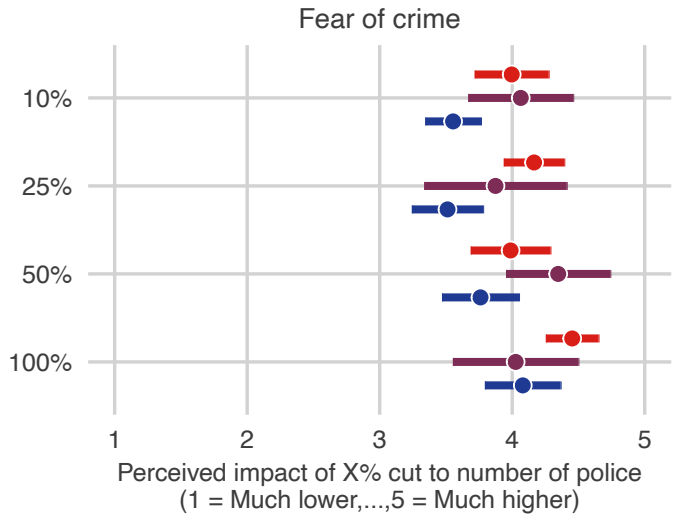

Sub-group: -0: Democrat ro: Independent -0: Republican

Notes. Point estimates and 95\% confidence intervals are group means from between subjects experiments for Democrat $(\mathrm{n}=$ 538), Independent $(n=136)$, and Republican $(n=463)$ sub-groups. Partisanship is measured with the standard 7-point branching question used in the American National Election Studies (ANES) Survey Panel a: responses to the questions "Think about people who support [abolishing, defunding, or reforming] the police. How do you think they want to change the number of police on the streets?" and "Do you believe most of these people want each of the following to be decreased, kept the same, or increased?" were captured using a 5-point scale ("Increase a lot" =1, "Increase a little" = 2, "Keep the same" = 3, "Decrease a little" = 4, "Decrease a lot" =5). Panel b: responses to the question "Suppose the city/town you live in cut the number of police officers by $[10 \%, 25 \%, 50 \%, 100 \%]$. Would the level of crime be lower, higher, or about the same?" were captured using a 5-point scale ("Much lower" = 1, "Slightly lower" = 2, "About the same" = 3, "Slightly higher" = 4, "Much higher" =5). Responses to the question "Would you feel less safe, more safe, or about the same?" were captured using a 5point scale ("Much more safe" = 1, "Slightly more safe" = 2, "About the same" = 3, "Slightly less safe" = 4, "Much less safe" = 5). See Table B11.1-B12.2 for point estimates, standard errors, and comparisons between weighted and unweighted estimates. 
Table B11.1. Weighted Group Means for Beliefs About Supporters' Preferences for Police Funding by Race/Ethnicity and Partisanship

\begin{tabular}{|c|c|c|c|c|c|c|}
\hline \multirow{2}{*}{ Race/ethnicity: } & \multicolumn{3}{|c|}{ Number of police on the street } & \multicolumn{3}{|c|}{ Spending on police services } \\
\hline & Black & Hispanic & White & Black & Hispanic & White \\
\hline Abolishing & $3.95(0.19)$ & $3.84(0.25)$ & $4.20(0.10)$ & $4.13(0.20)$ & $3.87(0.26)$ & $4.14(0.11)$ \\
\hline Defunding & $3.50(0.23)$ & $4.00(0.27)$ & $4.06(0.10)$ & $3.87(0.21)$ & $3.45(0.26)$ & $4.09(0.10)$ \\
\hline Reforming & $3.28(0.37)$ & $3.17(0.27)$ & $3.44(0.12)$ & $3.92(0.25)$ & $3.35(0.26)$ & $3.63(0.12)$ \\
\hline Partisanship: & Democrat & Independent & Republican & Democrat & Independent & Republican \\
\hline Abolishing & $4.16(0.12)$ & $3.79(0.35)$ & $4.19(0.13)$ & $4.20(0.12)$ & $3.42(0.34)$ & $4.20(0.13)$ \\
\hline Defunding & $3.82(0.12)$ & $3.98(0.19)$ & $4.10(0.14)$ & $3.73(0.12)$ & $3.76(0.24)$ & $4.25(0.13)$ \\
\hline Reforming & $3.10(0.14)$ & $3.36(0.24)$ & $3.76(0.16)$ & $3.30(0.13)$ & $4.02(0.22)$ & $3.89(0.15)$ \\
\hline
\end{tabular}

Notes. Point estimates with standard errors in parentheses.

Table B11.2. Unweighted Group Means for Beliefs About Supporters' Preferences for Police Funding by Race/Ethnicity and Partisanship

\begin{tabular}{|c|c|c|c|c|c|c|}
\hline \multirow{2}{*}{ Race/ethnicity: } & \multicolumn{3}{|c|}{ Number of police on the street } & \multicolumn{3}{|c|}{ Spending on police services } \\
\hline & Black & Hispanic & White & Black & Hispanic & White \\
\hline Abolishing & $3.80(0.17)$ & $3.93(0.18)$ & $4.17(0.08)$ & $3.82(0.18)$ & $3.87(0.18)$ & $4.09(0.08)$ \\
\hline Defunding & $3.52(0.15)$ & $3.79(0.19)$ & $4.00(0.07)$ & $3.82(0.16)$ & $3.44(0.19)$ & $4.01(0.08)$ \\
\hline Reforming & $3.21(0.20)$ & $3.20(0.17)$ & $3.46(0.09)$ & $3.59(0.20)$ & $3.35(0.17)$ & $3.62(0.08)$ \\
\hline Partisanship: & Democrat & Independent & Republican & Democrat & Independent & Republican \\
\hline Abolishing & $4.08(0.09)$ & $3.95(0.21)$ & $4.15(0.09)$ & $4.08(0.09)$ & $3.74(0.20)$ & $4.11(0.10)$ \\
\hline Defunding & $3.80(0.08)$ & $4.02(0.15)$ & $4.04(0.11)$ & $3.76(0.09)$ & $3.98(0.18)$ & $4.12(0.10)$ \\
\hline Reforming & $3.17(0.09)$ & $3.44(0.17)$ & $3.60(0.12)$ & $3.36(0.09)$ & $3.98(0.16)$ & $3.75(0.11)$ \\
\hline
\end{tabular}

Notes. Point estimates with standard errors in parentheses. 
Table B12.1. Weighted Group Means for Perceived Impact of Cuts on Crime and Safety by Race/Ethnicity and Partisanship

\begin{tabular}{|c|c|c|c|c|c|c|}
\hline \multirow{2}{*}{ Race/ethnicity: } & \multicolumn{3}{|c|}{ Crime levels } & \multicolumn{3}{|c|}{ Fear of crime } \\
\hline & Black & Hispanic & White & Black & Hispanic & White \\
\hline $10 \% \mathrm{cut}$ & $3.52(0.22)$ & $3.69(0.26)$ & $3.81(0.10)$ & $3.88(0.23)$ & $3.79(0.25)$ & $3.81(0.10)$ \\
\hline $25 \% \mathrm{cut}$ & $3.34(0.29)$ & $4.07(0.29)$ & $3.71(0.11)$ & $3.44(0.24)$ & $4.21(0.26)$ & $3.82(0.10)$ \\
\hline $50 \%$ cut & $3.53(0.24)$ & $4.56(0.19)$ & $4.04(0.11)$ & $3.27(0.33)$ & $4.32(0.29)$ & $3.91(0.12)$ \\
\hline $100 \% \mathrm{cut}$ & $3.78(0.24)$ & $4.10(0.21)$ & $4.38(0.09)$ & $3.91(0.26)$ & $4.04(0.18)$ & $4.34(0.10)$ \\
\hline \multicolumn{7}{|l|}{ Partisanship: } \\
\hline & Democrat & Independent & Republican & Democrat & Independent & Republican \\
\hline $10 \% \mathrm{cut}$ & $3.55(0.11)$ & $3.82(0.21)$ & $3.96(0.13)$ & $3.55(0.11)$ & $4.06(0.20)$ & $4.00(0.14)$ \\
\hline $25 \% \mathrm{cut}$ & $3.42(0.14)$ & $3.64(0.29)$ & $4.04(0.13)$ & $3.51(0.14)$ & $3.87(0.26)$ & $4.17(0.12)$ \\
\hline $50 \% \mathrm{cut}$ & $3.84(0.12)$ & $4.10(0.20)$ & $4.22(0.14)$ & $3.76(0.15)$ & $4.35(0.19)$ & $3.99(0.15)$ \\
\hline $100 \% \mathrm{cut}$ & $4.20(0.13)$ & $4.08(0.22)$ & $4.39(0.10)$ & $4.08(0.14)$ & $4.03(0.23)$ & $4.45(0.10)$ \\
\hline
\end{tabular}

Notes. Point estimates with standard errors in parentheses.

Table B12.2. Unweighted Group Means for Perceived Impact of Cuts on Crime and Safety by Race/Ethnicity and Partisanship

\begin{tabular}{|c|c|c|c|c|c|c|}
\hline \multirow{2}{*}{ Race/ethnicity: } & \multicolumn{3}{|c|}{ Crime levels } & \multicolumn{3}{|c|}{ Fear of crime } \\
\hline & Black & Hispanic & White & Black & Hispanic & White \\
\hline $10 \% \mathrm{cut}$ & $3.52(0.15)$ & $3.58(0.17)$ & $3.76(0.07)$ & $3.58(0.19)$ & $3.91(0.15)$ & $3.79(0.07)$ \\
\hline $25 \% \mathrm{cut}$ & $3.39(0.21)$ & $3.94(0.19)$ & $3.79(0.08)$ & $3.46(0.20)$ & $4.00(0.17)$ & $3.82(0.09)$ \\
\hline $50 \%$ cut & $3.79(0.17)$ & $4.19(0.21)$ & $4.02(0.07)$ & $3.61(0.21)$ & $3.96(0.26)$ & $3.92(0.08)$ \\
\hline $100 \% \mathrm{cut}$ & $3.60(0.17)$ & $4.03(0.18)$ & $4.32(0.08)$ & $3.84(0.16)$ & $3.97(0.18)$ & $4.18(0.09)$ \\
\hline \multicolumn{7}{|l|}{ Partisanship: } \\
\hline & Democrat & Independent & Republican & Democrat & Independent & Republican \\
\hline $10 \% \mathrm{cut}$ & $3.53(0.08)$ & $3.88(0.12)$ & $3.82(0.10)$ & $3.57(0.08)$ & $4.08(0.13)$ & $3.88(0.10)$ \\
\hline $25 \% \mathrm{cut}$ & $3.50(0.09)$ & $3.86(0.20)$ & $4.01(0.09)$ & $3.54(0.10)$ & $3.96(0.21)$ & $4.08(0.10)$ \\
\hline $50 \% \mathrm{cut}$ & $3.87(0.08)$ & $3.95(0.15)$ & $4.19(0.11)$ & $3.75(0.10)$ & $4.11(0.16)$ & $4.06(0.12)$ \\
\hline $100 \% \mathrm{cut}$ & $4.13(0.09)$ & $3.97(0.19)$ & $4.26(0.10)$ & $4.01(0.10)$ & $3.97(0.19)$ & $4.27(0.11)$ \\
\hline
\end{tabular}

Notes. Point estimates with standard errors in parentheses. 


\section{Additional Details for Primary Survey}

\section{C.1 Exclusion of Inattentive Survey Respondents}

There is growing concern about rising inattention among online survey respondents. This inattention leads to measurement error in web-based surveys, and attention check questions (ACQs) are typically used to screen out inattentive survey respondents (Berinsky, Margolis and Sances, 2014, 2016; Berinsky et al., 2019). Screening out respondents based on attention checks placed near the end of the survey or after treatments are administered can induce bias, but using attention checks administered early in the survey or prior to experimental treatments does not induce bias (Montgomery, Nyhan and Torres, 2018; Aronow, Baron and Pinson, 2019).

Arechar and Rand (2020) and Aronow et al. (2020) provide evidence of rising inattention among survey takers sourced from Amazon Mechanical Turk (MTurk) and Lucid throughout 2020. Peyton et al. (2020) formalize the conditions under which this inattention uniformly shrinks treatment effect estimates toward zero and, using a series of replication studies fielded in 2020, show that estimates among attentive respondents are closer to previously published estimates. They recommend that researchers conducting online surveys in 2020 - particularly via the Lucid platform - should use attention checks placed near the beginning of the survey to screen out participants that provide low-quality data (e.g., speeding through surveys without reading question content).

We therefore administered an attention task at the beginning of the survey to screen out inattentive respondents. Immediately after consenting to participate in the study, respondents read the following prompt: "We'd like to know how you feel about local news coverage. Please read this short article. On the next page, we will ask you a few questions about your reactions to this article." The below excerpt from a news article appeared on the next page. 


\section{MAN ARRESTED FOR STRING OF BANK THEFTS}

Columbus Police have arrested a man they say gave his driver's license to a teller at a bank he was robbing. According to court documents, Bryan Simon is accused of robbing four Central Ohio banks between October 3 and November 5, 2018.

During a robbery on November 5 at the Huntington Bank, the sheriff's office says Simon was tricked into giving the teller his drivers' license.

According to court documents, Simon approached the counter and presented a demand note for money that said "I have a gun." The teller gave Simon about $\$ 500$, which he took.

Documents say Simon then told the teller he wanted more money. The teller told him a driver's license was required to use the machine to get our more cash. Simon reportedly then gave the teller his license to swipe through the machine and then left the bank with about $\$ 1000$ in additional cash, but without his ID.

Detectives arrested him later that day at the address listed on his ID.

After viewing the article, participants were asked the following two ACQs, with correct responses bolded and underlined:

1. How was Simon identified by police for the crime he allegedly committed? [A police officer recognized him, From video surveillance, Because he left his ID, He turned himself in, None of the above]

2. How much money did Simon allegedly steal? [About $\$ 500$, About $\$ 1500$, About $\$ 25,000$, About $\$ 1$ million dollars, None of the above]

Individuals could not go back and view the article before providing their responses. Among the 2,060 individuals who consented to participate in the study, 55\% passed the first ACQ. Among the 1,149 individuals who passed the first ACQ, 60\% also passed the second ACQ. Only those individuals who provided incorrect answers to the first ACQ or refused to answer were terminated from the survey. Twelve of the 1,149 individuals that passed the ACQ did not continue beyond the ACQ and were not assigned any treatments (see Figure A1 for summary of survey design and randomizations). Figure C1 shows the marginal distribution of responses to each ACQ. 


\section{Figure C1. Distribution of Responses to Attention Check Questions}

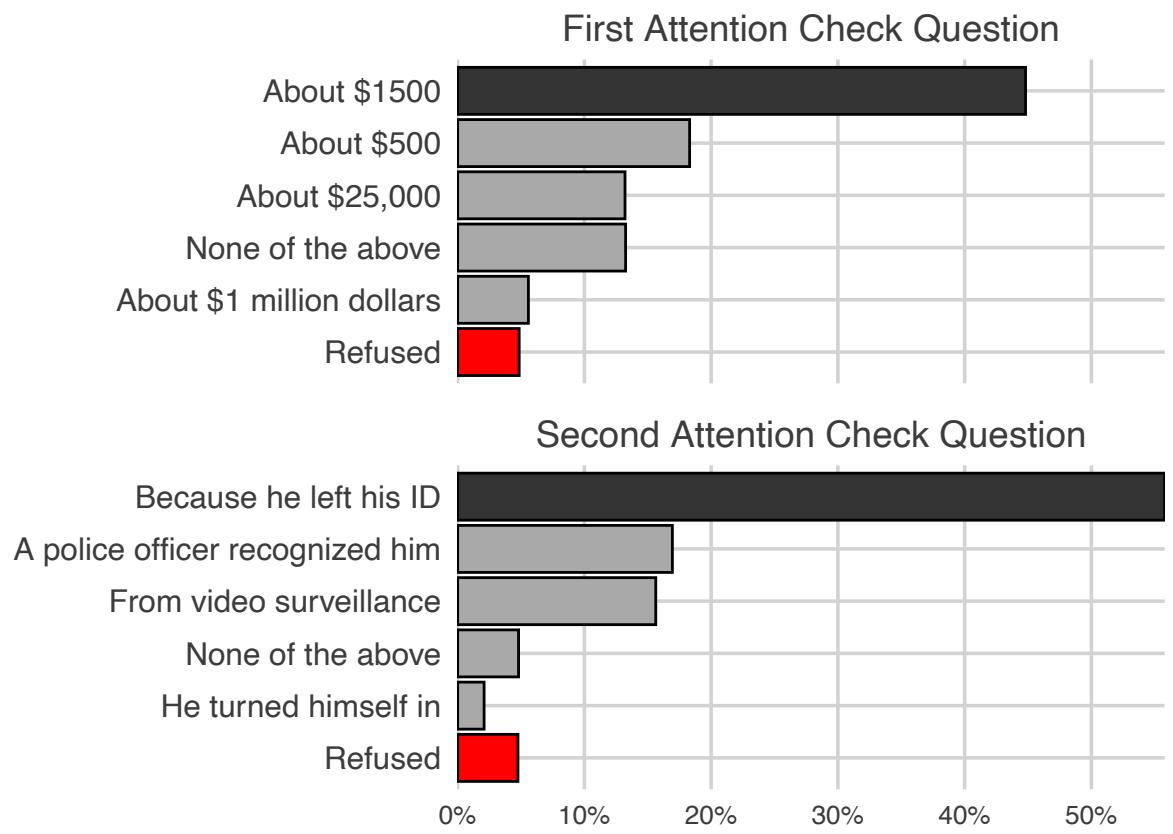

Notes. Black bars denote the proportion of participants providing the correct answer, grey bars denote incorrect answers, and red bars denote refusals. Individuals who provided incorrect answers or refused to answer the first attention check question were terminated from the survey. 


\section{C.2 Survey Representativeness and Weighting Methodology}

Survey data were collected on 29 October 2020 using the Lucid platform. Lucid is an aggregator of survey respondents that sources from a wide variety of providers. Participants are paid directly by the vendor either in US dollars or through a points program at a similar rate. Among those that consented $(2,060$ of 2,145$)$ and passed the attention screener $(1,149$ of 2,060$)$, the median time to completion was 12 minutes. Lucid provides customers with quota samples that approximate US census margins on age, gender, race/ethnicity and region, and Lucid samples compare favorably with nationally representative samples on demographics and experimental estimates (Coppock and McClellan, 2018). Although descriptive estimates of public opinion obtained from quota samples may differ significantly from nationally representative opinion polls, this is not generally a concern for survey experimental estimates (Mullinix et al., 2015; Coppock et al., 2018; Coppock, 2019; Coppock and McClellan, 2019; Peyton et al., 2020).

We construct survey weights to adjust for potential differences in respondent demographics along the following characteristics: gender, region, Hispanic, race, household income, education, and age. Our target proportions for these characteristics are the estimates reported by the American Community Survey (ACS). Weights are constructed using the autumn package in $R$ (Rudkin, 2020), which implements an iterative raking procedure used by the American National Election Study (ANES) survey (see DeBell and Krosnick, 2009). Applying the weights reduced the average difference between the sample proportions and ACS targets by $21 \%$ (from 0.03 to 0.006 ) for an effective sample size of 615 units from a nominal size of 1,137 (implying a design effect of 1.85). Table C1compares the unweighted sample proportions, weighted sample proportions, and the target ACS proportions across background covariates. 
Table C1. Comparisons Among Unweighted, Weighted, and ACS Proportions Across Covariates

\begin{tabular}{|c|c|c|c|c|c|c|}
\hline \multicolumn{2}{|c|}{ Variable (level) } & $\begin{array}{l}\text { Unweighted } \\
\text { Proportion }\end{array}$ & $\begin{array}{c}\text { Weighted } \\
\text { Proportion }\end{array}$ & $\begin{array}{c}\text { ACS } \\
\text { Proportion }\end{array}$ & $\begin{array}{l}\text { Unweighted } \\
\text { error }\end{array}$ & $\begin{array}{c}\text { Weighted } \\
\text { error }\end{array}$ \\
\hline \multicolumn{7}{|l|}{ Female: } \\
\hline & Yes & 0.516 & 0.53 & 0.517 & 0.001 & 0.012 \\
\hline & No & 0.483 & 0.468 & 0.483 & 0 & 0.015 \\
\hline \multicolumn{7}{|l|}{ Region: } \\
\hline & South & 0.376 & 0.378 & 0.379 & 0.003 & 0.001 \\
\hline & West & 0.227 & 0.238 & 0.238 & 0.011 & 0.001 \\
\hline & Midwest & 0.179 & 0.208 & 0.208 & 0.029 & 0 \\
\hline & Northeast & 0.217 & 0.174 & 0.174 & 0.043 & 0 \\
\hline \multicolumn{7}{|c|}{ Hispanic: } \\
\hline & No & 0.846 & 0.84 & 0.837 & 0.009 & 0.003 \\
\hline & Yes & 0.146 & 0.155 & 0.163 & 0.017 & 0.008 \\
\hline \multicolumn{7}{|l|}{ Race: } \\
\hline & AAPI & 0.058 & 0.047 & 0.069 & 0.011 & 0.022 \\
\hline & Black & 0.124 & 0.118 & 0.121 & 0.003 & 0.003 \\
\hline & White & 0.733 & 0.756 & 0.741 & 0.008 & 0.015 \\
\hline & Other race & 0.085 & 0.079 & 0.07 & 0.015 & 0.009 \\
\hline \multicolumn{7}{|c|}{ Household income: } \\
\hline & $\$ 19,999$ or less & 0.199 & 0.097 & 0.097 & 0.102 & 0 \\
\hline & $\$ 20,000-\$ 34,999$ & 0.148 & 0.106 & 0.106 & 0.042 & 0 \\
\hline & $\$ 35,000-\$ 49,999$ & 0.101 & 0.109 & 0.109 & 0.008 & 0 \\
\hline & $\$ 50,000-\$ 64,999$ & 0.106 & 0.104 & 0.104 & 0.002 & 0 \\
\hline & $\$ 65,000-\$ 79,999$ & 0.078 & 0.091 & 0.091 & 0.013 & 0 \\
\hline & $\$ 80,000-\$ 99,999$ & 0.051 & 0.103 & 0.103 & 0.052 & 0 \\
\hline & $\begin{array}{l}\$ 100,000- \\
\$ 124,999\end{array}$ & 0.068 & 0.101 & 0.101 & 0.033 & 0 \\
\hline & $\begin{array}{l}\$ 125,000- \\
\$ 199,999\end{array}$ & 0.108 & 0.146 & 0.146 & 0.038 & 0 \\
\hline & $\begin{array}{l}\$ 200,000 \text { and } \\
\text { above }\end{array}$ & 0.075 & 0.09 & 0.09 & 0.016 & 0 \\
\hline & Unanswered & 0.066 & 0.052 & 0.052 & 0.014 & 0 \\
\hline \multicolumn{7}{|c|}{ Education: } \\
\hline & $\begin{array}{l}\text { No high school } \\
\text { diploma }\end{array}$ & 0.026 & 0.068 & 0.116 & 0.089 & 0.048 \\
\hline & $\begin{array}{l}\text { High school } \\
\text { diploma }\end{array}$ & 0.192 & 0.284 & 0.273 & 0.081 & 0.011 \\
\hline & Some college & 0.215 & 0.228 & 0.219 & 0.004 & 0.008 \\
\hline & Associate's degree & 0.084 & 0.087 & 0.084 & 0.001 & 0.003 \\
\hline & Bachelor's degree & 0.233 & 0.201 & 0.193 & 0.04 & 0.007 \\
\hline & Graduate degree & 0.244 & 0.12 & 0.115 & 0.128 & 0.004 \\
\hline \multicolumn{7}{|l|}{ Age: } \\
\hline & $18-23$ & 0.125 & 0.074 & 0.094 & 0.031 & 0.02 \\
\hline & $24-29$ & 0.089 & 0.106 & 0.109 & 0.02 & 0.003 \\
\hline & $30-39$ & 0.212 & 0.177 & 0.174 & 0.038 & 0.003 \\
\hline & $40-49$ & 0.193 & 0.168 & 0.163 & 0.03 & 0.005 \\
\hline & $50-59$ & 0.14 & 0.17 & 0.17 & 0.03 & 0 \\
\hline & $60-69$ & 0.141 & 0.159 & 0.152 & 0.011 & 0.008 \\
\hline & $70+$ & 0.1 & 0.144 & 0.138 & 0.038 & 0.005 \\
\hline
\end{tabular}




\section{Supplemental Survey Experiment}

Figure D1. Summary of Survey Design and Randomizations

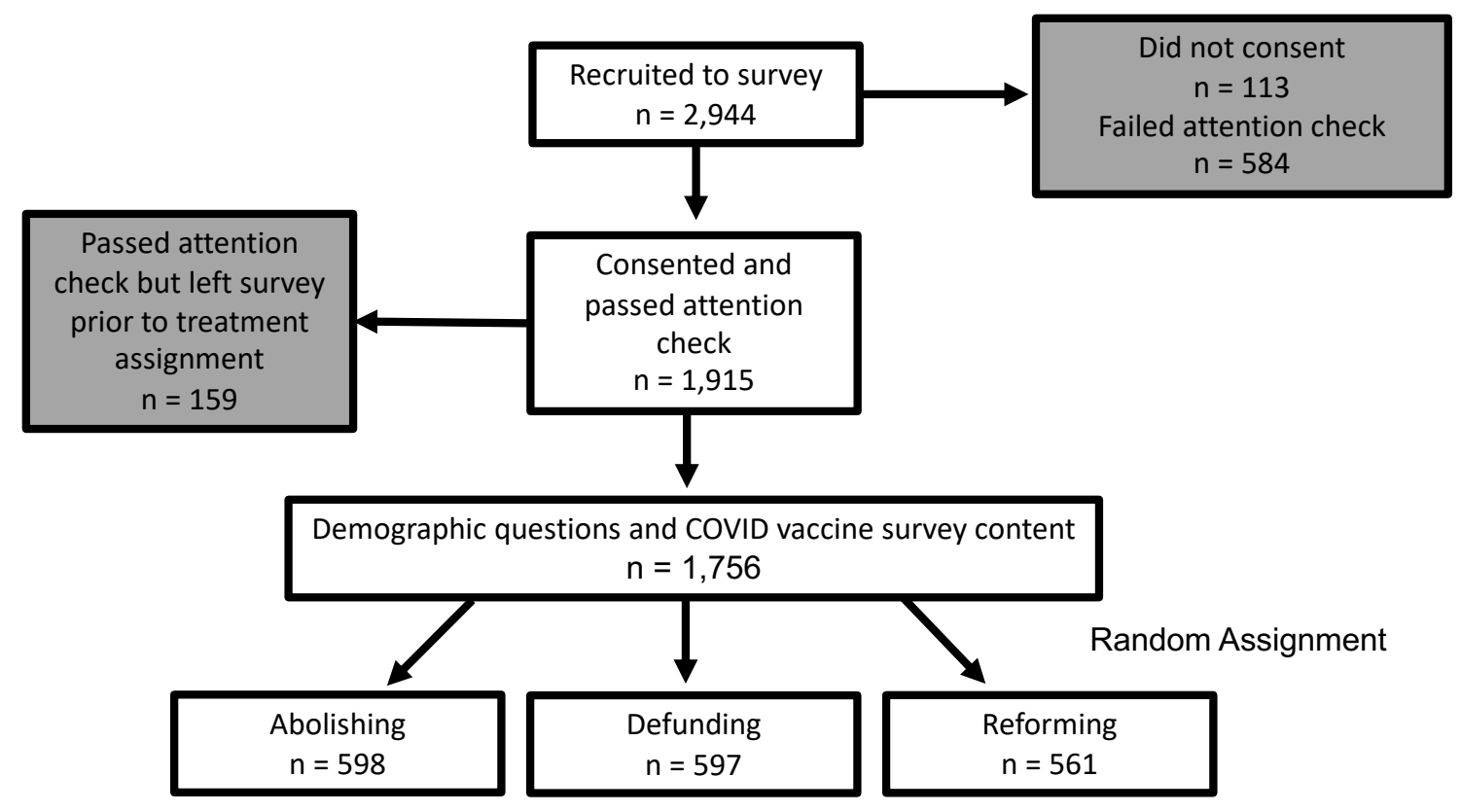

A supplementary survey experiment was conducted on 18 February 2020 using the Lucid platform described in Section C. This survey experiment was placed at the end of an unrelated survey about attitudes toward COVID-19 vaccines. Among those that consented to take this survey and passed the attention screener (1,915 of 2,944), 1,756 completed the unrelated survey on COVID-19 vaccines and were assigned treatment. The median time to completion was 11 minutes (159 of 1,915 respondents that passed the attention screener left the survey prior to treatment assignment). Figure D1 provides a summary of the survey design and the randomizations. Additional details on the attention check questions and weighting methodology are provided in Sections D.1-D.2.

In this survey experiment, 1,756 respondents were randomly assigned to the Abolishing, Defunding, or Reforming arms. Within each arm, beliefs about the demographic composition of movement supporters were measured using the following questions, presented in random order within each arm:

1. Think about the people who support $\$\{\mathrm{e}: / / \mathrm{Field} / \mathrm{Z}\}$ the police. Out of every 100 supporters, how many do you think are Black? For your reference, approximately $13 \%$ of the US population is Black.

2. Think about the people who support $\$\{\mathrm{e}: / /$ Field $/ Z\}$ the police. Out of every 100 supporters, how many do you think are Female? For your reference, approximately $50 \%$ of the US population is Female. 
3. Think about the people who support $\$\{\mathrm{e}: / /$ Field $/ \mathrm{Z}\}$ the police. Out of every 100 supporters, how many do you think voted for Joe Biden? For your reference, among those who voted in 2020, about $51 \%$ voted for Biden.

4. Think about the people who support $\$\{\mathrm{e}: / /$ Field $/ \mathrm{Z}\}$ the police. Out of every 100 supporters, how many do you think voted in the 2020 presidential election? For your reference, about $67 \%$ of the voting eligible population voted in the 2020 presidential election.

Responses to each question were recorded using a sliding scale from 0 to 100 . Estimates are presented in Section D.3.

\section{D.1 Exclusion of Inattentive Survey Respondents}

This survey used the same procedure for screening out inattentive respondents described in Section C.1. Among the 2,831 individuals who consented to participate in the study, 77\% passed the first ACQ. Among the 1,915 individuals who passed the first ACQ, 83\% also passed the second ACQ. Only those individuals who provided incorrect answers to the first ACQ, or refused to answer, were terminated from the survey. One hundred and fifty-nine of the 1,915 individuals that passed the ACQ left the survey environment prior to our experiment and were not assigned any treatments. Figure D2 shows the marginal distribution of responses to each ACQ. 
Figure D2. Distribution of Responses to Attention Check Questions

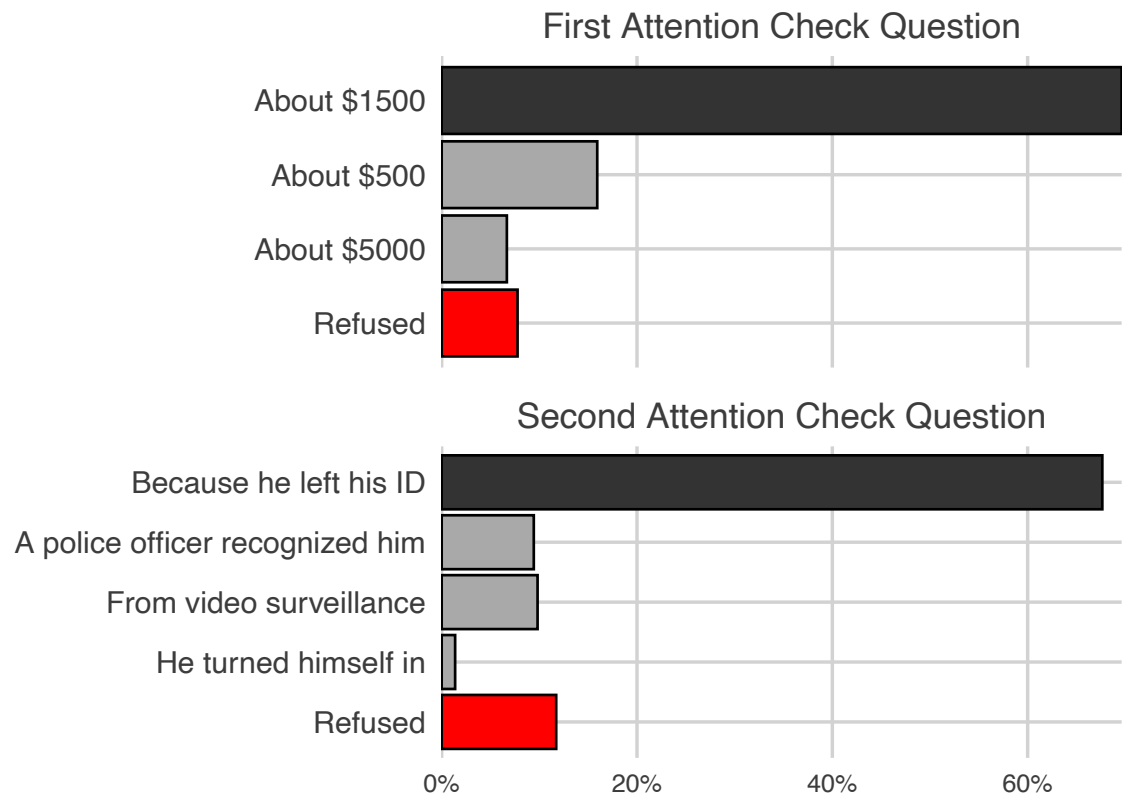

Notes. Black bars denote the proportion of participants providing the correct answer, grey bars denote incorrect answers, and red bars denote refusals. Individuals who provided incorrect answers or refused to answer the first attention check question were terminated from the survey.

\section{D.2 Survey Representativeness and Weighting Methodology}

Applying the weighting procedure described in Section C.2 reduced the average difference between the sample proportions and ACS targets from 0.03 to 0.002 , for an effective sample size of 884 units from a nominal size of 1,756 (implying a design effect of 1.99). Table X compares the unweighted sample proportions, weighted sample proportions, and the target ACS proportions. 
Table D1. Comparisons Among Unweighted, Weighted, and ACS Proportions Across Covariates

\begin{tabular}{|c|c|c|c|c|c|c|}
\hline \multicolumn{2}{|c|}{ Variable (level) } & $\begin{array}{l}\text { Unweighted } \\
\text { Proportion }\end{array}$ & $\begin{array}{c}\text { Weighted } \\
\text { Proportion }\end{array}$ & $\begin{array}{c}\text { ACS } \\
\text { Proportion }\end{array}$ & $\begin{array}{c}\text { Unweighted } \\
\text { error }\end{array}$ & $\begin{array}{c}\text { Weighted } \\
\text { error }\end{array}$ \\
\hline \multicolumn{7}{|l|}{ Female: } \\
\hline & Yes & 0.512 & 0.502 & 0.517 & 0.005 & 0.015 \\
\hline & No & 0.488 & 0.498 & 0.483 & 0.005 & 0.015 \\
\hline \multicolumn{7}{|l|}{ Region: } \\
\hline & South & 0.375 & 0.379 & 0.379 & 0.005 & 0 \\
\hline & West & 0.225 & 0.238 & 0.238 & 0.013 & 0 \\
\hline & Midwest & 0.192 & 0.208 & 0.208 & 0.016 & 0 \\
\hline & Northeast & 0.208 & 0.174 & 0.174 & 0.033 & 0 \\
\hline \multicolumn{7}{|l|}{ Hispanic: } \\
\hline & No & 0.866 & 0.83 & 0.837 & 0.029 & 0.007 \\
\hline & Yes & 0.12 & 0.162 & 0.163 & 0.043 & 0.001 \\
\hline \multicolumn{7}{|l|}{ Race: } \\
\hline & AAPI & 0.056 & 0.069 & 0.069 & 0.013 & 0 \\
\hline & Black & 0.118 & 0.12 & 0.121 & 0.003 & 0.001 \\
\hline & White & 0.737 & 0.742 & 0.741 & 0.003 & 0.002 \\
\hline & Other race & 0.088 & 0.069 & 0.07 & 0.018 & 0.001 \\
\hline \multicolumn{7}{|c|}{ Household income: } \\
\hline & $\$ 19,999$ or less & 0.199 & 0.097 & 0.097 & 0.102 & 0 \\
\hline & $\$ 20,000-\$ 34,999$ & 0.182 & 0.106 & 0.106 & 0.077 & 0 \\
\hline & $\$ 35,000-\$ 49,999$ & 0.12 & 0.109 & 0.109 & 0.01 & 0 \\
\hline & $\$ 50,000-\$ 64,999$ & 0.097 & 0.105 & 0.104 & 0.008 & 0 \\
\hline & $\$ 65,000-\$ 79,999$ & 0.081 & 0.092 & 0.091 & 0.01 & 0 \\
\hline & $\$ 80,000$ - $\$ 99,999$ & 0.069 & 0.104 & 0.103 & 0.034 & 0 \\
\hline & $\begin{array}{l}\$ 100,000- \\
\$ 124,999\end{array}$ & 0.056 & 0.101 & 0.101 & 0.045 & 0 \\
\hline & $\begin{array}{l}\$ 125,000- \\
\$ 199,999\end{array}$ & 0.085 & 0.146 & 0.146 & 0.061 & 0 \\
\hline & $\begin{array}{l}\$ 200,000 \text { and } \\
\text { above }\end{array}$ & 0.035 & 0.089 & 0.09 & 0.055 & 0.002 \\
\hline & Unanswered & 0.076 & 0.052 & 0.052 & 0.024 & 0 \\
\hline \multicolumn{7}{|c|}{ Education: } \\
\hline & $\begin{array}{l}\text { No high school } \\
\text { diploma }\end{array}$ & 0.043 & 0.107 & 0.116 & 0.073 & 0.009 \\
\hline & $\begin{array}{l}\text { High school } \\
\text { diploma }\end{array}$ & 0.215 & 0.276 & 0.273 & 0.058 & 0.003 \\
\hline & Some college & 0.249 & 0.221 & 0.219 & 0.03 & 0.002 \\
\hline & Associate's degree & 0.088 & 0.085 & 0.084 & 0.004 & 0.001 \\
\hline & Bachelor's degree & 0.236 & 0.195 & 0.193 & 0.043 & 0.002 \\
\hline & Graduate degree & 0.169 & 0.116 & 0.115 & 0.054 & 0.001 \\
\hline \multicolumn{7}{|l|}{ Age: } \\
\hline & $18-23$ & 0.12 & 0.091 & 0.094 & 0.026 & 0.003 \\
\hline & $24-29$ & 0.101 & 0.109 & 0.109 & 0.008 & 0 \\
\hline & $30-39$ & 0.176 & 0.175 & 0.174 & 0.002 & 0.001 \\
\hline & $40-49$ & 0.14 & 0.162 & 0.163 & 0.023 & 0.001 \\
\hline & $50-59$ & 0.154 & 0.171 & 0.17 & 0.016 & 0.001 \\
\hline & $60-69$ & 0.203 & 0.152 & 0.152 & 0.051 & 0 \\
\hline & $70+$ & 0.106 & 0.14 & 0.138 & 0.032 & 0.001 \\
\hline
\end{tabular}




\section{D.3 Figures and Tables Referenced in Main Text}

Figure D3. Respondents' Beliefs About the Proportion of Movement Supporters in Each Group

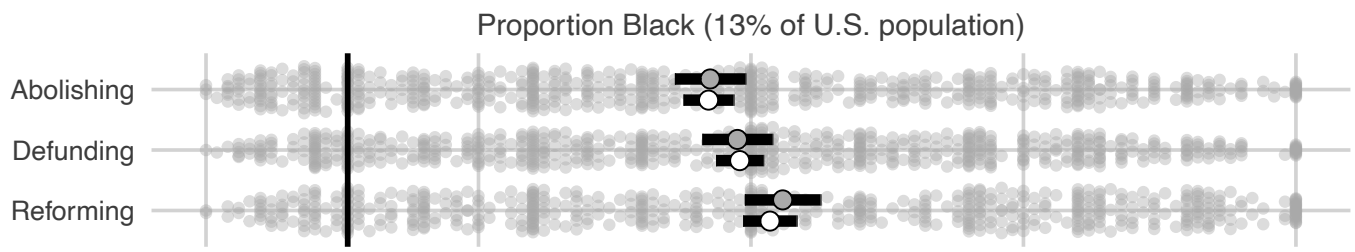

Proportion Female (50\% of U.S. population)

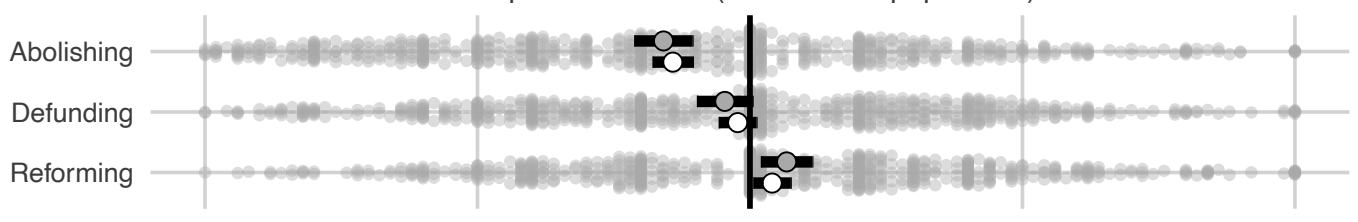

Proportion voted for Biden (51\% of voting population)

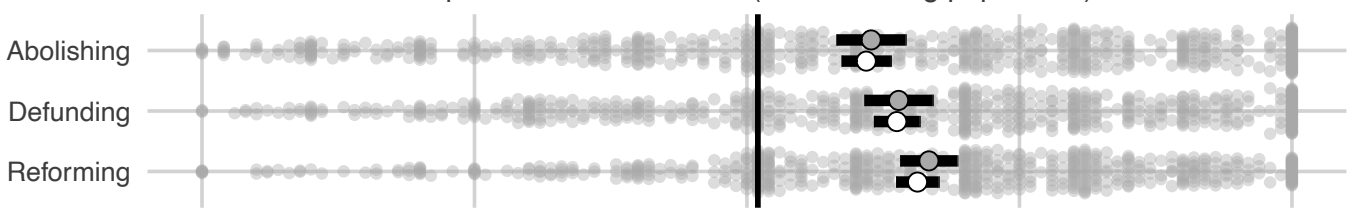

Proportion voted in 2020 (67\% of eligible population)

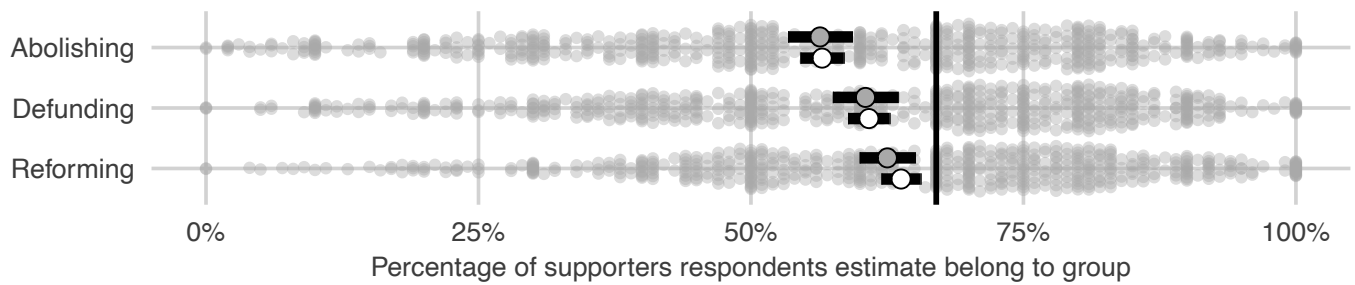

Notes. Point estimates and 95\% confidence intervals are group means from a between-subjects experimental design that randomly assigned "abolishing", "defunding", or "reforming" with equal probability. Dark grey point estimates are weighted and white point estimates are unweighted. Light grey dots (jittered to reduce overplotting) denote individual responses. Black vertical bars denote the population estimates provided to respondents. See Table D3.1 for group means and Table D3.2 for estimated effects, using "Reforming the police" as the reference group, with and without covariate adjustment. 
Table D3.1. Group Means for Respondents' Beliefs About the Proportion of Movement Supporters in Each Group

\begin{tabular}{ccccccccc} 
& \multicolumn{2}{c}{ Proportion Black } & \multicolumn{2}{c}{ Proportion Female } & \multicolumn{2}{c}{ Proportion voted for Biden } & $\begin{array}{c}\text { Proportion voted in 2020 } \\
\text { election }\end{array}$ \\
\cline { 2 - 8 } & Unweighted & Weighted & Unweighted & Weighted & Unweighted & Weighted & Unweighted & Weighted \\
\hline Abolish & $46.11(1.17)$ & $46.26(1.65)$ & $42.92(0.94)$ & $42.07(1.36)$ & $60.95(1.15)$ & $61.39(1.62)$ & $56.53(1.01)$ & $56.34(1.49)$ \\
Defund & $48.97(1.10)$ & $48.75(1.64)$ & $48.87(0.88)$ & $47.69(1.30)$ & $63.75(1.07)$ & $63.92(1.59)$ & $60.82(0.97)$ & $60.51(1.52)$ \\
Reform & $51.74(1.25)$ & $52.91(1.77)$ & $52.03(0.87)$ & $53.37(1.20)$ & $65.65(0.99)$ & $66.69(1.34)$ & $63.77(0.92)$ & $62.51(1.29)$ \\
\hline \hline
\end{tabular}

Notes. Point estimates with standard errors in parentheses.

Table D3.2. Estimated Effects on Respondents’ Beliefs About the Proportion Of Movement Supporters in Each Group

\begin{tabular}{|c|c|c|c|c|c|c|c|c|}
\hline & \multicolumn{2}{|c|}{ Proportion Black } & \multicolumn{2}{|c|}{ Proportion Female } & \multicolumn{2}{|c|}{ Proportion voted for Biden } & \multicolumn{2}{|c|}{$\begin{array}{c}\text { Proportion voted in } 2020 \\
\text { election }\end{array}$} \\
\hline & Unweighted & Weighted & Unweighted & Weighted & Unweighted & Weighted & Unweighted & Weighted \\
\hline \multicolumn{9}{|c|}{ Difference-in-Means Estimator: } \\
\hline Abolish & $-5.63(1.71)^{*}$ & $-6.65(2.41)^{*}$ & $-9.11(1.29)^{*}$ & $-11.30(1.82)^{*}$ & $-4.70(1.52)^{*}$ & $-5.30(2.09)^{*}$ & $-7.24(1.37)^{*}$ & $-6.18(1.97)^{*}$ \\
\hline Defund & $-2.77(1.66)$ & $-4.16(2.41)$ & $-3.16(1.24)^{*}$ & $-5.68(1.77)^{*}$ & $-1.90(1.46)$ & $-2.78(2.08)$ & $-2.95(1.34)^{*}$ & $-2.01(2.00)$ \\
\hline \multicolumn{9}{|c|}{ Covariate-adjusted Estimator: } \\
\hline Abolish & $-5.27(1.79)^{*}$ & $-5.44(2.45)^{*}$ & $-9.16(1.29)^{*}$ & $-11.56(1.77)^{*}$ & $-4.22(1.56)^{*}$ & $-4.22(2.11)^{*}$ & $-7.40(1.41)^{*}$ & $-6.07(1.97)^{*}$ \\
\hline Defund & $-2.34(1.74)$ & $-3.65(2.29)$ & $-3.62(1.25)^{*}$ & $-6.88(1.67)^{*}$ & $-1.15(1.53)$ & $-2.08(2.10)$ & $-3.24(1.39)^{*}$ & $-1.95(1.98)$ \\
\hline
\end{tabular}

Notes. Point estimates for between-subjects estimators with robust standard errors in parentheses. "Reforming the police" is the reference group ("control"). The covariate-adjusted estimator includes age, sex, region, household income, employment status, race/ethnicity, education, and partisanship. $* \mathrm{P}<0.05$. 


\section{E References for Appendices}

Arechar, Antonio A and David Rand. 2020. "Turking in the time of COVID." PsyArXiv https://doi.org/10.31234/osf.io/vktqu

Aronow, Peter M, Jonathon Baron and Lauren Pinson. 2019. "A note on dropping experimental subjects who fail a manipulation check." Political Analysis 27(4):572-589.

Aronow, Peter Michael, Joshua Kalla, Lilla Orr and John Ternovski. 2020. "Evidence of Rising Rates of Inattentiveness on Lucid in 2020." SocArXiv https://doi.org/10.31235/osf.io/8sbe4

Benjamini, Yoav, and Yosef Hochberg. 1995. "Controlling the false discovery rate: a practical and powerful approach to multiple testing." Journal of the Royal Statistical Society 57(1): 289-300.

Berinsky, Adam J., Gregory A. Huber, and Gabriel S. Lenz. 2012. "Evaluating online labor markets for experimental research: Amazon. com's Mechanical Turk." Political Analysis 20(3): 351-368.

Berinsky, Adam J, Michele F Margolis and Michael W Sances. 2014. "Separating the shirkers from the workers? Making sure respondents pay attention on self-administered surveys." American Journal of Political Science 58(3):739-753.

Berinsky, Adam J, Michele F Margolis and Michael W Sances. 2016. "Can we turn shirkers into workers?” Journal of Experimental Social Psychology 66:20-28.

Berinsky, Adam J, Michele F Margolis, Michael W Sances and Christopher Warshaw. 2019. "Using screeners to measure respondent attention on self-administered surveys: Which items and how many?" Political Science Research and Methods pp. 1-8.

Coppock, Alexander. 2019. “Generalizing from Survey Experiments Conducted on Mechanical Turk: A Replication Approach.” Political Science Research and Methods 7(3):613-628.

Coppock, Alexander, and Oliver A. McClellan. 2019. "Validating the demographic, political, psychological, and experimental results obtained from a new source of online survey respondents." Research \& Politics 6.1: 2053168018822174.

Coppock, Alexander, Thomas J. Leeper and Kevin J. Mullinix. 2018. "Generalizability of heterogeneous treatment effect estimates across samples." Proceedings of the National Academy of Sciences 115(49):12441-12446.

DeBell, Matthew, and Jon A. Krosnick. 2009. Computing Weights for American National Election Study Survey Data. ANES Technical Report series, no. nes012427. Ann Arbor, MI, and Palo Alto, CA: American National Election Studies. Available at http://www.electionstidies.org

Lin, W. 2013. "Agnostic notes on regression adjustments to experimental data: Reexamining Freedman's critique.” Annals of Applied Statistics 7(1): 295-318.

Mullinix, Kevin J., Thomas J. Leeper, James N. Druckman and Jeremy Freese. 2015. "The Generalizability of Survey Experiments.” Journal of Experimental Political Science 2:109- 138.

Peyton, Kyle, Gregory A. Huber, and Alexander Coppock. 2020. "The Generalizability of Online Experiments Conducted During the COVID-19 Pandemic.” SocArXiv doi:10.31235/osf.io/s45yg 
Rudkin, Aaron. 2020. autumn: Fast, Modern, and Tidy-Friendly Iterative Raking. R package version 0.1 . Available at https://github.com/aaronrudkin/autumn/. 